\title{
Generation of procoagulant activity in blood cells : studies on the process of lipid scrambling
}

Citation for published version (APA):

Wolfs, J. L. N. (2009). Generation of procoagulant activity in blood cells : studies on the process of lipid scrambling. [Doctoral Thesis, Maastricht University]. Datawyse / Universitaire Pers Maastricht. https://doi.org/10.26481/dis.20090910jw

Document status and date:

Published: 01/01/2009

DOI:

10.26481/dis.20090910jw

Document Version:

Publisher's PDF, also known as Version of record

\section{Please check the document version of this publication:}

- A submitted manuscript is the version of the article upon submission and before peer-review. There can be important differences between the submitted version and the official published version of record.

People interested in the research are advised to contact the author for the final version of the publication, or visit the DOI to the publisher's website.

- The final author version and the galley proof are versions of the publication after peer review.

- The final published version features the final layout of the paper including the volume, issue and page numbers.

Link to publication

\footnotetext{
General rights rights.

- You may freely distribute the URL identifying the publication in the public portal. please follow below link for the End User Agreement:

www.umlib.nl/taverne-license

Take down policy

If you believe that this document breaches copyright please contact us at:

repository@maastrichtuniversity.nl

providing details and we will investigate your claim.
}

Copyright and moral rights for the publications made accessible in the public portal are retained by the authors and/or other copyright owners and it is a condition of accessing publications that users recognise and abide by the legal requirements associated with these

- Users may download and print one copy of any publication from the public portal for the purpose of private study or research.

- You may not further distribute the material or use it for any profit-making activity or commercial gain

If the publication is distributed under the terms of Article $25 \mathrm{fa}$ of the Dutch Copyright Act, indicated by the "Taverne" license above, 


\section{Generation of Procoagulant Activity in Blood Cells}

Studies on the Process of Lipid Scrambling 
Financial support by the Netherlands Heart Foundation and the dr. ir. J.H.J. van de Laar Stichting for the publication of this thesis is grafefully acknowledged.

(C) JLN Wolfs, Maastricht 2009

Cover illustration: Bea Vangertruyden

Layout: Tiny Wouters

Production: Datawyse | Universitaire Pers Maastricht

ISBN: 9789052788500 


\title{
Generation of Procoagulant Activity in Blood Cells \\ Studies on the Process of Lipid Scrambling
}

\author{
PROEFSCHRIFT \\ ter verkrijging van de graad van doctor \\ aan de Universiteit Maastricht, \\ op gezag van de Rector Magnificus, Prof. mr. G.P.M.F. Mols \\ volgens het besluit van het College van Decanen, \\ in het openbaar te verdedigen \\ op donderdag 10 september 2009 om 14.00 uur \\ door \\ Joseph Louis Nicolas Wolfs
}

Geboren op 20 maart 1940

$\mathrm{UM}_{\mathrm{M}}^{\mathrm{M}}$ 


\section{Promotores}

Prof. dr. J. Rosing

Prof. dr. R.F.A. Zwaal

\section{Copromotor}

Dr. E.M. Bevers

\section{Beoordelingscommissie}

Prof. dr. J.F.C. Glatz (voorzitter)

Prof. dr. C.A. Bruggeman

Prof. dr. M.C.E. van Dam-Mieras (Universiteit Leiden)

Prof. dr. F.C.S. Ramaekers

Prof. dr. H.A.J. Struijker Boudier 
Voor allen die mij dierbaar zijn 


\section{Contents}

Chapter 1 General introduction 9

Chapter 2 Activated scramblase and inhibited 35 aminophospholipid translocase cause phosphatidylserine exposure in a distinct platelet fraction

Chapter 3 Influence of erythrocyte shape on the rate of $\mathrm{Ca}^{2+}$-induced scrambling of phosphatidylserine

Chapter 4 Reversible inhibition of the platelet procoagulant response through manipulation of the Gardos channel

Chapter 5 Direct inhibition of phospholipid scrambling activity in erythrocytes by potassium ions.

Chapter 6 General discussion

List of publications

Dankwoord 


\section{Chapter 1}

\section{Generall introduction}

Platelets and the propagation of coagulation How platelets control surface-exposed procoagulant phospholipids

Bevers EM, Wolfs JLN, Comfurius P, Zwaal RFA (2003) Platelets and the propagation of coagulation.

Thrombosis: Fundamental and Clinical Aspects, chapter 9, 143-159, Arnout J, de Gaetano G, Hoylaerts M, Peerlinck K, Van Geet C, Verhaeghe $R$ (ed.), Leuven Universtity Press 


\section{Summary}

Platelets serve an important function in the hemostatic process. Besides the physical barrier they form upon aggregation in order to prevent further blood loss, platelets also contribute to the propagation of the blood coagulation process. They do so by providing a platform for the assembly of enzymatic complexes of coagulation proteins that promote the formation of thrombin, which subsequently converts fibrinogen into insoluble fibrin. Conversely, thrombin, as a potent platelet agonist, will contribute to modify the platelet surface to become procoagulant. Platelet procoagulant activity is primarily due to surface exposure of anionic phospholipids, mainly phosphatidylserine, normally present in the cytoplasmic leaflet of the plasma membrane. The role of phospholipids in coagulation and the mechanisms that are presently thought to control the appearance of phosphatidylserine at the platelet surface is the subject of this review. 


\section{Introduction}

Platelets are crucial cellular elements in the process of hemostasis and thrombosis. Upon vessel wall damage, platelets adhere to components present in the subendothelial layer, become activated and aggregate to form a platelet plug that causes arrest of a bleeding. The simultaneously initiated cascade of blood coagulation will produce an insoluble meshwork of fibrin, which consolidates the platelet plug resulting in a stable thrombus. Although in vitro both processes can proceed independently, in vivo they are mutually dependent and complementary in the hemostatic process. Platelets play a role in the initiation phase of coagulation as well as in the propagation phase. ${ }^{1,2}$ In the initiation phase, the tissue factor-factor VIIa complex on the vessel wall or from monocyte-derived microparticles interacting with adhering platelets produces traces of factor IXa, $X a$ and thrombin. Traces of factor $X a$ activate prothrombin to produce thrombin. The latter activates platelets to facilitate binding of factor $X I$ to the glycoprotein Ib-V-IX complex. Thrombin subsequently activates platelet bound factor XI, which activates factor IX to make the transition to the propagation phase of the coagulation process. This assures sustained generation of factor $X a$ and thrombin, once TFPI (tissue factor pathway inhibitor) has terminated the tissue factor pathway. The factor $X$ and prothrombin activating complexes of the propagation phase are assembled on the surface of platelets through interaction with anionic phospholipids. In quiescent platelets, anionic phospholipids are almost exclusively located in the cytoplasmic leaflet of the membrane, but become exposed as part of the activation process. This review will mainly focus on the significance of (platelet) phospholipids in thrombin formation and on the plasma membrane machinery that controls transbilayer distribution of (procoagulant) phospholipids in platelets and other blood cells.

\section{How lipids contribute in the coagulation process.}

After the down regulation of the initiation phase of coagulation, two sequential reactions of the coagulation cascade assure sustained thrombin formation (Figure 1.1). Factor $X$ is activated to factor $X a$ by the 'tenase' complex, consisting of factors IXa and VIIIa; factor Xa assembles with factor $\mathrm{Va}$ to form the prothrombinase complex, which promotes the conversion of prothrombin to thrombin. ${ }^{3,4} \mathrm{~A}$ negatively 
charged phospholipid surface enables assembly of these complexes through both electrostatic and hydrophobic interactions with the vitamin K-dependent enzymes, factor IXa and $\mathrm{Xa}$ and the nonenzymatic cofactors VIIIa and Va. The significance of phospholipids is $i$. to increase the local concentration of coagulation factors, ii. to induce conformational changes required for optimal function of coagulation factors, iii. to facilitate transfer of substrate and product between coagulation complexes and finally, $i v$. to restrict the activity of the coagulation process to areas of injury $y^{5-7}$, since procoagulant phospholipids are mainly provided by activated platelets.

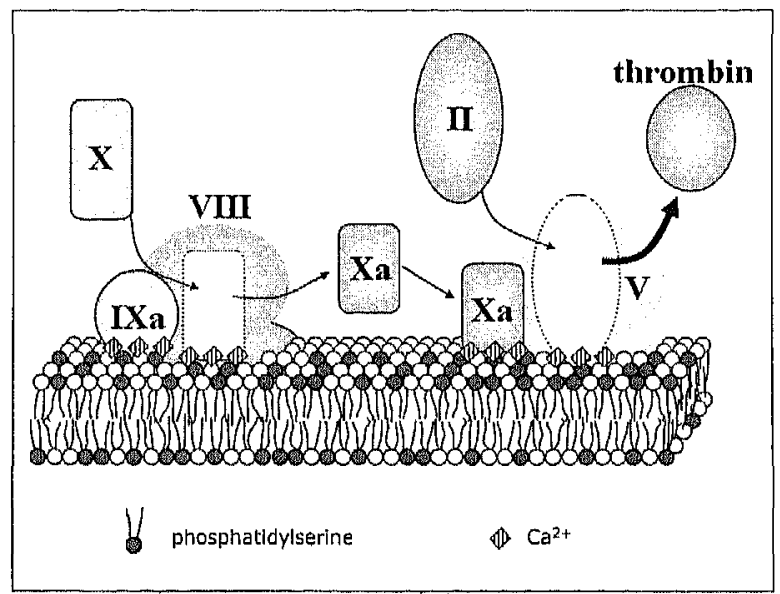

Figure 1.1 Model of the tenase and prothrombinase complex assembled on a phospholipid surface. The proteolytic enzyme, factor IXa, interacts with the non-enzymatic factor VIIIa to form the tenase complex that activates the zymogen factor $X$ to its active form, factor $X a$. The latter associates with the non-enzymatic factor $V a$ to assemble the prothrombinase complex, which activates prothrombin to thrombin. A negatively-charged phospholipid surface and the presence of $\mathrm{Ca}^{2+}$-ions enable formation of these complexes through both electrostatic and hydrophobic interactions.

While a variety of negatively charged lipids, when mixed with neutral phospholipids like phosphatidylcholine (PC), are generally capable of enhancing the activity of the coagulation complexes, phosphatidylserine (PS) is the most effective anionic phospholipid. ${ }^{8}$ Phospholipid surfaces containing 10-15 mol\% PS are optimal for tenase- and prothrombinase activity; a PS content exceeding $15 \mathrm{~mol} \%$ becomes less efficient for catalytic activity. ${ }^{9}$ Interestingly, the interaction of factors IXa and VIIIa in the tenase complex, and factors $X a$ and $V a$ in the prothrombinase complex with naturally 
occurring phosphatidyl-L-serine $\left(P_{L} S\right)$ is stereoselective and occurs with much higher affinity than binding to phosphatidyl-D-serine $\left(P_{D} S\right)$ or other anionic phospholipids. ${ }^{10-12}$ Moreover, it was demonstrated that changing the surface charge from negative to positive by incorporation of cationic stearylamine in vesicles containing anionic phospholipids has virtually no effect on the procoagulant activity of

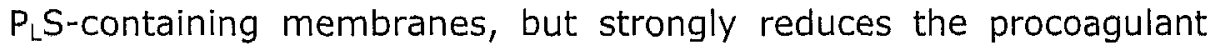
capacity of vesicles containing $P_{D} S$ or other anionic phosphorlipids. ${ }^{10,11,13}$ These findings support the notion that $\mathrm{P}_{\mathrm{L}} \mathrm{S}$ mediates functionally important hydrophobic binding of coagulation proteins to lipid surfaces, unlike other anionic lipids including its enantiomer $P_{D} S$, which mainly seem to bind coagulation factors via polar interactions. This, however, does not implicate that phospholipids other than PS are of no importance. Although phosphatidylethanolamine (PE) has no net charge at physiological $\mathrm{pH}$, incorporation of $\mathrm{PE}$ in PS-PC vesicles significantly promotes their procoagulant activity. ${ }^{14,15}$ The effect of PE is most pronounced for membranes with low mol\% PS as shown for the prothrombinase activity in Figure 1.2. It has been demonstrated that PE induces high affinity bindings sites for the cofactors VIIIa and Va in particular at vesicles with less than $5 \mathrm{~mol} \%$ PS. As can be seen from Figure 1.2, the advantage of the presence of PE disappears at higher mole fractions PS (>10 mol\%). Opposite to the effect of $P E$, the prothrombinase activity is profoundly reduced when sphingomyelin (SM) is substituted for PC in PS-containing vesicles (Figure 1.2).

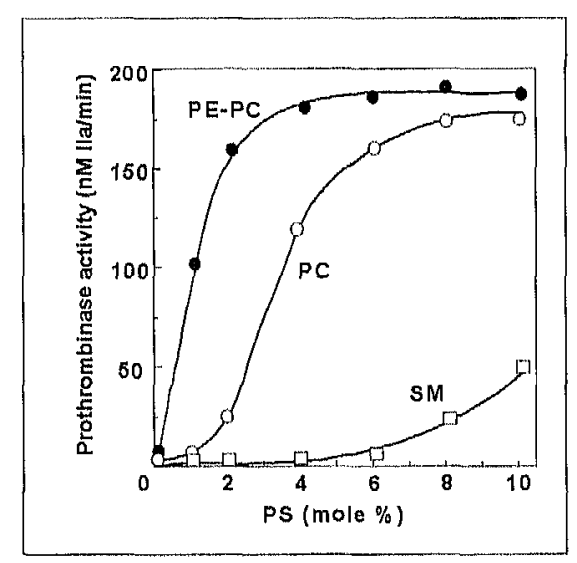

Figure 1.2 Prothrombinase activity as a function of PS content of phospholipid vesicles with different phospholipid composition. PS is titrated in vesicles composed of PC, SM or a mixture of PC and PE (30 mole\%). (IIa, thrombin). (adapted from ref. ${ }^{15}$ ). 
The reasons for the modulating effects of these phospholipids prothrombinase are presently unknown. In addition to the contribution of the polar headgroup, the composition of the acyl chains of the phospholipids also exerts a significant influence on the procoagulant properties of a membrane surface. Depending on the ratio of saturated and unsaturated acyl chains and the temperature of the environment, membranes can exist in a liquid-crystalline (fluid) or in a gel state. Membranes in the fluid phase have a higher prothrombinase activity than those in the gel state. ${ }^{16}$ This may be due to changes in the reaction pathway of prothrombin activation as well as to a lower affinity of the prothrombinase complex for saturated versus unsaturated lipids. Finally, it should be mentioned that cholesterol, as a spacing molecule, moderately improves the procoagulant activity of SM-PS vesicles, whereas it has no effect on the activity of PS-PC vesicles. ${ }^{15}$ For a more complete review on lipidprotein interactions in blood coagulation, the reader is referred to ref. ${ }^{3}$ The modulating effects of various lipids present in biological membranes may explain discrepancies found between the catalytic properties of PS-exposing platelets and those of artificial PS-PC vesicles. This notion may in part resolve a long-lasting debate on the possible involvement of protein receptors for several components of the tenase and prothrombinase complex on the platelet membrane.

As will be clear from the foregoing, transversal distribution of the various lipid components in the plasma membrane determines the procoagulant properties of platelets and other blood cells. Therefore, tight control of the transbilayer lipid distribution forms an essential part of the control of the hemostatic process. The following paragraph will focus on the proteins involved in these regulation mechanisms.

\section{Regulation of transbilayer lipid distribution: controlling surface-exposed PS}

The plasma membrane of platelets is composed of the cholinecontaining phospholipids, PC and SM, comprising somewhat more than half of the total phospholipids, and the aminophospholipids PE and PS. The amount of procoagulant PS in platelets amounts to approximately $10 \%$. The lipids are distributed over both leaflets of the plasma membrane in a non-random fashion (Figure 1.3, left panel). SM and PC dominate the external leaflet of the membrane, whereas PS and PE are predominantly sequestered in the inner leaflet. Specific interactions of aminophospholipids with the 
cytoskeleton have not been rigorously ruled out to contribute to the maintenance of transbilayer lipid asymmetry. However, current concepts focus on a role for integral membrane proteins that act as transporters to shuttle lipids back and forth between both leaflets of the membrane. At least three distinct protein-mediated activities can be distinguished (Figure 1.3, middle panel): i. 'flippase', which facilitates a rapid inward transport of lipids, ii. 'floppase', which mediates an opposite directed outward transport and iii. 'scramblase', which enables rapid bi-directional transport. Whereas the first two activities generate an asymmetric lipid distribution over the membrane, the latter is responsible for its collapse.
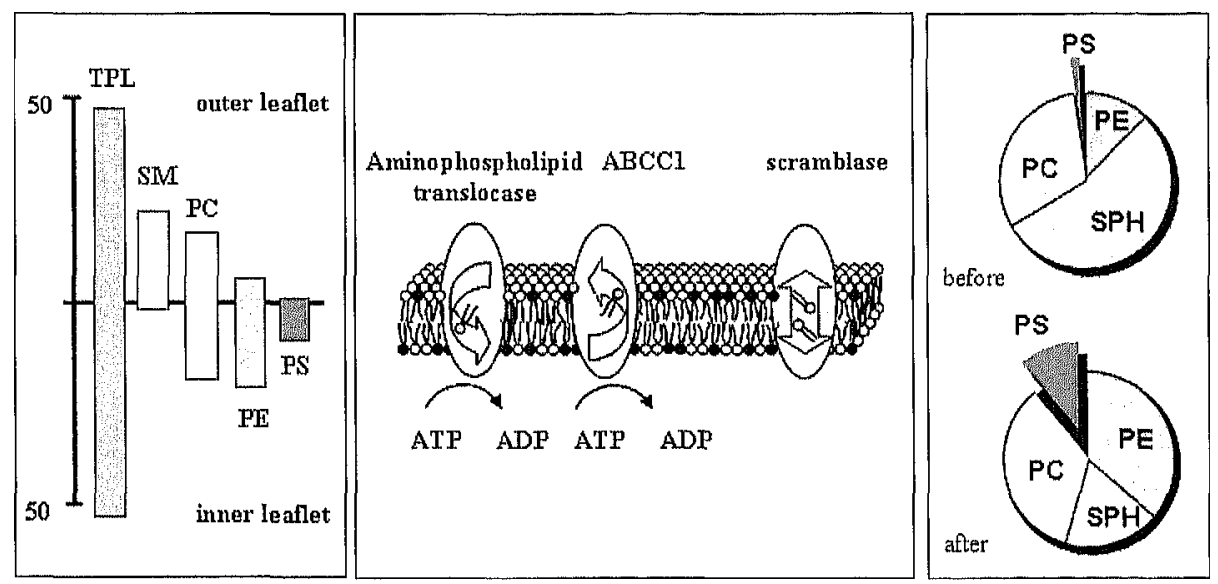

Figure 1.3 Control of transbilayer phospholipld distribution. Left panel: distribution of the major phospholipids in the plasma membrane of blood platelets. The membrane outer leaflet consists mainly of choline-containing phospholipids; the aminophospholipids are almost exclusively located in the cytofacial leaflet of the membrane. Middle panel: the concerted action of two oppositely directed phospholipid transporters, aminophospholipid translocase and $A B C C 1$, maintains a dynamic asymmetric steady state distribution of the lipids at the expense of ATP. Phospholipid scramblase facilitates transmembrane lipid migration in both directions and causes the asymmetric distribution to dissipate. Right panel: phospholipid composition of the outer leaflet of the platelet plasma membrane before and after co-stimulation with collagen and thrombin. Note the increased exposure of PS after stimulation, but also the increased PE and decreased SM content of the outer leaflet. 
The first evidence for a specific lipid transporting system came from experiments with erythrocytes, some twenty years ago. Using spinlabeled phospholipid probes, it was demonstrated that aminophospholipids, but not choline-containing phospholipids, are rapidly transported from outer to inner leaflet of the cell membrane. ${ }^{17}$ Several other investigators using either fluorescent-labeled, radiolabeled, or short acyl chain phospholipids corroborated the activity of this transporter, referred to as aminophospholipid translocase or flippase. ${ }^{18-20}$ Inward movement of PS occurs rapidly with half times of 5-10 min and is more efficient than that of PE. Transport is stereospecific with respect to the naturally occurring L-isomers of the glycerol moiety ${ }^{21}$ and is sensitive to sulfhydryl reagents and bromophenacylbromide, suggesting the requirement for one or more cysteine and histidine residues, respectively. ${ }^{22,23}$ One molecule of ATP is hydrolysed per lipid molecule transported ${ }^{24}$, in line with the sensitivity to inhibition by vanadate. ${ }^{17}$ When cytoplasmic $\mathrm{Ca}^{2+}$-levels reach the micromolar range, aminophospholipid transport is inhibited. ${ }^{25}$ Aminophospholipid translocase activity has been demonstrated in a wide variety of cell types ${ }^{26}$, which underscores its importance in maintaining or restoring lipid asymmetry. Platelets activated with thrombin exhibit a more than twofold increase in translocase activity ${ }^{27}$, but it is not clear whether this is caused by a change in catalytic efficiency per se, or is due to an increased number of translocase copies in the plasma membrane resulting from fusion of internal membranes with the plasma membrane during the secretory event. The identity of the aminophospholipid translocase is still not unequivocally resolved. A purified $\mathrm{Mg}^{2+}$-ATPase from red blood cells, reconstituted into proteoliposomes, could enhance transport of spin-labeled PS analogs across the bilayer. ${ }^{28}$ However, the active protein fraction was inhomogeneous, with proteins ranging from 32-165 kDa and further effects to purify the enzyme have been unsuccesful in demonstricting flippase activity. ${ }^{29}$ In another approach to establish the identity of the transporter, a c-DNA of a P-type ATPase from chromaffin granules with aminophospholipid translocase activity was cloned and found to be highly homologous to the drs 2 gene in yeast. ${ }^{30}$ Drs null mutants were demonstrated to have a phenotype deficient in PS translocation ${ }^{30,31}$, although other groups have been unable to confirm these findings. ${ }^{32,33}$

Studies with a photo-activatable PS analog in red blood cells showed preferential labeling of a $31 \mathrm{kDa}$ protein only under conditions conducive to PS transport. ${ }^{18,34}$ The protein, however, did not appear to be a member of the family of ATPase proteins, making its function 
as a transporter less likely. It has been suggested that this $31 \mathrm{kDa}$ protein acts in concert with the above mentioned P-type ATPase, conceivably as a regulatory component of the translocase machinery. ${ }^{35}$

Another transporter, called 'floppase', facilitates transbilayer lipid migration in opposite direction to the aminophospholipid translocase. ${ }^{23,36}$ This inward to outward movement is less specific with respect to the lipid polar headgroup as it mediates transport of both choline- and aminophospholipids. The rate of transport is about ten times slower $\left(t_{1 / 2} \sim 1.5 \mathrm{~h}\right)$ than that of the translocase-mediated inward movement of PS and PE. Floppase activity is abrogated by ATP-depletion and is inhibited by sulfhydryl- and histidine reactive agents. Recently, experiments with inhibitors and with red blood cells from knock-out mice have unravelled the identity of the floppase as ABCC1, formerly called multidrug resistance protein 1 (MRP1). ${ }^{37,38}$ $A B C C 1$ is a $180 \mathrm{kDa}$ protein, which belongs to a family of ATPbinding cassette proteins ( $A B C$ transporters) known to drive transport of various molecules and hydrophobic drugs from the cytoplasmic leaflet to the outer leaflet of the membrane. ${ }^{39,40}$ Inhibition of $A B C C 1$ results in a more random distribution of the choline-containing phospholipids, but has no appreciable effect on the localisation of the aminophospholipids, presumably due to the high rate of inward transport of these lipids by the aminophospholipid translocase. ${ }^{41}$ Thus a dynamic asymmetric steady state distribution of membrane phospholipids is accomplished by the concerted action of these two transporters (see Figure 1.3), which allows correction of alterations in lipid asymmetry that for example may result from membrane fusion events during endo- or exocytosis.

As described above, lipid asymmetry is a dynamic equilibrium maintained by ATP-consuming oppositely directed transporters. However, ATP depletion does not readily lead to a change in lipid distribution, presumably because spontaneous transbilayer migration of a phospholipid headgroup through the hydrophobic core of the bilayer is thermodynamically unfavourable. Particular conditions of cellular activation, however, may cause collapse of lipid asymmetry, a phenomenon also referred to as lipid scrambling. A paradigm of cells undergoing this rapid transverse reorganisation of membrane lipids is the platelet, which was the first cell in which this phenomenon was recognized. ${ }^{42,43}$ The most prominent feature of phospholipid scrambling is exposure of PS at the cell surface, which 
has direct implications for the procoagulant activity of these cells (vide supra). Lipid scrambling, however, is bidirectional and involves all phospholipids, regardless of their headgroup, including PE and SM (Figure 1.3, right panel). ${ }^{44}$ Bearing in mind that PE amplifies and SM attenuates the procoagulant activity of PS-PC mixtures, the net outward migration of PE and net inward migration of SM during lipid scrambling will enforce the procoagulant activity of platelets. In comparison to rates of lipid transport by the translocase and the floppase, the scrambling of lipids is fast and may occur in minutes, depending on the cell type and activator. ${ }^{44,45}$

A persistent increase in intracellular $\mathrm{Ca}^{2+}$-concentration $\left(\left[\mathrm{Ca}^{2+}\right]_{i}\right)$ is required for an active scrambling process. ${ }^{44}$ Simultaneously, increased levels of $\left[\mathrm{Ca}^{2+}\right]_{1}$ will inhibit aminophospholipid translocase activity, thereby preventing the pumping back of surface exposed PS and PE. ${ }^{25}$ Reducing intracellular $\mathrm{Ca}^{2+}$ will arrest lipid scrambling and eventually re-activate aminophospholipid translocase (provided this transporter has not been degraded by activated intracellular calpain) to restore lipid asymmetry and reduce procoagulant activity. ${ }^{46}$ It should be emphasized, however, that there is no direct relationship between the level of $\left[\mathrm{Ca}^{2+}\right]_{i}$ and the extent or rate of lipid scrambling. ${ }^{47-49}$

Scrambling of phospholipids is not directly coupled to hydrolysis of ATP. However, as shown for red blood cells $5^{50}$, prolonged ATP depletion results in a gradual loss of $\mathrm{Ca}^{2+}$-induced scrambling activity, which can be reversed by ATP repletion, suggesting that one or more components of the transporter may be constitutively phosphorylated. ${ }^{25}$ Lipid scrambling is also sensitive to the sulfhydryl reagent pyridyldithioethylamine ${ }^{44}$ and to a synthetic compound referred to as R5421, which was shown to inhibit lipid scrambling at $\mu \mathrm{M}$ concentrations without affecting aminophospholipid translocase. ${ }^{51}$.

A protein fraction from platelet- and erythrocyte membranes has been successfully reconstituted into proteoliposomes with a functional $\mathrm{Ca}^{2+}$-inducible scrambling activity that appeared pronase-, heat-, and sulfhydryl sensitive. ${ }^{52,53}$ Sims and coworkers purified and cloned the active protein from erythrocyte membranes, which they termed human phospholipid scramblase, hPLSCR1 (reviewed in ref. ${ }^{54}$ ). The recombinant protein, composed of 318 amino acid residues, is most likely a type II plasma membrane protein with a predicted single pass transmembrane domain near the $\mathrm{C}$-terminus of the protein. A short stretch of nine amino acids is present at the exoplasmic face of the membrane. At the cytoplasmic site, in the 
proximity of the transmembrane segment, there is a $\mathrm{Ca}^{2+}$-binding loop motive as well as a number of palmitoylated cysteinyl residues possibly involved in membrane anchoring. Although a number of properties of this protein are not inconsistent with those proposed for a lipid scrambling function, other data strongly suggest that this protein may not function as a lipid scramblase (reviewed in refs 25 and ${ }^{54)}$. In particular, transcriptional up-regulation of the cloned protein by treatment with interferon was not accompanied by increased scrambling activity. Moreover, B-lymphocytes from a patient with Scott syndrome, despite of being deficient in scramblase activity (vide infra), have normal levels of this protein and a corresponding mRNA with a nucleotide sequence identical to that of controls. Finally, lipid scrambling appeared not impaired in mice with the hPLSCR1 gene deleted, although scrambling activity may have been rescued by related proteins (hPLSCR2-4).

While the identity of the scramblase remains obscure, it has been suggested that complexes of $\mathrm{Ca}^{2+}$ and phosphatidylinositol 4,5bisphosphate $\left(\mathrm{PIP}_{2}\right)$, a minor membrane phospholipid component, may cause perturbation of the bilayer to the extent that lipid scrambling occurs without involvement of a protein. ${ }^{55}$ However, subsequent studies showed that scramblase deficient cells (Scott blood cells; porcine erythrocytes) have a higher PIP $_{2}$ content than normal blood platelets, which have the highest scramblase activity so far observed. ${ }^{56}$

Lipid scrambling is not restricted to platelets and erythrocytes, but has been demonstrated in several other cells types such as lymphocytes, endothelial cells, smooth muscle cells and tumorigenic cells. ${ }^{25}$ Appearance of PS in the outer membrane leaflet is a hallmark of cells undergoing apoptosis, thereby marking these cells for uptake and removal by macrophages. ${ }^{57,58}$ In addition, surface exposure of aminophospholipids plays a distinct role in early cell development ${ }^{59}$ and in fusion events during formation of multinucleated cells in heart- and skeletal muscle. ${ }^{60}$

Progressive scrambling of membrane phospholipids during platelet activation is generally accompanied by outward blebbing of the platelet plasma membrane and subsequent shedding of microvesicles $^{48,61,62}$ The strong correlation between PS exposure and production of microvesicles originally led to the proposal that membrane fusion events, as part of the shedding process, cause transient perturbations of the normal bilayer structure, which would account for the collapse of lipid asymmetry. Evidence has been 
presented, however, that lipid scrambling and microvesicle formation can be uncoupled and that these processes proceed along independent pathways. ${ }^{48,63-66}$ Whereas microvesicle membranes are generally lipid-symmetric, collapse of lipid asymmetry in the plasma membrane of the remnant platelets is usually partial. This may be the result of a difference in balance between the activities of the various lipid transporters. Moderate $\mathrm{Ca}^{2+}$-levels could lead to a circumstance in which both aminophospholipid translocase and lipid scramblase are active but oppose each other. Conceivably, this situation can accommodate a wide range of steady state distributions of membrane phospholipids. ${ }^{25,67}$

\section{Scott syndrome, a bleeding disorder caused by impaired lipid scrambling}

The significance of surface-exposed PS in the platelet procoagulant response is illustrated by a rare bleeding disorder known as the Scott syndrome, named after the first patient described with this defect. ${ }^{68}$ Only three female patients (from USA, France and Wales) have been documented thus far with the characteristic features of this disorder ${ }^{49,68,69}$ (for extended reviews of the Scott syndrome, the reader is referred to refs ${ }^{70}$ and ${ }^{71}$ ). The bleeding phenotype appears to transmit as an autosomal recessive trait as was concluded from family studies and studies on dogs with Scott syndrome. As first shown in the 1980's, Scott syndrome originates from a defective scrambling mechanism, which normally exposes PS at the outer surface of activated blood platelets. ${ }^{72}$ The most straightforward laboratory diagnosis is a complete absence of a procoagulant response due to lack of PS exposure in platelets and erythrocytes upon treatment with $\mathrm{Ca}^{2+}$-ionophore. Platelet activation by combined action of collagen and thrombin induces a procoagulant activity, which is approximately $30 \%$ of normal when measured as tenase and prothrombinase activity. ${ }^{72}$ The reduced procoagulant activity appeared to correlate well with a much lower extent of surface exposed PS as measured by phospholipases. Associated with the reduced procoagulant activity, Scott cells exhibit also an impaired microvesicle production, which could not be related to a defective calpain activity. ${ }^{61,73}$ Whether or not the impaired procoagulant activity is associated with a reduced store operated calcium entry is still a matter of debate; no defective $\mathrm{Ca}^{2+}$-response was observed for the American and Welsh Scott patients, whereas in the French Scott patient the store regulated calcium influx was markedly 
diminished. ${ }^{49,74}$ Some studies with Scott platelets indicate a reduced tyrosine phosphorylation ${ }^{51,73}$ and decreased pseudopod formation ${ }^{75}$, but the implications of these finding in relation to impaired lipid scrambling remain unclear.

The Scott phenotype is not restricted to platelets, but appears to affect multiple haematological lineages, including erythrocytes and lymphocytes. ${ }^{69,70,76}$ Also erythrocyte ghosts have an impaired scramblase, indicating that the defect is restricted to the plasma membrane or to a tightly membrane-associated component. While these data are suggestive for a mutation in one or more proteins responsible for, or involved in lipid scrambling, normal levels of hPLSCR1 mRNA were found in Epstein-Barr virus transformed lymphoblasts from Scott patients, with a deduced amino acid sequence identical to that of controls. ${ }^{77,78}$ This finding could argue against the function of hPLSCR as a scramblase, but may also indicate a functional defect in a regulatory component. In this respect it is of interest to mention that B-lymphocytes from a Scott patient, which are defective in exposing PS upon treatment with $\mathrm{Ca}^{2+}$-ionophore, have a normal PS exposure upon induction of apoptosis. ${ }^{45}$ This may suggest the existence of different pathways to activate the scramblase, one of which is impaired in Scott syndrome or, alternatively, that cells possess more than one type of scramblase.

Receptors and activators involved in platelet procoagulant response

Bypassing all receptor-signalling pathways, the most powerful inducer of platelet procoagulant activity is $\mathrm{Ca}^{2+}$-ionophore. ${ }^{25,43,79}$ Platelets, stimulated in this way undergo large changes in shape, rounding off to balloon-like structures, a process accompanied by extensive degradation of cytoskeletal components. ${ }^{79,80}$ The plasma membrane forms outward-directed blebs, which are subsequently shed in the form of procoagulant microparticles. The most potent physiological trigger to evoke a procogulant response of washed platelets in suspension is the combined action of collagen and thrombin. ${ }^{42,43}$ Thrombin alone, although being a potent activator to induce platelet aggregation and release, does not cause appreciable surface exposure of PS. ${ }^{43,44,81}$ It appears that the interaction of platelets with collagen is crucial to cause the signalling that leads to a procoagulant response. This is also observed for model systems in which platelets are deposited on collagen-coated glass surfaces. ${ }^{82}$ 
Also, platelets bound to fibrin (but not fibrinogen) and subsequently activated by thrombin show a procoagulant response ${ }^{83,84}$, which might be required to ensure exposure of procoagulant phospholipids in the periphery of a growing thrombus. The precise signalling steps that lead to PS exposure are still not completely understood (consult ref. $^{2}$ for a recent review). There is increasing evidence that interaction of collagen with glycoprotein VI plays a predominant role ${ }^{85,86}$, although a simultaneous interaction with integrin $\alpha_{2} \beta_{1}$ seems to potentiate the response to GP VI activation. ${ }^{85,87}$ Activation via glycoprotein VI can also be accomplished by collagen related peptides (triple helical structured peptides of glycine, proline and hydroxyproline ${ }^{88}$ ), or by the snake venom toxin convulxin. ${ }^{89}$ Since antibodies against integrin $\alpha_{I I b} \beta_{3}$ and glycoprotein Ib-V-IX suppress platelet-dependent thrombin formation in plasma, these receptors may also seem to play a role in the procoagulant response..$^{90,91}$ Although von Willebrand factor-glycoprotein Ib interaction is required for adhesion of platelets to collagen under flow at high shear rates ${ }^{92}$, it is presently unclear whether this interaction per se contributes to the process of exposing PS.

There appears to be consensus that a sustained increased $\left[\mathrm{Ca}^{2+}\right]_{1}$ is essential to induce a procoagulant response and concomitant blebbing and microvesicle production. ${ }^{2}$ This may explain why thrombin is only a weak agonist to induce a procoagulant response on its own, since the rise in $\left[\mathrm{Ca}^{2+}\right]_{i}$ observed with this agonist is transient. It could be hypothesized that a transient rise in $\mathrm{Ca}^{2+}$ is accompanied by a temporary and partial activation of the scrambling process, which together with an increased translocase activity observed in platelets after stimulation with thrombin ${ }^{27}$ may result in a limited exposure of PS. The combined action of collagen and thrombin acts in a synergistic manner, possibly by promoting a persistent high $\left[\mathrm{Ca}^{2+}\right]_{\mathrm{i}}$, although some authors have claimed that thrombin alone is sufficient for PS exposure. ${ }^{91,93}$ The additional effect of thrombin on the collagen-induced procoagulant response can also be produced by SFLLNR, a synthetic peptide which mimics the tethered peptide ligand that becomes unmasked on the thrombinreceptors' $N$-terminal exodomain, suggesting involvement of G-protein-coupled protease-activated receptor 1 (PAR1) rather than PAR4. ${ }^{93}$ Inhibitors of sarco/endoplasmic reticulum $\mathrm{Ca}^{2+}$-ATPases such as thapsigargin, strongly potentiate and prolong the $\mathrm{Ca}^{2+}$-response evoked by thrombin, which results in a significant PS exposure, once more underscoring the role of elevated $\left[\mathrm{Ca}^{2+}\right]_{i}$ in the lipid scrambling process. ${ }^{47,48}$ 
The contribution of platelets to an efficient and rapid production of fibrin is not restricted to the generation of an anionic phospholipid surface as catalytic platform for enzyme complexes, but also involves protein components. Small amounts of factor Xa, produced by the tissue factor/factor VIIa complex, can activate prothrombin bound to platelet integrin $\alpha_{I I b} \beta_{3}$ to form localized thrombin, as suggested by Plow and co-workers. ${ }^{94}$ After the initiation phase of the coagulation process has been terminated by the action of TFPI, the production of factor IXa proceeds through the pathway of factor XIa to ensure continuation of the coagulation process. Walsh and coworkers have proposed a model for the activation of factor IX by platelet-bound factor XIa. ${ }^{95,96}$ They found that thrombin-activated platelets cause a 5000-10,000 fold enhancement of the conversion of factor XI into factor XIa by thrombin, a stimulation that could not be mimicked by procoagulant phospholipids. The glycoprotein $\mathrm{Ib}_{a}$ of the $\mathrm{GPI}_{b}-\mathrm{V}$-IX complex was identified as the binding site for factor XI. ${ }^{97}$

Besides the anionic phospholipid surface to accelerate the subsequent formation of factor $X a$ and thrombin, protein receptors for both the tenase and prothrombinase complexes have been postulated. However, direct evidence for the existence of specific protein receptors for any of the components of both complexes is still lacking. Moreover, comparisons between platelets and phospholipid vesicles have often been made with platelets activated by thrombin, which may not be relevant since this agonist does not lead to appreciable exposure of PS. Moreover, lipid vesicles used in most of these comparative studies were usually composed of mixtures of PS and PC (20-25 mole\% PS), ignoring the modulating effects of other membrane phospholipids such as PE and SM. The involvement of protein receptors has been discussed in two recent reviews. ${ }^{1,2}$

As part of the prothrombinase complex, factor Va has an important function in the coagulation process. Approximately $20 \%$ of factor $V$ in whole blood is present in the platelet $\alpha$-granules and can be secreted upon activation of the platelets. ${ }^{98,99}$ Some bleeding disorders have been related to quantitative and qualitative abnormalities in platelet factor $V$, such as for factor $V$ Quebec ${ }^{100}$ and factor $V$ New York. ${ }^{101}$ Furthermore, it has been demonstrated that platelet factor $V$, in contrast to plasma factor $V$, when bound to platelets, is protected from proteolytic inactivation by activated protein $C^{102}$ Recently, it was demonstrated that co-stimulation of platelets with collagen and thrombin (so-called COAT platelets) results in the formation of a subpopulation (approximately 30\%) of platelets, which have a higher prothrombinase activity than produced by any other physiological 
agonist examined. ${ }^{103}$ This appeared to be related to the expression of high levels of surface-bound, $\alpha$-granule derived factor $V a$, the functional significance of which was demonstrated by the preferential binding of factor Xa. Expression of COAT factor $V$ parallels the exposure of PS. Later, it was demonstrated that several other adhesive and coagulation proteins bind to COAT platelets through transglutaminase catalyzed serotonin conjugation to an as yet unidentified receptor. ${ }^{104}$

\section{Platelets and coagulation: an overview}

Platelets are indispensable for the normal hemostatic process because they participate in various steps of the coagulation pathway as is summarized in Figure 1.4. After the onset of coagulation and the formation of small amounts of factor IXa and Xa by vessel wallor leucocyte-derived tissue factor/factor VIIa, localized thrombin formation ensures adaptation of adhering and accumulating platelets required for propagation of the coagulation, once the TFPI pathway has terminated the initiation steps. Activation of $\alpha_{I I b} B_{3}$-bound prothrombin generates surface-localized thrombin, which subsequently activates platelets to enable binding of factor XI to $\mathrm{GPI}_{b}$. These steps form the link between the initiation and propagation phase, since subsequent activation of platelet-bound factor XI in turn will set off the tenase complex via activation of factor IX, to take over Xa production from tissue factor/factor VIIa. To allow the tenase and prothrombinase reaction to proceed at high rates, the platelet surface requires reorganization to expose PS. This process is predominantly effectuated through a GP VI-dependent signalling pathway, which causes a sustained elevation of $\left[\mathrm{Ca}^{2+}\right]_{i}$. This condition activates a phospholipid scramblase, which brings about a collapse of membrane lipid asymmetry resulting in exposure of PS at the platelet outer surface. Simultaneous inhibition of the aminophospholipid translocase prevents PS from being pumped back to the inner leaflet, hence ensuring a persistent procoagulant lipid surface to support propagation of the coagulation process. Many details of this process still need to be filled in to come to an understanding of the role of platelets in coagulation and to allow development of sophisticated anti-platelet drugs for intervention in thrombosis and hemostasis. 


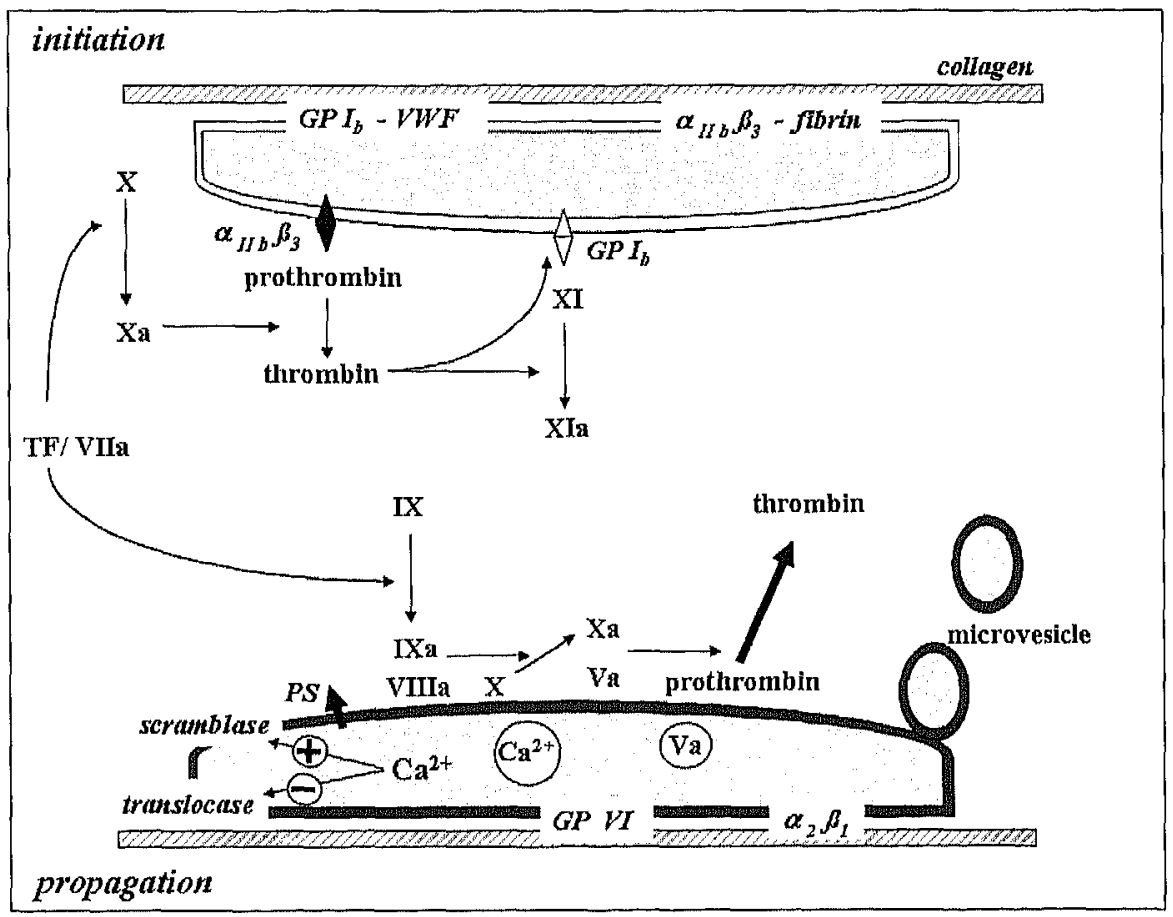

Figure 1.4 Role of platelets in the process of blood coagulation. For details, refer to the text. 


\section{Aims and outline of the thesis}

The objective of this thesis is to elucidate further details of the phospholipid scrambling process in blood platelets and erythrocytes. In chapter 2, we have made an attempt to study lipid scrambling at the level of single cells and have specifically focused on the activity of phospholipid scramblase and aminophospholipid translocase. This may provide an answer to the question how various agonists cause a different extent of procoagulant response, and whether the response is present in all platelets in suspension or restricted to a sub-fraction of the platelets.

Lipid scrambling is usually accompanied by changes in cell morphology, partially explained by differences in the rate of inward and outward movement of various lipids resulting in an excess of mass in the outer monolayer with subsequent exfoliation of the membrane. In chapter $\mathbf{3}$ we have investigated the consequences of changes in (membrane) morphology on $\mathrm{Ca}^{2+}$-induced lipid scrambling by manipulating cell morphology through incorporation of amphipatic compounds in either one of the two leaflets of the plasma membrane. The question is addressed whether a mass excess in the outer- or inner leaflet of the bilayer stimulates or inhibits lipid scrambling.

Elevation of the intracellular $\mathrm{Ca}^{2+}$ concentration not only induces lipid scrambling, but also activates $\mathrm{Ca}^{2+}$-sensitive $\mathrm{K}^{+}$channels, resulting in a loss of intracellular $\mathrm{K}^{+}$and $\mathrm{Cl}^{-}$ions. As a consequence, the change in osmolarity leads to cell shrinkage and morphological changes, including microvesicle formation. In chapter 4, we have studied the effect of inhibitors of $\mathrm{K}^{+}$efflux on the development of procoagulant activity upon platelet activation. In chapter $\mathbf{5}$, as a follow up of chapter IV, we have addressed the question whether the intracellular cation composition has a direct effect on the lipid scramblase. Finally, chapter 6 provides a general discussion in which the results of our studies are placed in a broader context of the present knowledge of the lipid scrambling process. 


\section{References}

1. Monroe DM, Hoffman $M$, Roberts HR. Platelets and thrombin generation. Arterioscler Thromb Vasc Biol 2002; 22: 1381-9.

2. Heemskerk JW, Bevers EM, Lindhout T. Platelet activation and blood coagulation. Thromb Haemost 2002; 88: 186-93.

3. Zwaal RF, Comfurius $P$, Bevers $E M$. Lipid-protein interactions in blood coagulation. Biochim Biophys Acta 1998; 1376: 433-53.

4. Mann KG, Butenas 5 , Brummel $K$. The dynamics of thrombin formation. Arterioscler Thromb Vasc Biol 2003; 23: 17-25.

5. Van Rijn JL, Govers-Riemslag JW, Zwaal RF, Rosing J. Kinetic studies of prothrombin activation: effect of factor $V a$ and phospholipids on the formation of the enzyme-substrate complex. Biochemistry 1984; 23: 4557-64.

6. Kalafatis M, Swords NA, Rand MD, Mann KG. Membrane-dependent reactions in blood coagulation: role of the vitamin K-dependent enzyme complexes. Biochim Biophys Acta 1994; 1227: 113-29.

7. Chen $Q$, Lentz $B R$. Fluorescence resonance energy transfer study of shape changes in membrane-bound bovine prothrombin and meizothrombin. Biochemistry 1997; 36: 4701-11.

8. Gerads I, Govers-Riemslag JW, Tans G, Zwaal RF, Rosing J. Prothrombin activation on membranes with anionic lipids containing phosphate, sulfate, and/or carboxyl groups. Biochemistry 1990; 29: 7967-74.

9. Pei G, Powers DD, Lentz BR. Specific contribution of different phospholipid surfaces to the activation of prothrombin by the fully assembled prothrombinase. J Biol Chem 1993; 268: 3226-33.

10. Gibert GE, Drinkwater D. Specific membrane binding of factor VIII is mediated by O-phospho-L-serine, a moiety of phosphatidylserine. Biochemistry 1993; 32: 9577-85.

11. Comfurius P, Smeets EF, Willems GM, Bevers EM, Zwaal RF. Assembly of the prothrombinase complex on lipid vesicles depends on the stereochemical configuration of the polar headgroup of phosphatidylserine. Biochemistry 1994; 33: 10319-24.

12. Gilbert GE, Arena AA. Activation of the factor VIIIa-factor IXa enzyme complex of blood coagulation by membranes containing phosphatidyl-L-serine. J Biol Chem 1996; 271: 11120-25.

13. Rosing 3, Speijer H, Zwaal RF. Prothrombin activation on phospholipid membranes with positive electrostatic potential. Biochemistry 1988; 27: 8-11.

14. Gilbert GE, Arena $A A$. Phosphatidylethanolamine induces high affinity binding sites for factor VIII on membranes containing phosphatidyl-L-serine. J Biol Chem 1995; 270: 18500-5.

15. Smeets EF, Comfurius P, Bevers EM, Zwaal RF. Contribution of different phospholipid classes to the prothrombin converting capacity of sonicated lipid vesicles. Thromb Res 1996; 81: 419-26.

16. Govers-Riemslag JW, Janssen MP, Zwaal RF, Rosing J. Effect of membrane fluidity and fatty acid composition on the prothrombin-converting activity of phospholipid vesicles. Blochemistry 1992; 31: 10000-8.

17. Seigneuret M, Devaux PF. ATP-dependent asymmetric distribution of spin-labeled phospholipids in the erythrocyte membrane: relation to shape changes. Proc Nat! Acad Sci U S A 1984; 81 : 3751-5.

18. Connor J, Schroit AJ. Transbilayer movement of phosphatidylserine in erythrocytes: inhibition of transport and preferential labeling of a 31,000-dalton protein by sulfhydryl reactive reagents. Biochemistry $1988 ; 27: 848-51$. 
19. Tilley L, Cribier S, Roelofsen B, Op den Kamp JA, van Deenen LL. ATP-dependent translocation of amino phospholipids across the human erythrocyte membrane. FEBS Lett 1986; 194: 21-7.

20. Daleke $\mathrm{DL}$, Huestis $\mathrm{WH}$. Incorporation and translocation of aminophospholipids in human erythrocytes. Biochemistry 1985; 24: 5406-16.

21. Martin OC, Pagano RE. Transbilayer movement of fluorescent analogs of phosphatidylserine and phosphatidylethanolamine at the plasma membrane of cultured cells. Evidence for a protein-mediated and ATP-dependent process(es). J Biol Chem 1987; 262: 5890-8.

22. Zachowski A, Favre E, Cribier S, Herve P, Devaux PF. Outside-inside translocation of aminophospholipids in the human erythrocyte membrane is mediated by a specific enzyme. Biochemistry 1986; 25: 2585-90.

23. Connor J, Pak CH, Zwaal RF, Schroit AJ. Bidirectional transbilayer movement of phospholipid analogs in human red blood cells. Evidence for an ATP-dependent and protein-mediated process. J Biol Chem 1992; 267: 19412-7.

24. Beleznay Z, Zachowski A, Devaux PF, Ott P. Characterization of the correlation between ATP-dependent aminophospholipid translocation and Mg2+-ATPase activity in red blood cell membranes. Eur J Blochem 1997; 243: 58-65.

25. Bevers EM, Comfurius $P$, Dekkers DW, Zwaal RF. Lipld translocation across the plasma membrane of mammalian cells. Biochim Biophys Acta 1999; 1439: 317-30.

26. Connor J, Schroit AJ. Transbilayer movement of phosphatidylserine in nonhuman erythrocytes: evidence that the aminophospholipid transporter is a ubiquitous membrane protein. Biochemistry 1989; 28:9680-5.

27. Tilly RH, Senden JM, Comfurius P, Bevers EM, Zwaal RF. Increased aminophospholipid translocase activity in human platelets during secretion. Biochim Biophys Acta 1990; 1029: 188-90.

28. Auland ME, Roufogalis BD, Devaux PF, Zachowski A. Reconstitution of ATPdependent aminophospholipid translocation in proteoliposomes. Proc Natl Acad Sci U S A 1994; 91: 10938-42.

29. Daleke DL, Lyles JV. Identification and purification of aminophospholipid flippases. Biochim Biophys Acta 2000; 1486: 108-27.

30. Tang $X$, Halleck MS, Schlegel RA, Williamson P. A subfamily of P-type ATPases with aminophospholipid transporting activity. Science 1996; 272: 1495-7.

31. Gomes E, Jakobsen MK, Axelsen KB, Geisler M, Paimgren MG. Chilling tolerance in Arabidopsis involves ALA1, a member of a new family of putative aminophospholipid translocases. Plant Cell 2000; 12: 2441-54.

32. Siegmund $A$, Grant $A$, Angeletti $C$, Malone L, Nichols JW, Rudolph HK. Loss of Drs2p does not abolish transfer of fluorescence-labeled phospholipids across the plasma membrane of Saccharomyces cerevisiae. J Biol Chem 1998; 273: 34399-405.

33. Marx $U$, Polakowski. $T$, Pomorski $T$, Lang $C$, Nelson $H$, Nelson $N$, Herrmann A. Rapid transbilayer movement of fluorescent phospholipid analogues in the plasma membrane of endocytosis-deficient yeast cells does not require the Drs2 protein. Eur J Biochem 1999; 263: 254-63.

34. Connor J, Schroit AJ. Transbilayer movement of phosphatidylserine in erythrocytes. Inhibitors of aminophospholipid transport block the association of photolabeled lipid to Its transporter. Biochim Biophys Acta 1991; 1066: 37-42.

35. Schroit AJ, Zwaal RF. Transbilayer movement of phospholipids in red cell and platelet membranes. Biochim Biophys Acta 1991; 1071: 313-29.

36. Bitbol M, Devaux PF. Measurement of outward translocation of phospholipids across human erythrocyte membrane. Proc Natl Acad Sci U S A 1988; 85: 6783-7. 
37. Dekkers DW, Comfurius $P$, Schroit $A J$, Bevers EM, Zwaal RF. Transbilayer movement of NBD-labeled phospholipids in red blood cell membranes: outwarddirected transport by the multidrug resistance protein 1 (MRP1). Biochemistry 1998; 37: 14833-7.

38. Kamp D, Haest CW. Evidence for a role of the multidrug resistance protein (MRP) in the outward translocation of NBD-phospholipids in the erythrocyte membrane. Biochim Biophys Acta 1998; 1372: 91-101.

39. Borst $P$, Zelcer $N$, van Helvoort $A$. ABC transporters in lipid transport. Biochim Biophys Acta 2000; 1486: 128-44.

40. Dean $M$, Hamon $Y$, Chimini $G$. The human ATP-binding cassette (ABC) transporter superfamily. J Lipid Res 2001; 42: 1007-17.

41. Dekkers DW, Comfurius P, van Gool RG, Bevers EM, Zwaal RF. Multidrug resistance protein 1 regulates lipid asymmetry in erythrocyte membranes. Biochem J 2000; 350 Pt 2: 531-5.

42. Bevers EM, Comfurius P, van Rijn JL, Hemker HC, Zwaal RF. Generation of prothrombin-converting activity and the exposure of phosphatidylserine at the outer surface of platelets. Eur J Biochem 1982; 122: 429-36.

43. Bevers EM, Comfurius $P$, Zwaal RF. Changes in membrane phospholipid distribution during platelet activation. Biochim Biophys Acta 1983; 736: 57-66.

44. Williamson $P$, Bevers EM, Smeets EF, Comfurius $P$, Schlegel RA, Zwaal RF. Continuous analysis of the mechanism of activated transbilayer lipid movement in platelets. Biochemistry 1995; 34: 10448-55.

45. Williamson $P$, Christie $A$, Kohlin $T$, Schlegel RA, Comfurius $P$, Harmsma $M$, Zwaal RF, Bevers EM. Phospholipid scramblase activation pathways in lymphocytes. Biochemistry 2001; 40: 8065-72.

46. Bevers EM, Tilly RH, Senden JM, Comfurius P, Zwaal RF. Exposure of endogenous phosphatidylserine at the outer surface of stimulated platelets is reversed by restoration of aminophospholipid translocase activity. Biochemistry 1989; 28: 2382-7.

47. Smeets EF, Heemskerk JW, Comfurius P, Bevers EM, Zwaal RF. Thapsigargin amplifies the platelet procoagulant response caused by thrombin. Thromb Haemost 1993; 70: 1024-9.

48. Dachary-Prigent J, Pasquet JM, Freyssinet JM, Nurden AT. Calcium involvement in aminophospholipid exposure and microparticle formation during platelet activation: a study using Ca2+-ATPase inhibitors. Biochemistry 1995; 34: 11625-34.

49. Munnix IC, Harmsma $M$, Giddings JC, Collins PW, Feijge MA, Comfurius $P$, Heemskerk JW, Bevers EM. Store-mediated calcium entry in the regulation of phosphatidylserine exposure in blood cells from Scott patients. Thromb Haemost 2003; 89: 687-95.

50. Martin DW, Jesty J. Calcium stimulation of procoagulant activity in human erythrocytes. ATP dependence and the effects of modifiers of stimulation and recovery. J Biol Chem 1995; 270: 10468-74.

51. Dekkers DW, Comfurius P, Vuist WM, Billheimer JT, Dicker I, Weiss HJ, Zwaal RF, Bevers EM. Impaired $\mathrm{Ca} 2+$-induced tyrosine phosphorylation and defective lipid scrambling in erythrocytes from a patient with Scott syndrome: a study using an inhibitor for scramblase that mimics the defect in Scott syndrome. Blood 1998; 91: 2133-8.

52. Comfurius $P$, Williamson $P$, Smeets EF, Schlegel RA, Bevers EM, Zwaal RF. Reconstitution of phospholipid scramblase activity from human blood platelets. Biochemistry 1996; 35: 7631-4.

53. Basse F, Stout JG, Sims PJ, Wiedmer T. Isolation of an erythrocyte membrane protein that mediates $\mathrm{Ca} 2+-$ dependent transbilayer movement of phospholipid. J Biol Chem 1996; 271: 17205-10. 
54. Sims PJ, Wiedmer T. Unraveling the mysteries of phospholipid scrambling. Thromb Haemost 2001; 86: 266-75.

55. Sulpice JC, Zachowski A, Devaux PF, Giraud F. Requirement for phosphatidylinositol 4,5-bisphosphate in the $\mathrm{Ca}(2+)$-induced phospholipid redistribution in the human erythrocyte membrane. J Biol Chem 1994; 269: 6347-54.

56. Bevers EM, Wiedmer T, Comfurius $P$, Zhao J, Smeets EF, Schlegel RA, Schroit AJ, Weiss HJ, Williamson $P, Z$ waal RF, et al. The complex of phosphatidylinositol 4,5bisphosphate and calcium ions is not responsible for $\mathrm{Ca}(2+)$-induced loss of phospholipid asymmetry in the human erythrocyte: a study in Scott syndrome, a disorder of calcium-induced phospholipid scrambling. Blood 1995; 86: 1983-91.

57. Fadok VA, Bratton DL, Rose DM, Pearson A, Ezekewitz RA, Henson PM. A receptor for phosphatidylserine-specific clearance of apoptotic cells. Nature 2000; 405: 85-90.

58. Fadok VA, de Cathelineau A, Daleke DL, Henson PM, Bratton DL. Loss of phospholipid asymmetry and surface exposure of phosphatidylserine is required for phagocytosis of apoptotic cells by macrophages and fibroblasts. J Biol Chem 2001; 276: 1071-7.

59. Gadella BM, Harrison RA. Capacitation induces cyclic adenosine $3^{\prime}, 5^{\prime}$ monophosphate-dependent, but apoptosis-unrelated, exposure of aminophospholipids at the apical head plasma membrane of boar sperm cells. Biol Reprod 2002; 67: 340-50.

60. van den Eijnde $S M$, van den Hoff MJ, Reutelingsperger $C P$, van Heerde $W L$, Henfling ME, Vermeij-Keers C, Schutte B, Borgers M, Ramaekers FC. Transient expression of phosphatidylserine at cell-cell contact areas is required for myotube formation. J Cell Sci 2001; 114: 3631-42.

61. Sims PJ, Wiedmer T, Esmon CT, Weiss HJ, Shattil SJ. Assembly of the platelet prothrombinase complex is linked to vesiculation of the platelet plasma membrane. Studies in Scott syndrome: an isolated defect in platelet procoagulant activity. J Biol Chem 1989; 264: 17049-57.

62. Zwaal RF, Comfurius P, Bevers EM. Platelet procoagulant activity and microvesicle formation. Its putative role in hemostasis and thrombosis. Biochim Biophys Acta 1992; 1180: 1-8

63. Williamson P, Kulick A, Zachowski A, Schlegel RA, Devaux PF. Ca2+ induces transbilayer redistribution of all major phospholipids in human erythrocytes. Biochemistry $1992 ; 31: 6355-60$.

64. Fox JE, Austin CD, Reynolds CC, Steffen PK. Evidence that agonist-induced activation of calpain causes the shedding of procoagulant-containing microvesicles from the membrane of aggregating platelets. J Biol Chem 1991; 266: 13289-95.

65. Basse F, Gaffet P, Rendu F, Bienvenue A. Translocation of spin-labeled phospholipids through plasma membrane during thrombin- and ionophore A23187-induced platelet activation. Biochemistry 1993; 32: 2337-44.

66. Bucki R, Bachelot-Loza C, Zachowskl A, Giraud F, Sulpice JC. Calcium induces phospholipid redistribution and microvesicle release in human erythrocyte membranes by independent pathways. Biochemistry 1998; 37: 15383-91.

67. Diaz C, Schroit AJ. Role of translocases in the generation of phosphatidylserine asymmetry. J Membr Biol 1996; 151: 1-9.

68. Weiss $\mathrm{HJ}$, Vicic $W J$, Lages $B A$, Rogers $\mathrm{J}$. Isolated deficiency of platelet procoagulant activity. Am J Med 1979; 67: 206-13.

69. Toti F, Satta N, Fressinaud E, Meyer D, Freyssinet JM. Scott syndrome, characterized by impaired transmembrane migration of procoagulant phosphatidylserine and hemorrhagic complications, is an inherited disorder. Blood 1996; 87: 1409-15.

70. Weiss HJ, Lages B. Family studies in Scott syndrome. Blood 1997; 90: 475-6. 
71. Zwaal RFA, Comfurius P, Bevers EM. Scott Syndrome, a bleeding disorder caused by defective scrambling of membrane phospholipids. Biochim Biophys Acta Biochim Biophys Acta. 2004; 1636: 119-28

72. Rosing J, Bevers EM, Comfurius P, Hemker HC, van Dieijen G, Weiss HJ, Zwaal RF. Impaired factor $X$ and prothrombin activation associated with decreased phospholipid exposure in platelets from a patient with a bleeding disorder. Blood 1985; 65: 1557-61.

73. Dachary-Prigent J, Pasquet JM, Fressinaud E, Toti $F$, Freyssinet JM, Nurden AT, Aminophospholipid exposure, microvesiculation and abnormal protein tyrosine phosphorylation in the platelets of a patient with Scott syndrome: a study using physiologic agonists and local anaesthetics. $\mathrm{Br} J$ Haematol 1997; 99: 959-67.

74. Martinez MC, Martin S, Toti F, Fressinaud E, Dachary-Prigent J, Meyer D, Freyssinet JM. Significance of capacitative Ca2+ entry in the regulation of phosphatidylserine expression at the surface of stimulated cells. Biochemistry 1999; 38: 10092-8.

75. Bettache N, Gaffet P, Allegre N, Maurin L, Toti F, Freyssinet JM, Bienvenue A. Impaired redistribution of aminophospholipids with distinctive cell shape change during $\mathrm{Ca} 2+-$ induced activation of platelets from a patient with Scott syndrome. $\mathrm{Br}$ J Haematol 1998; 101: 50-8.

76. Bevers EM, Wiedmer T, Comfurius P, Shattil SJ, Weiss $H J$, Zwaal RF, Sims PJ. Defective $\mathrm{Ca}(2+)$-induced microvesiculation and deficient expression of procoagulant activity in erythrocytes from a patient with a bleeding disorder: a study of the red blood cells of Scott syndrome. Blood 1992; 79:380-8.

77. Zhou Q, Sims PJ, Wiedmer T. Expression of proteins controlling transbilayer movement of plasma membrane phospholipids in the $B$ lymphocytes from a patient with Scott syndrome. Blood 1998; 92: 1707-12.

78. Janel N, Leroy C, Laude I, Toti F, Fressinaud E, Meyer D, Freyssinet JM, KerbiriouNabias D. Assessment of the expression of candidate human plasma membrane phospholipid scramblase in Scott syndrome cells. Thromb Haemost 1999; 81: 322-3.

79. Verhallen PF, Bevers EM, Comfurius P, Zwaal RF. Correlation between calpainmediated cytoskeletal degradation and expression of platelet procoagulant activity. A role for the platelet membrane-skeleton in the regulation of membrane lipid asymmetry? Blochim Biophys Acta 1987; 903: 206-17.

80. Heemskerk JW, Siljander PR, Bevers EM, Farndale RW, Lindhout T. Receptors and signalling mechanisms in the procoagulant response of platelets. Platelets 2000; 11: $301-6$.

81. Briede JJ, Heemskerk JW, van't Veer C, Hemker HC, Lindhout T. Contribution of platelet-derived factor $V a$ to thrombin generation on immobilized collagen- and fibrinogen-adherent platelets. Thromb Haemost 2001; 85: 509-13.

82. Heemskerk JW, Vuist WM, Feijge MA, Reutelingsperger CP, Lindhout T. Collagen but not fibrinogen surfaces induce bleb formation, exposure of phosphatidylserine, and procoagulant activity of adherent platelets: evidence for regulation by protein tyrosine kinase-dependent $\mathrm{Ca} 2+$ responses. Blood 1997; 90: 2615-25.

83. Beguin $S$, Kumar R. Thrombin, fibrin and platelets: a resonance loop in which von Willebrand factor is a necessary link. Thromb Haemost 1997; 78: 590-4.

84. Billy D, Briede J, Heemskerk JW, Hemker HC, Lindhout T. Prothrombin conversion under flow conditions by prothrombinase assembled on adherent platelets. Blood Coagul Fibrinolysis 1997; 8: 168-74.

85. Heemskerk JW, Siljander P, Vuist WM, Breikers G, Reutelingsperger CP, Barnes $M]$, Knight CG, Lassila R, Farndale RW. Function of glycoprotein VI and integrin alphazbeta1 in the procoagulant response of single, collagen-adherent platelets. Thromb Haemost 1999; 81: 782-92. 
86. Siljander $P$, Farndale RW, Feijge MA, Comfurius $P$, Kos $S$, Bevers EM, Heemskerk JW. Platelet adhesion enhances the glycoprotein VI-dependent procoagulant response: Involvement of p38 MAP kinase and calpain. Arterioscler Thromb Vasc Biol 2001; 21: 618-27.

87. Kuijpers $M J$, Schulte $V$, Bergmeier $W$, Lindhout $T$, Brakebusch $C$, Offermanns $S$, Fassler R, Heemskerk JW, Nieswandt B. Complementary roles of glycoprotein VI and alpha2beta 1 integrin in collagen-induced thrombus formation in flowing whole blood ex vivo. Faseb $32003 ; 17: 685-7$.

88. Knight $C G$, Morton $L F$, Onley DJ, Peachey $A R$, Ichinohe $T$, Okuma $M$, Farndale RW, Barnes MJ. Collagen-platelet interaction: Gly-Pro-Hyp is uniquely specific for platelet Gp VI and mediates platelet activation by collagen. Cardiovasc Res 1999; 41: $450-7$.

89. Jandrot-Perrus $M$, Lagrue $A H$, Okuma $M$, Bon $C$. Adhesion and activation of human platelets induced by convulxin involve glycoprotein VI and integrin alpha2beta1. J Biol Chem 1997; 272: 27035-41.

90. Reverter JC, Beguin S, Kessels H, Kumar R, Hemker HC, Coller BS. Inhibition of platelet-mediated, tissue factor-induced thrombin generation by the mouse/human chimeric 7E3 antibody. Potential implications for the effect of C7E3 Fab treatment on acute thrombosis and "clinical restenosis". J Clin Invest 1996; 98: 863-74.

91. Dormann D, Clemetson $\mathrm{KJ}$, Kehrel BE. The GPIb thrombin-binding site is essential for thrombin-induced platelet procoagulant activity. Blood 2000; 96: 2469-78.

92. Lankhof $H$, Wu YP, Vink T, Schiphorst ME, Zerwes HG, de Groot PG, Sixma JJ. Role of the glycoprotein Ib-binding A1 repeat and the RGD sequence in platelet adhesion to human recombinant von Willebrand factor. Blood 1995; 86: 1035-42.

93. Andersen $H$, Greenberg DL, Fujikawa K, Xu W, Chung DW, Davie EW. Proteaseactivated receptor 1 is the primary mediator of thrombin-stimulated platelet procoagulant activity. Proc Natl Acad Sci U S A 1999; 96: 11189-93.

94. Byzova TV, Plow EF. Networking in the hemostatic system. Integrin alphaiibbeta3 binds prothrombin and influences its activation. J Biol Chem 1997; 272: 27183-8.

95. Baglia FA, Walsh PN. Prothrombin is a cofactor for the binding of factor XI to the platelet surface and for platelet-mediated factor XI activation by thrombin. Biochemistry 1998; 37: 2271-81.

96. Baglia FA, Walsh PN. Thrombin-mediated feedback activation of factor XI on the activated platelet surface is preferred over contact activation by factor XIIa or factor XIa. J Biol Chem 2000; 275: 20514-9.

97. Baglia FA, Badellino KO, Li CQ, Lopez JA, Walsh PN. Factor XI binding to the platelet glycoprotein Ib-IX-V complex promotes factor XI activation by thrombin. ] Biol Chem 2002; 277: 1662-8.

98. Tracy $\mathrm{PB}$, Eide $L L$, Bowie $E J$, Mann KG. Radioimmunoassay of factor $V$ in human plasma and platelets. Blood 1982; 60: 59-63.

99. Chesney CM, Pifer D, Colman RW. Subcellular localization and secretion of factor $\checkmark$ from human platelets. Proc Natl Acad Sci U S A 1981; 78: 5180-4.

100. Tracy PB, Giles AR, Mann KG, Eide LL, Hoogendoorn H, Rivard GE. Factor $V$ (Quebec): a bleeding diathesis associated with a qualitative platelet Factor $V$ deficiency. J Clin Invest 1984; 74: 1221-8.

101. Weiss HJ, Lages B, Zheng S, Hayward CP. Platelet factor V New York: a defect in factor $V$ distinct from that in factor $V$ Quebec resulting in impaired prothrombinase generation. Am J Hematol 2001; 66: 130-9.

102. Camire RM, Kalafatis $M$, Simioni $P$, Girolami A, Tracy PB. Platelet-derived factor $\mathrm{Va} / \mathrm{Va}$ Leiden cofactor activities are sustained on the surface of activated platelets despite the presence of activated protein C. Blood 1998; 91: 2818-29. 
103. Alberio L, Safa O, Clemetson KJ, Esmon CT, Dale GL. Surface expression and functional characterization of alpha-granule factor $V$ in human platelets: effects of ionophore A23187, thrombin, collagen, and convulxin. Blood 2000; 95: 1694-702.

104. Dale GL, Friese P, Batar P, Hamilton SF, Reed GL, Jackson KW, Clemetson KJ, Alberio L. Stimulated platelets use serotonin to enhance their retention of procoagulant proteins on the cell surface. Nature $2002 ; 415 ; 175-9$. 


\section{Chapter 2}

Activated scramblase and inhibited aminophospholipid translocase cause phosphatidylserine exposure in a distinct platelet fraction

Jef LN Wolfs, Paul Comfurius, Jan T Rasmussen, Jeffrey FW Keuren, Theo Lindhout, Robert FA Zwaal, Edouard M Bevers Cell Mol Life Sci. 2005; 62: 1514-25. 


\section{Abstract}

Platelet procoagulant activity is mainly determined by the extent of surface-exposed phosphatidylserine (PS), controlled by the activity of aminophospholipid translocase and phospholipid scramblase. Here, we studied both transport activities in single platelets upon stimulation with various agonists. Besides the formation of procoagulant microparticles, the results show that a distinct fraction of the platelets exposes PS when stimulated. The extent of PS exposure in these platelet fractions was similar to that in platelets challenged with $\mathrm{Ca}^{2+}$-ionophore, where all cells exhibit maximal attainable PS exposure. The size of the PS-exposing fraction depends on the agonist and is proportional to the platelet procoagulant activity. Scramblase activity was observed only in the PS-exposing platelet fraction, whereas translocase activity was exclusively detectable in the fraction that does not expose PS. We conclude that, irrespective of the agonist, procoagulant platelets exhibit maximal surface exposure of PS by switching on scramblase and inhibiting translocase activity. 


\section{Introduction}

Studies over the past two decades have revealed that different lipid transporters function in the maintenance and rearrangement of the transversal distribution of membrane phospholipids. ${ }^{1,2}$ In quiescent cells, aminophospholipid translocase is responsible for a rapid inward directed transport, which is specific for the aminophospholipids, phosphatidylserine (PS) and phosphatidylethanolamine (PE). The activity of this transporter causes an asymmetric distribution of the lipids in the plasma membrane in which the aminophospholipids, in particular PS, are primarily located in the inner leaflet, whereas the outer leaflet is dominated by the choline-containing lipids, phosphatidylcholine and sphingomyelin. Membrane lipid asymmetry dissipates upon activation of a protein termed 'scramblase', which facilitates bidirectional movement of phospholipids, irrespective of the chemical nature of the polar head group. A major consequence of activating the scramblase in cells is the appearance of PS in the membrane outer leaflet. When this occurs in blood cells, particularly in activated platelets, surface exposed PS accelerates thrombus formation by offering a catalytic surface for several enzyme complexes of the coagulation process. ${ }^{1-3}$ Lipid scrambling is accompanied by membrane blebbing and production of PS-exposing, procoagulant microparticles, shed from the plasma membrane. ${ }^{4-6}$ Another major function of surface exposed PS is to signal the scavenging of apoptotic cells by qualified macrophages. ${ }^{7,8}$

The potency of different physiological platelet agonists to evoke a procoagulant response varies from collagen plus thrombin $>$ collagen $>$ thrombin; maximal activity is obtained with the non-physiological agonist $\mathrm{Ca}^{2+}$-ionophore. ${ }^{9,10}$ The extent of procoagulant activity has been related to the amount of PS exposed at the cell surface. Since high cytoplasmic $\mathrm{Ca}^{2+}$ concentrations activate lipid scramblase and block aminophospholipid translocase, it has been proposed that intermediate $\mathrm{Ca}^{2+}$-levels can lead to a circumstance in which both transporters are active but oppose each other. ${ }^{2,11}$ Conceivably, these situations can accommodate a wide variety of PS mol fractions exposed at the cell surface

Although some authors have proposed the involvement of specific protein receptors ${ }^{12,13}$, it is widely appreciated that surface exposed PS forms an essential part of the procoagulant platelet surface. This is clearly illustrated by the fact that annexin A5 (previously known as annexin $V$ ), a protein with high affinity for PS, strongly inhibits the 
procoagulant activity of platelets or platelet-derived microparticles. ${ }^{14-16}$. Also lactadherin (MFG-E8), a glycoprotein of the milk fat globule membrane that binds to PS-containing lipid surfaces, has been demonstrated to inhibit platelet prothrombinase and factor $X$ activating activity. ${ }^{17,18}$ Platelet procoagulant activity increases 2- to 10-fold after thrombin stimulation ${ }^{9,19,20}$, suggesting an increased exposure of PS caused by this agonist. However, an increased outward movement of fluorescent-labelled PS could not be found in thrombin-stimulated platelets using a continuous assay to monitor transbilayer migration of lipids. ${ }^{21}$ On the contrary, stimulation of platelets with thrombin caused a 4-fold increased rate of inward transport of PS. ${ }^{22}$ This increased aminophospholipid translocase activity has been used as an argument that components other than PS in the outer surface of thrombin activated platelets are responsible for the increased procoagulant activity. ${ }^{13}$

A possible explanation for these apparent paradoxical findings could be that platelet stimulation causes activation of scramblase in a minor fraction of the platelets, whereas in the majority of the platelets aminophospholipid translocase is still active. We therefore analysed, by flow cytometry, both activities in single platelets using fluorescent lipid probes to monitor scramblase and translocase activity and fluorescent-labelled PS-binding proteins to detect surface-exposed endogenous PS.

\section{Materials and methods}

\section{Reagents}

Calcium ionophore ionomycin, $\mathrm{N}$-ethylmaleimide (NEM) and bovine serum albumin, essentially fatty acid free (BSA) were obtained from Sigma (St Louis, MO). 1-Oleoyl-2-[6-[(7-nitro-2-1,3-benzoxadiazol4-yl)amino]hexanoyl]-sn-Glycero-3-Phospho-L-Serine (NBD-PS) was from Avanti Polar Lipids (Alabaster, AL). Thrombin was purified from bovine blood as previously described ${ }^{23}$ and horse tendon collagen was from Horm, Nycomed (Münich, Germany). The coagulation proteins prothrombin, factor $X a$ and factor $V a$ were purified from bovine blood as described before. ${ }^{23}$ Thrombin-specific chromogenic substrate S2238 was obtained from Chromogenix (Mölndal, Sweden). FITC-conjugated anti-CD61 and control IgG were from BD Biosciences PharMingen (San Diego, CA). Alexa Fluor 647-conjugated annexin A5 and fluorescein isothiocyanate (FITC) was from Molecular 
Probes (Leiden, the Netherlands). Lactadherin (MGF-E8) was purified as described by Hvarregaard et al. ${ }^{24}$ and labelled with FITC using the manufacturer's procedure.

\section{Platelet isolation}

Platelet isolation was performed as described. ${ }^{25}$ Briefly, $10 \mathrm{ml}$ blood was collected in $2 \mathrm{ml}$ anticoagulant $A C D(80 \mathrm{mmol} / \mathrm{I}$ trisodium citrate, $52 \mathrm{mmol} / \mathrm{l}$ citric acid and $180 \mathrm{mmol} / \mathrm{l}$ glucose). Platelet rich plasma was obtained by centrifuging whole blood for $15 \mathrm{~min}$ at $200 \mathrm{~g}$. Platelets were spun down at $11,500 \mathrm{~g}$ for $1 \mathrm{~min}$ using a microfuge. The platelet pellet was resuspended and washed twice in HEPES buffer (10 mmol/l HEPES ( $\mathrm{N}$-2-hydroxyethylpiperazine- $\mathrm{N}^{\prime}-2$ ethanesulfonic acid), $137 \mathrm{mmol} / \mathrm{l} \mathrm{NaCl}, 2.7 \mathrm{mmol} / \mathrm{I} \mathrm{KCl}, 2 \mathrm{mmol} / \mathrm{l}$ $\mathrm{MgCl}_{2}, 5 \mathrm{mmol} / \mathrm{l}$ glucose and $0.5 \mathrm{mg} / \mathrm{mL} \mathrm{BSA}$, adjusted at $\mathrm{pH} 6.6$ ); before each centrifugation step, $100 \mu \mathrm{l} A C D$ was added to each $\mathrm{ml}$ resuspended platelets. Platelets were finally resuspended in the same HEPES buffer at $\mathrm{pH} 7.4$, without BSA. Platelet count was adjusted at $2 \times 10^{8}$ platelets $/ \mathrm{ml}$.

\section{Platelet activation}

Platelet activation was performed at $37^{\circ} \mathrm{C}$ at a concentration of $5 \times 10^{7}$ platelets $/ \mathrm{ml}$ in a volume of $0.5 \mathrm{ml}$ under continuous stirring (Teflon-coated stirring bar, $200 \mathrm{rpm}$ ) in the presence of $3 \mathrm{mmol} / \mathrm{l}$ $\mathrm{CaCl}_{2}$. Platelet agonists used were thrombin $(5 \mathrm{nmol} / \mathrm{l})$, collagen $(10 \mu \mathrm{g} / \mathrm{ml})$, the combination of thrombin and collagen $(5 \mathrm{nmol} / \mathrm{l}$ and $10 \mu \mathrm{g} / \mathrm{ml}$, respectively) or ionomycin $(1 \mu \mathrm{mol} / \mathrm{l})$.

\section{Platelet prothrombinase activity}

Platelet procoagulant activity was assayed as described in more detail elsewhere. ${ }^{23}$ Specifically, the following conditions were used: after activation at $5 \times 10^{7}$ platelets $/ \mathrm{ml}$, samples were diluted to $3 \times 10^{6}$ platelets $/ \mathrm{ml}$ in HEPES buffer containing $3 \mathrm{mmol} / \mathrm{l} \mathrm{CaCl}_{2}$ and $0.5 \mathrm{mg} / \mathrm{ml} \mathrm{BSA}$ and were incubated with $0.1 \mathrm{nmol} / \mathrm{l}$ factor $\mathrm{Xa}$ and $2 \mathrm{nmol} / \mathrm{l}$ factor $V a$ for one min at $37^{\circ} \mathrm{C}$. Thrombin formation was initiated by addition of $1 \mu \mathrm{mol} / \mathrm{l}$ prothrombin and arrested after two min by addition of $5 \mathrm{mmol} / \mathrm{l}$ EDTA (ethylenediaminetetraacetic acid). Thrombin was measured using the chromogenic substrate S2238. 
Separation of microparticles from remnant platelets after activation

Platelet activation has been demonstrated to be accompanied by the production of microparticles shed from the plasma membrane. ${ }^{4,6}$ To evaluate the contribution of microparticles in the present study, we have used a previously described method to separate microparticles from remnant cells. ${ }^{5}$ Briefly, after activation, platelet suspensions were centrifuged at $11,500 \mathrm{~g}$ for various time periods. Both the prothrombinase activity remaining in the supernatant and the lipid content of the supernatant appeared to approach constant values after three min centrifugation. This prothrombinase activity is operationally defined as derived from microparticles. The absence of platelets or remnant cells in the supernatant was confirmed by flow cytometry (see results).

\section{Measurement of scramblase and aminophospholipid translocase activity}

Distribution of fluorescent lipid probes over the two leaflets of the plasma membrane was measured using a BSA back exchange protocol which rapidly extracts lipid probe from the external leaflet as described by Connor et al. ${ }^{26}$ To measure scramblase activity, platelets $\left(2 \times 10^{8}\right.$ platelets $\left./ \mathrm{ml}\right)$ were preloaded at $37^{\circ} \mathrm{C}$ for $30 \mathrm{~min}$

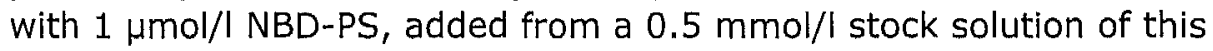
probe in dimethylsulfoxide. This concentration of NBD-PS thus added, amounts to approximately $1 \%$ of the endogenous phospholipid concentration. Subsequently, $5 \times 10^{7}$ platelets $/ \mathrm{ml}$ were stimulated at $37^{\circ} \mathrm{C}$ with the various agonists as described above. Five minutes after addition of the agonist, a sample of $50 \mu \mathrm{l}$ was transferred to $50 \mu \mathrm{l}$ HEPES buffer containing $2 \%(\mathrm{w} / \mathrm{v}) \mathrm{BSA}$, and another sample of $50 \mu \mathrm{l}$ was added to $50 \mu \mathrm{l} \mathrm{HEPES}$ without BSA to monitor the amount of NBD-PS present in the inner leaflet and the total amount present in both leaflets, respectively. After an additional five $\min , 10 \mu \mathrm{l}$ from both mixtures was diluted in $240 \mu \mathrm{l}$ HEPES buffer containing $3 \mathrm{mmol} / \mathrm{l} \mathrm{CaCl}$; the platelet concentration in the diluted samples was $10^{6}$ platelets $/ \mathrm{ml}$. Detection of surface exposed endogenous PS was achieved by addition of $1 \mu$ Alexa Fluor 647-conjugated annexin A5 and incubation for five min. Samples were analysed by flow cytometry.

To measure aminophospholipid translocase activity, the following protocol was used: prior to addition of NBD-PS, platelets $\left(5 \times 10^{7}\right.$ platelets $/ \mathrm{ml}$ ) were activated for five $\mathrm{min}$ at $37^{\circ} \mathrm{C}$ as described above. 
Subsequently, $0.5 \mu \mathrm{mol} / \mathrm{I}$ NBD-PS was added and $50 \mu \mathrm{l}$ samples were taken at different times, mixed with $50 \mu$ HEPES with or without BSA and further processed as described for the scramblase assay.

For flow cytometry, all buffers were passed through a $0.2 \mu \mathrm{m}$ Millipore filter before use.

\section{Flow cytometry}

Samples were analyzed with a FACScan flow cytometer (Beckton Dickinson, CA, USA) with light scatter and fluorescence channels set at logarithmic gain. Forward angle light scatter (FSC) was detected at EOO and side scatter (SSC) was detected at 520 with no thresholds. The NBD- and the Alexa Fluor 647 probes were excited with the $488 \mathrm{~nm}$ argon laser and the $633 \mathrm{~nm}$ HeNe laser, respectively, and their emission signals were measured simultaneously in FL $1(530 \pm 30 \mathrm{~nm}$ bandpass filter) and FL 4 (661 $\pm 16 \mathrm{~nm}$ bandpass filter). Scatter parameters and fluorescence intensities were collected from 10,000 platelets and were analyzed using WinMDI version 2.8 software (http://facs.scripps.edu/ software.html). For detection of microparticles, the setting for FSC was changed to E01 and 100,000 events were collected. FITCconjugated anti-CD61, specific for the integrin $\beta_{3}$ subunit of $a_{\mathrm{II}} \beta_{3}$, and FITC-conjugated non-specific IgG were used to discriminate platelet material from background and electronic noise. Only CD61 positive events above the control IgG background were collected and analysed.

\section{Results}

Scramblase and aminophospholipid translocase activity in platelet microparticles

Activation of platelets is usually accompanied by production of microparticles shed from the plasma membrane. ${ }^{4,6}$ We have previously defined microparticles based on procoagulant activity which remained in the supernatant of activated platelets after centrifugation at $17,000 \mathrm{~g} \cdot \mathrm{min} .{ }^{5}$ As shown in Figure $2.1 \mathrm{~A}$, the residual prothrombinase activity of a suspension of ionomycinstimulated platelets approached constant values after $90 \mathrm{~s}$ centrifugation at $11,500 \mathrm{~g}$. We found that this fraction of nonsedimentable procoagulant activity varied between $20-30 \%$ of the 
total and was independent of the agonist used, in agreement with observations of Sims et al. ${ }^{4}$ When microparticles isolated from NBD-PS loaded platelets were incubated with BSA, the NBD-PS appears completely extractable by BSA, indicative for an activated scramblase. On the other hand, microparticles were unable to accumulate non-exchangeable NBD-PS when added exogenously, indicating that aminophospholipid translocase activity is inhibited or unable to oppose the scramblase activity (data not shown).
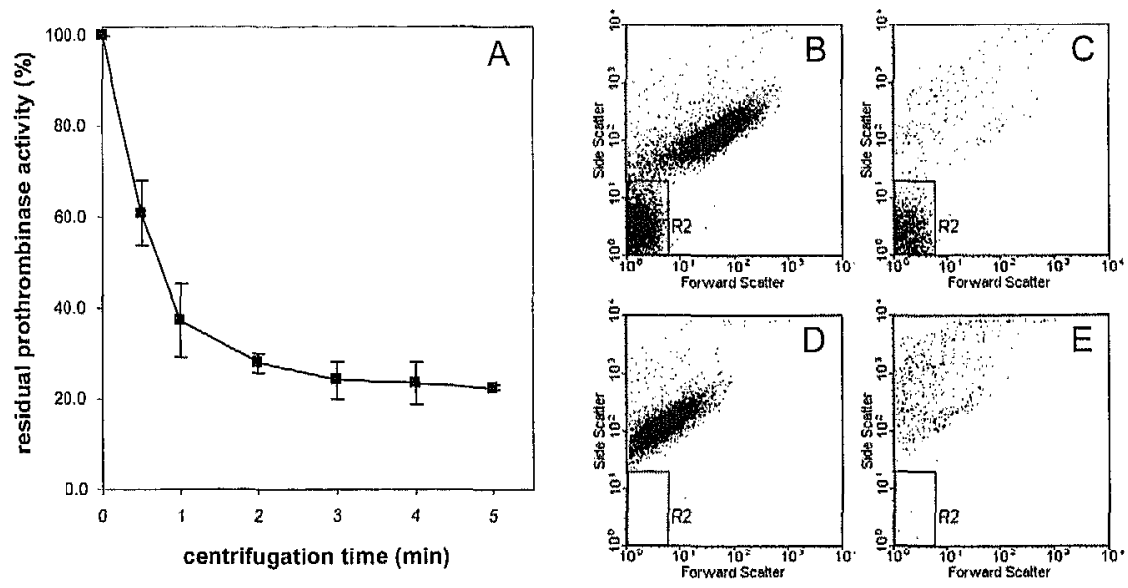

Figure 2.1. Platelet microparticle detection by flow cytometry. Platelets $\left(5.10^{7}\right.$ platelets $/ \mathrm{ml}$ ) were activated with ionomycin $(1 \mu \mathrm{mol} / \mathrm{l})$ in the presence of 3 $\mathrm{mmol} / \mathrm{L} \mathrm{CaCl}$ for $15 \mathrm{~min}$. Samples from this incubation were centrifuged at $11.500 \mathrm{~g}$ for various time periods and prothrombinase activity of the supernatant was measured as described in materials and methods and expressed as percentage of the prothrombinase activity of the total platelet suspension (A) (data are mean values \pm S.D. from three separate experiments). Samples from the total incubation ( $B$ and $D$ ) and the supernatant obtained after 3 min centrifugation ( $C$ and $E$ ) were stained with FITC-conjugated anti-CD61 and analysed in a Becton Dickinson FACScan flow cytometer using either the setting EO1 (B and C) or EOO (D and E) for FSC. Represented are dot plots of FSC versus SSC exclusively for CD61 positive events. The region $\mathrm{R} 2$ is set to mark the area in which the microparticles appear using E01 for FSC. Note that events are no longer observed in this region when FSC is set at EOO.

Because of their small size, the fluorescence signal of microparticles labelled with Alexa 647-conjugated annexin A5 or NBD-PS will generate events in a flow cytometer with a low fluorescence signal relative to that of activated platelets. To avoid interference of 
microparticles in the flow cytometric approach to detect scramblase and aminophospholipid translocase activity in activated platelet suspensions, flow cytometer settings were chosen to exclude these events. To establish the position of microparticles in the dot plots of forward-versus side scatter, we used a fluorescence-gated detection based on anti-CD61 as a marker for platelets and platelet-derived microparticles. Figure 2.1B shows a dot plot of forward- versus side scatter of a suspension of ionomycin-activated platelets in which the microparticles form a population of events distinct from that of the remnant platelets (region R2 in Figure 2.1B). The position of the microparticles in the dot plots of FSC versus SSC was further confirmed by analysis of a supernatant of ionomycin-treated platelets obtained after 3 min centrifugation at $11,500 \mathrm{~g}$ (region R2 in Figure 2.1C). Changing the setting for FSC to EOO caused the microparticles to become undetectable in the flow cytometer as illustrated in Figure 2.1D and 2.1E. All subsequent experiments to measure scramblase and translocase activity were performed using these settings for flow cytometry.

\section{PS exposure occurs in a distinct platelet fraction}

PS exposure as a result of platelet activation, was measured in single platelets using fluorescent marker proteins, which selectively recognize PS. Figure 2.2 shows histograms of Alexa 647-conjugated annexin A5 staining of platelets in suspension, activated with thrombin, collagen or collagen plus thrombin. It can be seen that only a fraction of the platelets becomes annexin A5 positive, the size of which depends on the agonist used. Remarkably, the mean fluorescence intensity of the annexin A5-positive platelet fraction is comparable for the different agonists and coincides with the mean fluorescence intensity of annexin A5 binding found upon stimulation with $\mathrm{Ca}^{2+}$-ionophore, in which case virtually all cells become annexin A5 positive. Figure 2.3 shows that there is a good correlation $(r=0.99)$ between the percentage annexin A5 positive cells and the corresponding procoagulant activity, measured as prothrombinase activity. Thus, the differences in procoagulant activity observed for various platelet stimuli do not seem to be determined by a gradual increase in the extent of surface exposed PS of each platelet, but rather by a fraction of the platelets that exhibits maximal PS exposure such as elicited by $\mathrm{Ca}^{2+}$-ionophore. It should be noted in Figure 2.3 that the prothrombinase activity is related to the whole platelet suspension, including the microparticles, whereas, due to the 
settings of the flow cytometer, the annexin A5 positive events represent exclusively platelets or remnant cells. The contribution of the microparticles to the prothrombinase activity (approximately 20-30\%) appeared to be independent of the agonist used. The dashed line in Figure 2.3 shows the relationship between prothrombinase activity and annexin A5 binding corrected for the microparticle contribution to the prothrombinase activity.
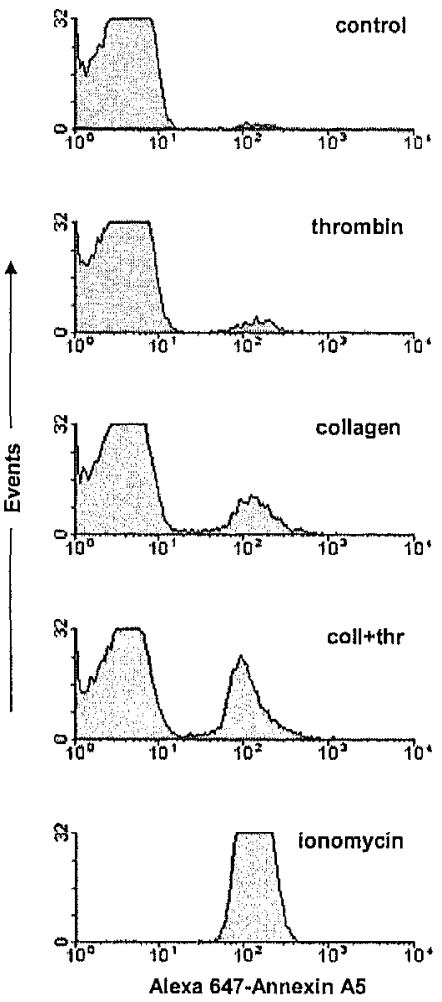

Figure 2.2 Histograms of annexin A5 binding to platelets stimulated with various agonists. Platelets $\left(5.10^{7}\right.$ platelets $\left./ \mathrm{ml}\right)$ in suspension were activated with thrombin $(5 \mathrm{nmol} / \mathrm{l})$, collagen $(10 \mu \mathrm{g} / \mathrm{mL})$, collagen plus thrombin $(10 \mu \mathrm{g} / \mathrm{ml}$ and $5 \mathrm{nmol} / \mathrm{l}$, respectively) or ionomycin $(1 \mu \mathrm{mol} / \mathrm{I})$ in the presence of $3 \mathrm{mmol} / \mathrm{CaCl}_{2}$ for 5 min under continuous stirring. Samples were 50-fold diluted and analysed with Alexa 647-conjugated annexin A5. A scale of maximal 32 events was chosen to have a better visualisation of the fraction annexin $A 5$ positive events induced in the control and thrombin stimulated platelets. Shown are the histograms of a representative experiment out of five thus performed. 


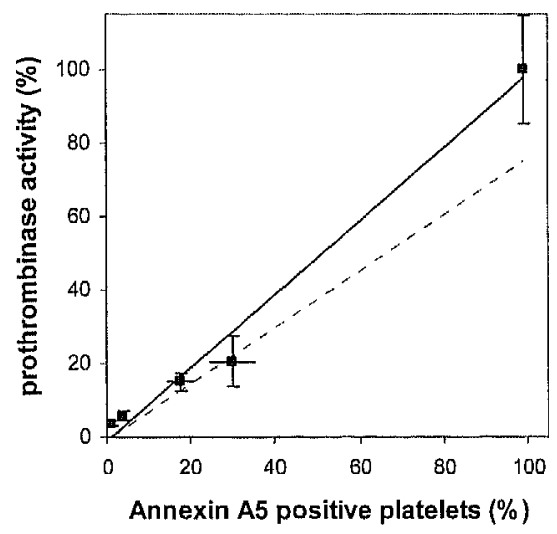

Figure 2.3 Correlation between platelet prothrombinase activity and binding of Alexa 647-conjugated annexin A5. Platelets $\left(5.10^{7}\right.$ platelets $\left./ \mathrm{ml}\right)$ were stimulated for 5 min with various agonists after which prothrombinase activity and annexin $A 5$ binding were measured as described in materials and methods. Prothrombinase activity is expressed as a percentage of the maximal activity observed for ionomycin-activated platelets, which was $224 \pm 33 \mathrm{nmol} / \mathrm{l}$ thrombin per minute. Note that prothrombinase activity includes that of the microparticles. When corrected for the contribution of the microparticles to the prothrombinase activity, the actual correlation between prothrombinase activity and number of PSexposing remnant cells is represented by the dashed line. Data are mean values $\pm S$.D. from 5 independent experiments.

It has been shown that under the conditions used in the present study, the threshold for binding of annexin A5 is about $4 \mathrm{~mol} \%$ $\mathrm{PS}^{17,27}$, from which it may be argued that the abrupt increase of the fluorescence signal to the level of ionomycin activated platelets might be an artefact of the detection limit of PS by annexin A5. Therefore, we have used FITC-conjugated lactadherin to analyse the number of positive platelets obtained with the different stimuli. This protein was recently described as an alternative PS-binding protein, which, in contrast to annexin A5, binds proportionally to membranes with a PS content varying from $0-2 \% .{ }^{17}$ The results, summarized in Table 1 demonstrate that the percentage positive cells, detected with either annexin A5 or lactadherin, are very similar for all agonists used, suggesting that both probes label the same platelets. This was confirmed by a double label experiment in which low, non-saturating concentrations of both Alexa-conjugated annexin A5 and FITCconjugated lactadherin were added to avoid mutual interference of the binding (Table 2.1 and Figure 2.4). Next to the population of 
platelets that binds neither annexin A5 nor lactadherin, there is only one population of cells that becomes positive for both labels. No platelets were found to be labelled exclusively with lactadherin (Figure $2.4 \mathrm{C}$ ), indicating that the labelled platelet fraction exposes at least $4 \mathrm{~mol} \% \mathrm{PS}$. As expected and in agreement with other

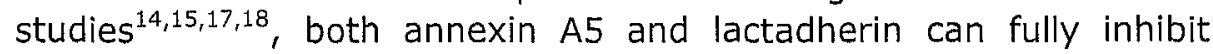
platelet prothrombinase activity, irrespective of the agonist used (data not shown).

Table 2.1 Binding of annexin A5 and lactadherin to stimulated platelets.

\begin{tabular}{lrrr}
\hline Agonist & \multicolumn{3}{c}{ \% positive platelets } \\
& Annexin A5 & Lactadherin & Anx+Lact \\
\hline none & $1.4 \pm 0.4$ & $2.3 \pm 0.1$ & $2.1 \pm 0.1$ \\
thrombin & $3.8 \pm 0.9$ & $4.4 \pm 0.2$ & $4.7 \pm 0.2$ \\
collagen & $17.5 \pm 2.9$ & $24.7 \pm 3.1$ & $20.3 \pm 4.2$ \\
collagen+thrombin & $29.7 \pm 5.2$ & $30.4 \pm 2.2$ & $27.3 \pm 1.6$ \\
ionomycin & $99.2 \pm 0.2$ & $98.5 \pm 2.9$ & $94.4 \pm 2.6$ \\
\hline
\end{tabular}

Platelets were stimulated with the indicated agonists for five min and subsequently incubated with Alexa 647-conjugated annexin A5, FITC-conjugated lactadherin or both labelled proteins and analysed by flow cytometry. For further details refer to the legend of Figure 2.4. Data represent mean values $\pm \operatorname{SD}(n=3)$
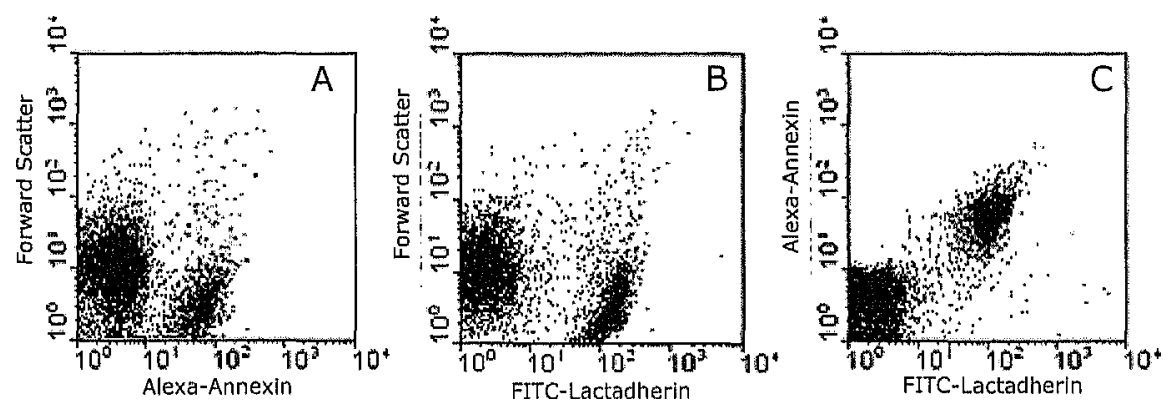

Figure 2.4 Dot plots of lactadherin and annexin A5 binding to collagen stimulated platelets. Platelets $\left(5.10^{7}\right.$ platelets $\left./ \mathrm{ml}\right)$ were stimulated for $5 \mathrm{~min}$ with collagen $(10 \mu \mathrm{g} / \mathrm{ml})+$ thrombin $(5 \mathrm{nmol} / \mathrm{l})$ under continuous stirring. From the same incubation, three samples were 50-fold diluted and analysed in the flow cytometer for binding of Alexa 647-conjugated annexin A5, FITC-conjugated lactadherin, or the combination of both labels. Concentrations of both annexin A5 and lactadherin were chosen to avoid appreciable mutual interference of the binding of each of these proteins: Alexa 647-conjugated annexin A5 was added at a dilution of 1 in 250 of the commercial preparation; FITC-conjugated lactadherin was added at a final concentration of $2 \mathrm{nmol} / \mathrm{L}$. A: binding of annexin $\mathrm{A} 5$ versus Forward scatter $\mathbf{B}$ : binding of lactadherin versus forward scatter C: binding of both annexin A5 and lactadherin. Shown are the dot plots of a typical experiment out of three thus performed. 
Scramblase is active in the platelet fraction which exposes PS and inactive in the fraction that does not expose PS

In order to relate PS exposure to activation of phospholipid scramblase, we have measured this activity in annexin A5 positiveand annexin A5 negative cells as depicted in Figure 2.5.

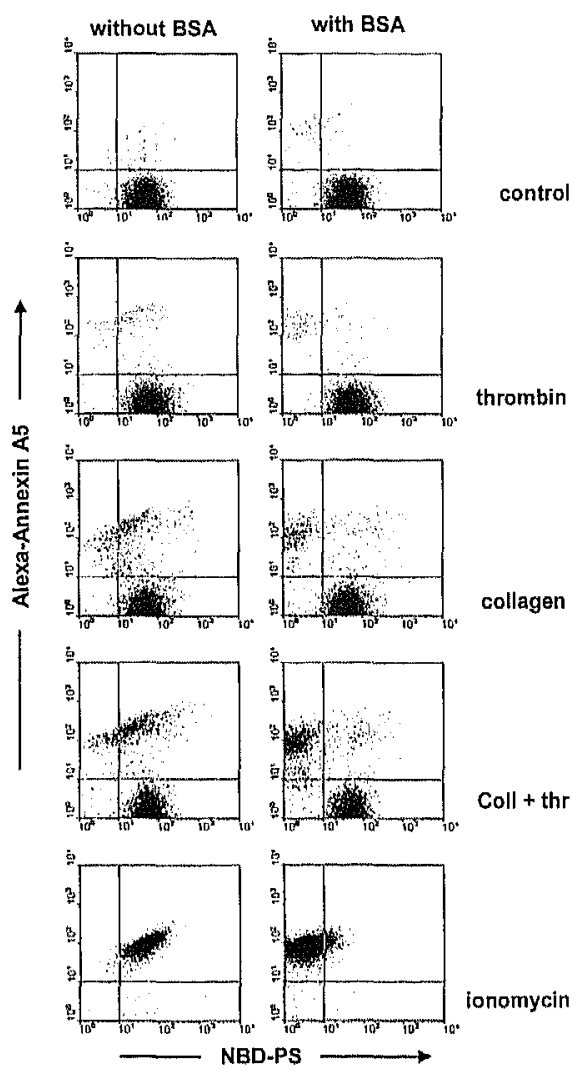

Figure 2.5 Scramblase activity in platelets stimulated with various agonists. Platelets, preloaded with NBD-PS, were stimulated at $5.10^{7}$ platelets $/ \mathrm{ml}$ with thrombin $(5 \mathrm{nmol} / 1)$, collagen $(10 \mu \mathrm{g} / \mathrm{ml})$, collagen plus thrombin (10 $\mu \mathrm{g} / \mathrm{ml}$ and $5 \mathrm{nmol} / \mathrm{l}$, respectively) or ionomycin $(1 \mu \mathrm{mol} / \mathrm{l})$ under continuous stirring. After $5 \mathrm{~min}$, samples are 50-fold diluted in buffer with and without BSA and Alexa 647-conjugated annexin A5 was added. After an additional $5 \mathrm{~min}$, samples were analysed by flow cytometry. Represented are dot plots of NBD-PS fluorescence versus Alexa 647annexin A5; left panels represent samples in absence of BSA, right panels show samples taken in presence of BSA. Based on control platelets in absence of BSA, quadrants are set to demarcate platelets that retain NBD-PS (upper- and lower right quadrants) or do not become annexin A5 positive (lower left and lower right quadrants). Shown are the dot plots of a representative experiment out of three thus performed. 
Scramblase was measured in platelets incubated with NBD-PS for a sufficient time to allow accumulation in the inner leaflet. After stimulation with the various agonists for $5 \mathrm{~min}$, the NBD-fluorescence signal decreases due to extraction by BSA of NBD-PS that appears in the outer leaflet by means of an activated scramblase. From the dot plots of NBD-fluorescence versus Alexa 647 staining, it is clear that the annexin A5-negative cells (lower quadrants of the right panels in Figure 2.5) do not lose NBD-PS upon addition of BSA, whereas in the annexin A5-positive cells, virtually all NBD-PS can be extracted by BSA (upper left quadrant of the right panels in Figure 2.5). This appears true for all agonists tested. Note that also in the absence of BSA (left panels in Figure 2.5), the NBD fluorescence signal in the annexin A5-positive cells is slightly shifted to the left when compared to that of the annexin A5 negative cells. We could demonstrate that this is caused by the presence of BSA in the Alexa 647-annexin A5 conjugate, which is added by the manufacturer (Molecular Probes) to stabilise the protein preparation (data not shown).

Aminophospholipid translocase can only be observed in the platelet fraction that does not expose PS

Next, we focused on the aminophospholipid translocase activity. Platelets were activated with various agonists for $5 \mathrm{~min}$ before adding NBD-PS to monitor inward transport by the translocase. The residual NBD-fluorescence after extraction with BSA can be taken as a measure for NBD-PS that has been transported to the inner leaflet of the plasma membrane by the aminophospholipid translocase. An example of such an experiment is presented in Figure 2.6, showing typical dot plots of the NBD-PS fluorescence versus Alexa 647-annexin A5 binding after 5 min inward transport of NBD-PS in the various stimulated platelet suspensions. The upper panels show the fluorescence signal of NBD-PS in absence of BSA, i.e. the total amount of probe that was added. Note that the probe distributes equally over the annexin A5-positive and negative platelets. The lower panels depict the residual NBD-PS fluorescence after extraction with BSA, i.e. the non-exchangeable NBD-PS present in the inner leaflet. Clearly, aminophospholipid translocase appears active exclusively in the annexin A5-negative platelet population. In the annexin A5-positive fraction, NBD-PS remains completely extractable by BSA. Time courses of the inward transport of NBD-PS in the annexin A5-negative and annexin A5-positive platelet fractions obtained with the various agonists are depicted in Figure 2.7. The 
results show that for all agonists used, aminophospholipid translocase is virtually absent in the annexin A5-positive fraction of the platelets and active in the annexin A5-negative platelets. Note that the rate of NBD-PS transport is significantly increased in platelets stimulated with thrombin or collagen plus thrombin in comparison to unstimulated platelets or platelets stimulated with collagen alone. A similar increase in rate of aminophospholipid transport was found when platelets were stimulated via protease activated receptors PAR 1 and 4 by the peptide agonists SFLLRN and AYPGKF, respectively (data not shown).

without BSA

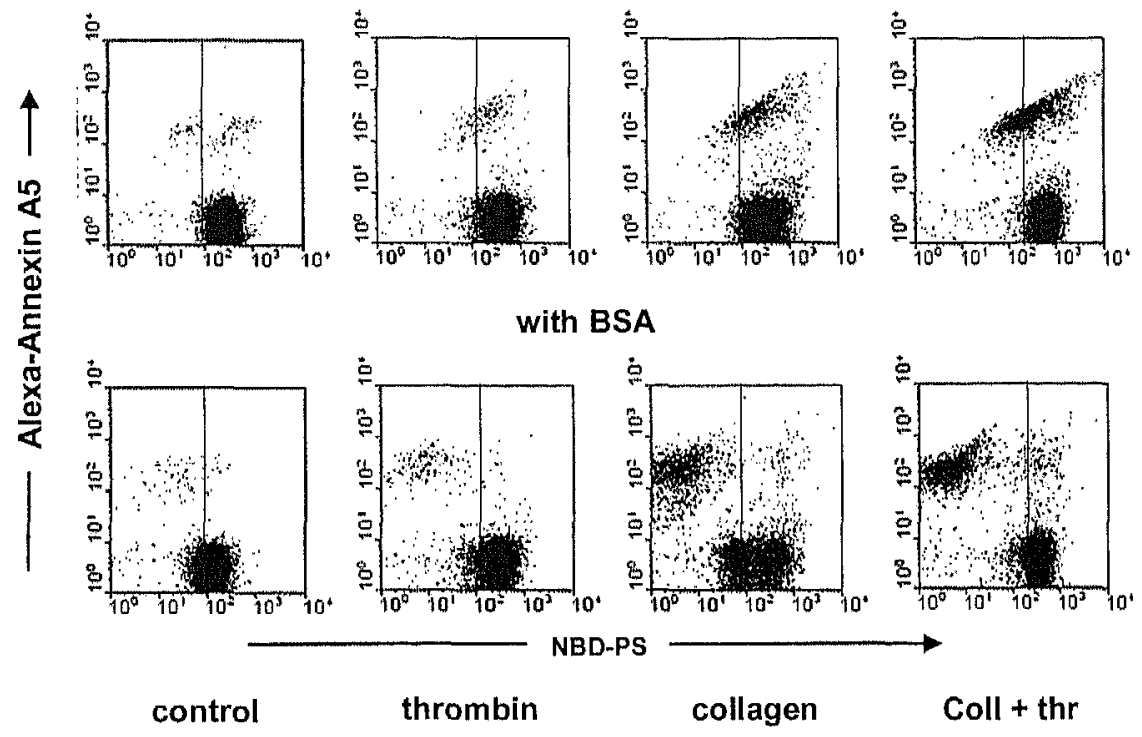

Figure 2.6 Translocase activity in platelets stimulated with various agonists. Platelets were stimulated at $5.10^{7}$ per $\mathrm{mL}$ with thrombin $(5 \mathrm{nmol} / \mathrm{l})$, collagen $(10 \mu \mathrm{g} / \mathrm{ml})$, collagen plus thrombin $(10 \mu \mathrm{g} / \mathrm{ml}$ and $5 \mathrm{nmol} / \mathrm{l}$, respectively) or ionomycin ( 1 umol/l) under continuous stirring. After 5 min, NBD-PS was added and translocase was allowed to proceed for another $5 \mathrm{~min}$. Subsequently, samples were taken and diluted 50-fold in buffer with and without BSA, followed by addition of Alexa 647conjugated annexin A5. Represented are dot plots of NBD-PS fluorescence versus Alexa 647-annexin A5, upper panels represent samples in absence of BSA, lower panels represent samples taken on BSA. The vertlcal line demarcates platelets with the total amount of NBDPS that was added, irrespective of the localisation of this probe in the inner or outer leaflet of the plasma membrane. Events left of this demarcation line represent platelets that have lost NBD-PS upon extraction with BSA, indicating incomplete translocation to the inner leaflet. Note that, also in the upper panel, annexin A5 positive platelets have lost NBD-PS signal, caused by carry over of BSA from the annexin A5 preparation (see text). Shown are the dot plots of a representative experiment out of three. 


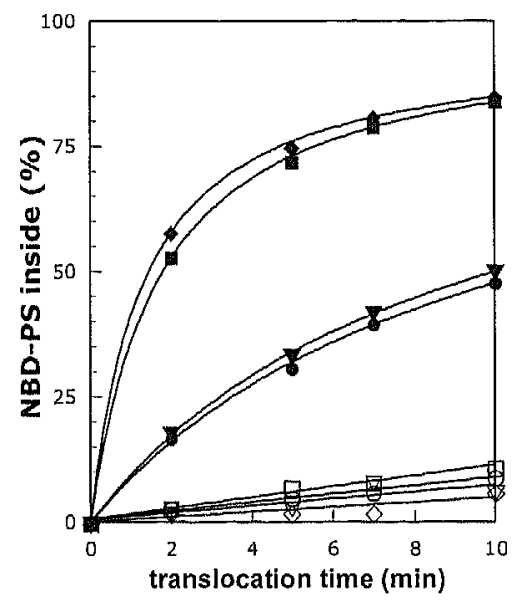

Figure 2.7 Aminophospholipid translocase activity in annexin A5 positive and annexin A5 negative platelets. NBD-PS was added to platelets suspensions that were activated with thrombin $(5 \mathrm{nmol} / \mathrm{l})$, collagen (10 $\mu \mathrm{g} / \mathrm{ml})$, collagen plus thrombin $(10 \mu \mathrm{g} / \mathrm{ml}$ and $5 \mathrm{nmol} / \mathrm{l}$, respectively) or ionomycin $(1 \mu \mathrm{mol} / \mathrm{l})$ for $5 \mathrm{~min}$. Timed samples were 50 -fold diluted in buffer with and without BSA and Alexa 647-annexin A5 was added. Translocase activities of the annexin A5 positive and annexin A5 negative platelet fraction were analysed by flow cytometry as described in the legend of Figure 5 and in the section Experimental Procedures. Translocase activity is expressed as the percentage of NBD-PS that is not extractable with BSA (NBD-PS inside). Symbols: $\bigcirc$, control; $\square$, thrombin; $\nabla \nabla$, collagen; $\diamond$, collagen plus thrombin. Open symbols: annexin A5-positive platelets, closed symbols: annexin A5-negative platelets.

Effect of inactivation of aminophospholipid translocase on PS exposure in platelets

The virtual absence of aminophospholipid translocase activity in the annexin A5-positive platelets raises the question as to whether mere inhibition of this transporter suffices to dissipate lipid asymmetry and cause surface exposure of PS as a result of a spontaneous transbilayer movement of this lipid. Being dependent on reduced sulfhydryl groups ${ }^{5,28,29}$, aminophospholipid translocase activity can be inhibited by sulfhydryl reactive agents such as $\mathrm{N}$-ethylmaleimide (NEM). Since NEM treatment of platelets affects the permeability barrier of the plasma membrane for $\mathrm{Ca}^{2+}$ (unpublished observations), annexin A5 could not be used to monitor the appearance of PS in the external membrane leaflet. We therefore have used lactadherin, 
since this protein does not require $\mathrm{Ca}^{2+}$ for binding to PS-containing lipid surfaces. ${ }^{17}$ Treatment of platelets for five min with $1 \mathrm{mmol} / \mathrm{l}$ NEM in the presence of $1 \mathrm{mmol} / \mathrm{I}$ EGTA completely abrogated the inward transport of NBD-PS (data not shown). It should be emphasized that under these conditions, scramblase can still be activated with $\mathrm{Ca}^{2+}$-ionomycin. Analysis of platelets with FITClactadherin showed no appreciable PS exposure for at least five min after addition of NEM, when compared with untreated platelets (Figure 2.8A).

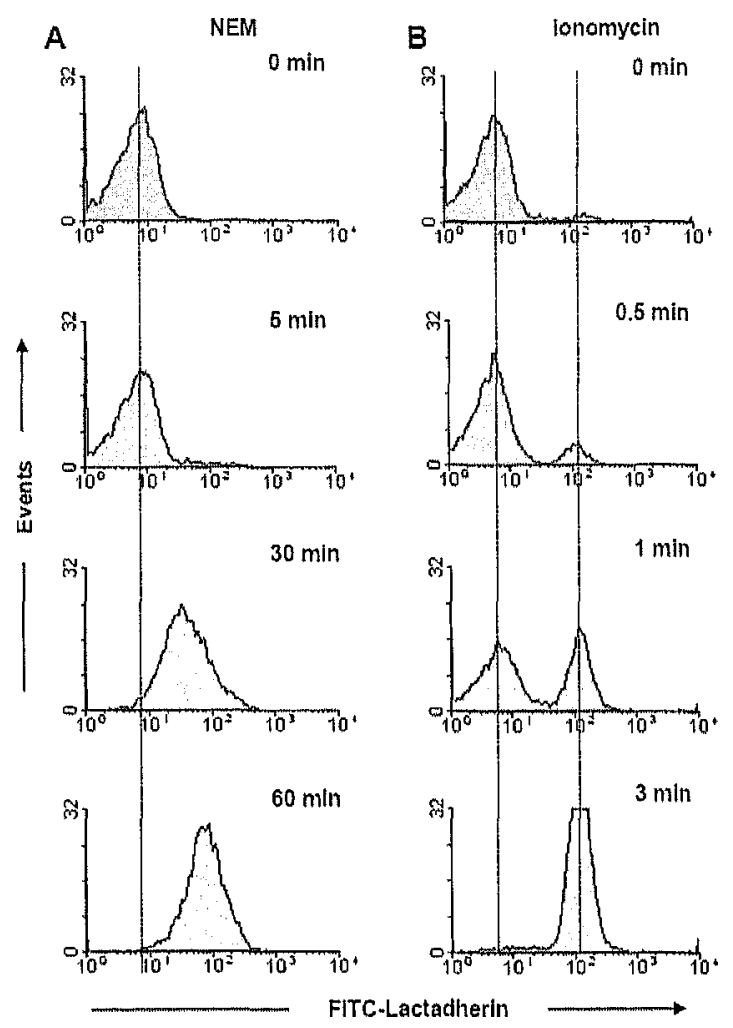

Figure 2.8 Binding of lactadherin to platelets treated with $\mathrm{N}$-ethylmaleimide and ionomycin. A. Platelets at $5.10^{7}$ per $\mathrm{ml}$ were treated with $1 \mathrm{mmol} / \mathrm{I}$ NEM in the presence of $1 \mathrm{mmol} / \mathrm{I}$ EGTA. At the times indicated, samples were 50-fold diluted and after addition of FITC-lactadherin analysed by flow cytometry. B. Platelets at $5.10^{7}$ per $\mathrm{mL}$ were treated with $1 \mu \mathrm{mol} / \mathrm{l}$ ionomycin in the presence of $3 \mathrm{mmol} / / \mathrm{CaCl}_{2}$. At the times indicated, samples were 50-fold diluted in buffer with $1 \mathrm{mmol} / \mathrm{I}$ EGTA to arrest the process of lipid scrambling. After addition of FITC-lactadherin, samples were analysed by flow cytometry. Shown are the histograms of a representative experiment out of two. 
Thus, the exposure of PS evoked within five min by thrombin, collagen, collagen plus thrombin or ionomycin, is not merely caused by inhibition of aminophospholipid translocase, but indeed requires the activity of a phospholipid scramblase. Prolongation of the time of NEM treatment to $60 \mathrm{~min}$ caused a gradual increase in lactadherin binding of the entire platelet population, in contrast to the observations with platelets stimulated with thrombin, collagen or ionomycin, where the increased binding of annexin A5 relates to an increased fraction of 'high binding' platelets (compare Figure 2.2). Figure $2.8 \mathrm{~B}$ shows a time course of ionomycin treatment of platelets as analysed by lactadherin. Scrambling of lipids was arrested by addition of EDTA ${ }^{21}$ and PS-exposing platelets were monitored by lactadherin. In contrast to the gradual surface accumulation of PS induced by NEM, which occurs in the entire platelet population, $\mathrm{Ca}^{2+}$ ionophore induced maximal PS exposure in only a fraction of the platelets, which increased in time to become maximal (100\%) in less than three min. No platelets with an intermediate extent of PS exposure could be observed during these three min.

\section{Discussion}

\section{Procoagulant activity is caused by a fraction of maximal PS-exposing platelets}

The platelet procoagulant response involves the exposure of PS, required for the acceleration of the lipid-dependent coagulation reactions that lead to the formation of Factor Xa and thrombin. Both the lipid concentration, i.e. the number of platelets, and the phospholipid composition of the outer leaflet of the plasma membrane, in particular the mol fraction PS, determine the extent of procoagulant activity of a platelet suspension. It is well appreciated that the platelet procoagulant response is dependent on the agonist used; maximal procoagulant activity is evoked when the membrane is selectively permeabilized for $\mathrm{Ca}^{2+}$ by means of $\mathrm{Ca}^{2+}$-ionophore, e.g. ionomycin. This corresponds to maximal surface exposure of PS, since as was shown previously, PS in ionomycin-treated platelets is completely randomized over both membrane leaflets. ${ }^{5,30}$ The most powerful physiological trigger to induce PS exposure in platelets is the combined action of collagen and thrombin, while each of these agonists alone appears less potent. Because a linear relationship was found between the percentage PS-exposing platelets and the 
prothrombinase activity (Figure 2.3 ), we conclude that the increased procoagulant activity of a platelet suspension as induced by the different agonists is related to an increase in the fraction of platelets exhibiting maximal PS exposure (i.e. as induced by $\mathrm{Ca}^{2+}$-ionophore), rather than to the entire platelet suspension in which each platelet gradually accumulates PS in the outer leaflet of the plasma membrane (Figures 2.2 and 2.3). The pivotal role of surface exposed PS to the procoagulant activity is supported by the observation that, in concordance with the literature ${ }^{14-16}$, annexin A5 completely blocked this activity (data not shown).

A heterogeneous response of platelets has also been observed previously by Dachary-Prigent and co-workers ${ }^{10}$ and recently by London et al. ${ }^{31}$ The formation of two platelet populations, i.e. one with and one without surface exposed PS, has been ignored in most equilibrium binding studies in the past, which has led to erroneous estimations of the number of binding sites per platelet for PS-binding proteins. Recently, the number of binding sites for Factor IXa on thrombin- or SFLLRN-stimulated platelets has been refined in view of these findings. ${ }^{31}$ A heterogeneous response of platelets to various agonists, e.g. thrombin, may also compromise interpretations on the comparison of procoagulant activity between platelets and synthetic phospholipid vesicles. ${ }^{12,13}$

The cause of this differential response of platelets to various stimuli is unknown. Studies from Dale and coworkers have demonstrated the existence of a population of platelets with high levels of surface bound alpha granule factor $V$ on stimulation with dual agonists such as collagen plus thrombin, which they termed 'coat platelets'. ${ }^{32,33}$ Although coinciding with the expression of 'coat-factor $V^{\prime}$, surface exposure of PS is not sufficient to generate coat platelets, as illustrated by the observation that stimulation with $\mathrm{Ca}$-ionophore did not cause high levels of factor $V$ binding. We emphasize that under our experimental conditions, the procoagulant activity was measured under saturating conditions of (exogenously added) factor $\mathrm{Va}$, showing a linear correlation with the fraction of PS-exposing platelets (Figure 2.3) independent of the agonist. Since PS exposure appears to relate to levels of intracellular $\mathrm{Ca}^{2+21,34,35}$, it cannot be excluded that the heterogeneity reflects differences in $\mathrm{Ca}^{2+}$-homeostasis of the platelets. Alternatively, differences in agonist receptor density, possibly related to age, may explain the heterogeneous procoagulant response. 
The cause of this differential response of platelets to various stimuli is unknown. Since PS exposure appears to relate to levels of intracellular $\mathrm{Ca}^{2+21,34,35}$, it cannot be excluded that the heterogeneity reflects differences in $\mathrm{Ca}^{2+}$-homeostasis of the platelets.

\section{Scramblase switched on and translocase switched off in PS-exposing platelets}

In principle, a concomitant partial activation of the scramblase and partial inhibition of aminophospholipid translocase, oppositely regulated by intracellular $\mathrm{Ca}^{2+}$, would suffice to accommodate a wide variety of PS mol fractions to become exposed in the exofacial leaflet of the platelet plasma membrane. ${ }^{2,11}$ In the present study, we clearly demonstrate that upon stimulation, scramblase is fully activated in the PS-exposing platelet fraction. Whether or not aminophospholipid translocase is completely inhibited in this fraction cannot be decided from these experiments. Some residual translocase activity may go unnoticed in platelets in which the scramblase is fully switched on, because all NBD-PS that appears in the outer leaflet will become extracted by BSA. Platelets that become scramblase positive abruptly reach a level of maximal PS exposure, as obtained when platelets are challenged with ionomycin. Experiments with ionomycin-activated platelets from a patient with Scott syndrome, deficient in phospholipid scramblase, have demonstrated that aminophospholipid translocase activity is completely abrogated upon a rise in intracellular $\mathrm{Ca}^{2+} .{ }^{36}$ Therefore, it is very likely that in the fraction of PS-exposing platelets, aminophospholipid translocase is fully blocked. In contrast, in the annexin A5-negative platelets, scramblase activity is absent, whereas translocase activity appears to be even higher than observed for unstimulated control platelets. This fully 'on-off' phenomenon of the scramblase and the oppositely regulated apparent 'on-off' mechanism of the aminophospholipid translocase are compatible with the jump in PS exposure shown in the histograms of Figure 2.2 and Figure 2.8B. Apparently, there is no partial activation of scramblase combined with a partial inactivation of translocase that can give rise to platelets with intermediate degrees of PS exposure. This is supported by the binding of lactadherin and annexin A5 in the stimulated platelet suspensions. Although binding of annexin A5 has a threshold of approx 4 mol\% PS and lactadherin binding was demonstrated to be proportional in the range from $0-2 \%$, both lactadherin and annexin $A 5$ label the same platelet fraction. This means that the platelet procoagulant response 
involves an abrupt exposure of at least $4 \mathrm{~mol} \%$ PS. It should be emphasized that the sudden exposure of PS in a fraction of the platelets is not caused by cell lysis (data not shown).

Inhibition of aminophospholipid translocase is insufficient to cause PS exposure during platelet activation

Mere inhibition of aminophospholipid translocase does not readily result in loss of lipid asymmetry. Platelets, treated with NEM to completely block aminophospholipid translocase activity, do not expose PS within five min (Figure 2.8), the time in which thrombin and/or collagen induce a procoagulant response. Thus, the mechanism of PS exposure upon stimulation with these agonists is not related to a spontaneous outward migration and concomitant inhibition of the translocase to avoid PS from being pumped back to the inner leaflet. Also, prolonged incubation with NEM shows a gradual increase in PS exposure in the entire platelet population, contrary to the abrupt increase in a fraction of the platelets seen with the various agonists. The different time scale of PS exposure in NEMtreated platelets is reminiscent to PS exposure observed in cells undergoing apoptosis. In a recent paper by Augereau et al. ${ }^{37}$ it was shown that local anaesthetics induce apoptotic-like mitochondrial events associated with PS exposure in blood platelets. However, using tetracaine to induce these apoptotic-like effects, we observed an increasing fraction of high PS exposing cells rather than a situation where all platelets gradually accumulate PS in their outer leaflets (results not shown). This may suggest that PS exposure in this apoptotic-like process is also an 'all or none' event in activating scramblase and inactivating translocase, similar to that observed with the various platelet agonists. Nevertheless, the mechanism of PS exposure during cell activation is distinct from that during apoptosis, as demonstrated in Scott syndrome, where PS exposure induced by $\mathrm{Ca}^{2+}$-ionophore is deficient and that induced by apoptosis is not. ${ }^{38}$ The mechanism through which PS accumulates at the outer surface of the platelet after treatment with NEM may reflect spontaneous dissipation of membrane lipid asymmetry.

Translocase activity is enhanced in the platelet fraction that does not expose PS

The separate analysis of aminophospholipid translocase activity and scramblase activity in the annexin A5-positive- and annexin A5negative fraction in a suspension of platelets offers an explanation 
for the previous observation that stimulation with thrombin leads both to an increased prothrombinase activity and an increased aminophospholipid translocase activity. ${ }^{22}$ Only a small, scramblase positive, PS-exposing fraction of the platelets contributes to the procoagulant response, whereas the majority of the platelets do not expose PS due to an active aminophospholipid translocase activity. This may also put a previous study by Larson et al. ${ }^{13}$ into a different perspective. These authors claimed that the increased aminophospholipid translocase activity indicated that thrombin activated platelets do not expose PS, and therefore other components than PS must be responsible for the procoagulant activity of thrombin activated platelets. Our results clearly show that surface exposed PS is required for the procoagulant activity of thrombin activated platelets.

Remarkably, the rate of inward transport of PS in the annexin A5negative fraction of a platelet suspension stimulated with thrombin or collagen plus thrombin is at least 4-fold increased compared to the rate in unstimulated platelets. This increased rate is not observed when platelets are stimulated with collagen alone. It may be speculated that the enhanced aminophospholipid translocase activity could be caused by additional copies of translocase originating from intracellular granula membranes that become part of the plasma membrane as a result of the release reaction. This is supported by the different extent of 5-HT release observed between collagen and thrombin stimulated platelets ${ }^{39}$, although this parameter relates to dense granule membranes only. Considering, however, that less than half of the total amount of membrane in the platelet is intracellular ${ }^{40}$, even a complete release of all intracellular granules would not account for a 4-fold increased rate of translocase activity. Apparently, other changes in the platelet plasma membrane induced by the action of thrombin must cause alterations in the properties of the aminophospholipid transporter. It cannot be excluded either, that the increased rate of translocase results from a looser packing of phospholipids in the membrane of thrombin activated platelets.

In summary, we have demonstrated that PS exposure upon platelet stimulation does not involve the entire platelet population but rather a fraction, the size of which is dependent on the agonist used. The fraction of PS exposing platelets always shows the same extent of PS exposure, irrespective of the agonist. Apparently, platelets with an intermediate PS exposure are not detectable. From this we infer that in the PS-exposing platelet fraction, aminophospholipid translocase 
might be switched off before scramblase becomes fully activated. Thus, once platelets reach the threshold for a procoagulant response, they suddenly change into maximal PS exposing cells. 


\section{References}

1. Sims PJ, Wiedmer $T$. Unraveling the mysteries of phospholipid scrambling. Thromb Haemost 2001; 86: 266-75.

2. Bevers EM, Comfurius P, Dekkers DW, Zwaal RF. Lipid translocation across the plasma membrane of mammalian cells. Biochim Biophys Acta 1999; 1439: 317-30.

3. Heemskerk JW, Bevers EM, Lindhout T. Platelet activation and blood coagulation. Thromb Haemost 2002; 88: 186-93.

4. Sims PJ, Wiedmer T, Esmon CT, Weiss HJ, Shattil SJ. Assembly of the platelet prothrombinase complex is linked to vesiculation of the platelet plasma membrane. Studies in Scott syndrome: an isolated defect in platelet procoagulant activity. J Biol Chem 1989; 264: 17049-57.

5. Comfurius P, Senden JM, Tilly RH, Schroit AJ, Bevers EM, Zwaal RF. Loss of membrane phospholipid asymmetry in platelets and red cells may be associated with calcium-induced shedding of plasma membrane and inhibition of aminophospholipid translocase. Biochim Biophys Acta 1990; 1026: 153-60.

6. Morel O, Toti F, Hugel B, Freyssinet JM. Cellular microparticles: a disseminated storage pool of bioactive vascular effectors. Curr Opin Hematol 2004; 11: 156-64.

7. Fadok VA, Xue D, Henson P. If phosphatidylserine is the death knell, a new phosphatidylserine-specific receptor is the bellringer. Cell Death Differ 2001; 8: 582-7.

8. Schlegel RA, Williamson P. Phosphatidylserine, a death knell. Cell Death Differ 2001; 8: 551-63.

9. Bevers EM, Comfurius P, Zwaal RF. Changes in membrane phospholipid distribution during platelet activation. Blochim Biophys Acta 1983; 736: 57-66.

10. Dachary-Prigent J, Freyssinet JM, Pasquet JM, Carron JC, Nurden AT. Annexin V as a probe of aminophospholipid exposure and platelet membrane vesiculation: a flow cytometry study showing a role for free sulfhydryl groups. Blood 1983; 81: 2554-65.

11. Diaz C, Schroit AJ. Role of translocases in the generation of phosphatidylserine asymmetry. J Membr Biol 1996; 151: 1-9.

12. Monroe DM, Hoffman M, Roberts HR. Platelets and thrombin generation. Arterioscler Thromb Vasc Biol 2002; 22: 1381-9.

13. Larson PJ, Camire RM, Wong D, Fasano NC, Monroe DM, Tracy PB, High KA. Structure/function analyses of recombinant variants of human factor $\mathrm{Xa}$ : factor $\mathrm{Xa}$ incorporation into prothrombinase on the thrombin-activated platelet surface is not mimicked by synthetic phospholipid vesicles. Biochemistry 1998; 37: 5029-38.

14. Thiagarajan $P$, Tait JF. Collagen-induced exposure of anionic phospholipid in platelets and platelet-derived microparticles. J Biol Chem 1991; 266: 24302-7.

15. Thiagarajan $\mathrm{P}$, Tait JF. Binding of annexin V/placental anticoagulant protein I to platelets. Evidence for phosphatidylserine exposure in the procoagulant response of activated platelets. J Biol Chem 1990; 265: 17420-3.

16. Pasquet JM, Toti $F$, Nurden AT, Dachary-Prigent J. Procoagulant activity and active calpain in platelet-derived microparticles. Thromb Res 1996; 82: 509-22.

17. Shi J, Heegaard CW, Rasmussen JT, Gilbert GE. Lactadherin binds selectively to membranes containing phosphatidy|-|-serine and increased curvature. Biochim Biophys Acta 2004; 1667: 82-90.

18. Gilbert GE, Shi J, Rasmussen JT, Heegaard CW, Zhao J, Price P. Limited exposure of phosphatidylserine on stimulated platelets is necessary for procoagulant activity and provides binding sites for lactadherin. ] Thromb Haemost 2003; 1, S1: Abstr. P1274. 
19. Dörmann D, Clemetson KJ, Kehrel BE. The GPIb thrombin-binding site is essential for thrombin-induced platelet procoagulant activity. Blood 2000; 96: 2469-78.

20. Dorsam RT, Tuluc M, Kunapuli SP. Role of protease-activated and ADP receptor subtypes in thrombin generation on human platelets. ] Thromb Haemost 2004; 2; 804-12.

21. Williamson $P$, Bevers $E M$, Smeets $E F$, Comfurius $P$, Schlegel RA, Zwaal RF, Continuous analysis of the mechanism of activated transbilayer lipid movement in platelets. Biochemistry 1995; 34: 10448-55.

22. Tilly RH, Senden JM, Comfurius P, Bevers EM, Zwaal RF. Increased aminophospholipid translocase activity in human platelets during secretion. Biochim Biophys Acta 1990; 1029: 188-90.

23. Rosing J, van Rijn JL, Bevers EM, van Dieijen G, Comfurius $P$, Zwaal RF. The role of activated human platelets in prothrombin and factor $X$ activation. Blood 1985; 65: 319-32.

24. Hvarregaard J, Andersen $M H$, Berglund $L$, Rasmussen JT, Petersen TE. Characterization of glycoprotein PAS-6/7 from membranes of bovine milk fat globules. Eur J Biochem 1996; 240: 628-36.

25. Heemskerk JW, Comfurius P, Feijge MA, Bevers EM. Measurement of the platelet procoagulant response. Methods Mol Biol 2004; 272: 135-44.

26. Connor J, Pak CH, Zwaal RF, Schroit AJ. Bidirectional transbilayer movement of phospholipid analogs in human red blood cells. Evidence for an ATP-dependent and protein-mediated process. J Biol Chem 1992; 267; 19412-7.

27. Stuart $M C$, Bevers $E M$, Comfurius $P, Z$ waal RF, Reutelingsperger $C P$, Frederik PM. Ultrastructural detection of surface exposed phosphatidylserine on activated blood platelets. Thromb Haemost 1995; 74: 1145-51.

28. de Jong $K$, Geldwerth $D$, Kuypers FA. Oxidative damage does not alter membrane phospholipid asymmetry in human erythrocytes. Biochemistry 1997; 36: 6768-76.

29. Connor J, Schroit AJ. Transbilayer movement of phosphatidylserine in erythrocytes. Inhibitors of aminophospholipid transport block the association of photolabeled lipid to its transporter. Biochim Biophys Acta 1991; 1066: 37-42.

30. van Rijn J, Rosing J, van Dieijen G. Activity of human blood platelets in prothrombin and in factor $X$ activation induced by ionophore A23187. Eur $\mathrm{J}$ Biochem 1983; 133: 1-10.

31. London FS, Marcinkiewicz M, Walsh PN. A subpopulation of platelets responds to thrombin- or SFLLRN-stimulation with binding sites for factor IXa. J Blol Chem 2004; 279: 19854-9.

32. Alberio L, Safa $O$, Clemetson KJ, Esmon CT, Dale GL. Surface expression and functional characterization of alpha-granule factor $V$ in human platelets: effects of ionophore A23187, thrombin, collagen, and convulxin. Blood 2000; 95: 1694-702.

33. Dale GL, Friese P, Batar P, Hamilton SF, Reed GL, Jackson KW, Clemetson KJ, Alberio L. Stimulated platelets use serotonin to enhance their retention of procoagulant proteins on the cell surface. Nature 2002; 415: 175-9.

34. Smeets EF, Heemskerk JW, Comfurius $P$, Bevers EM, Zwaal RF. Thapsigargin amplifies the platelet procoagulant response caused by thrombin. Thromb Haemost $1993 ; 70: 1024-9$.

35. Dachary-Prigent J, Pasquet JM, Freyssinet JM, Nurden AT. Calcium involvement in aminophospholipid exposure and microparticle formation during platelet activation: a study using Ca2+-ATPase inhibitors. Blochemistry 1995; 34: 11625-34. 
36. Bevers EM, Wiedmer $T$, Comfurius $P$, Zhao J, Smeets EF, Schlegel RA, Schroit AJ, Weiss HJ, Williamson P, Zwaal RF, Sims PJ. The complex of phosphatidylinositol 4,5-bisphosphate and calcium ions is not responsible for $\mathrm{Ca}(2+)$-induced loss of phospholipid asymmetry in the human erythrocyte: a study in Scott syndrome, a disorder of calcium-induced phospholipid scrambling. Blood 1995; 86: 1983-91.

37. Augereau O, Rossignol R, DeGiorgi $F$, Mazat JP, Letellier T, Dachary-Prigent $J$. Apoptotic-like mitochondrial events associated to phosphatidy/serine exposure in blood platelets induced by local anaesthetics. Thromb Haemost 2004; 92: 104-13.

38. Williamson P, Christie A, Kohlin T, Schlegel RA, Comfurius P, Harmsma M, Zwaal RF, Bevers EM. Phospholipid scramblase activation pathways in lymphocytes. Biochemistry 2001; 40: 8065-72.

39. Hsu-Lin S, Berman CL, Furie BC, August D, Furie B. A platelet membrane protein expressed during platelet activation and secretion. Studies using a monoclonal antibody specific for thrombin-activated platelets. J Biol Chem 1984; 259: 9121-6.

40. Chap HJ, Zwaal RF, van Deenen LL. Action of highly purified phospholipases on blood platelets. Evidence for an asymmetric distribution of phospholipids in the surface membrane. Biochim Biophys Acta 1977; 467: 146-64. 


\section{Chapter 3}

Influence of erythrocyte shape on the rate of $\mathrm{Ca}^{2+}$-induced scrambling of phosphatidylserine

Jef LN Wolfs, Paul Comfurius, Edouard M Bevers, Robert FA Zwaal Mol Membr Biol. 2003; 20: 83-91 


\section{Summary}

Membrane perturbing agents that cause transformation of biconcave erythrocytes into echinocytes or stomatocytes were used to investigate the influence of erythrocyte shape on the rate of $\mathrm{Ca}^{2+}-$ induced scrambling of phospholipids. Erythrocytes were treated with a variety of lipid-soluble compounds to induce these shape changes, followed by incubation with calcium and ionomycin to activate lipid scramblase. Prothrombinase activity of the cells was used to monitor the rate of surface exposure of phosphatidylserine, which is taken as a measure of scramblase activity. Echinocytes show an enhanced rate of scrambling whereas stomatocytes show a reduced rate, relative to normocytes. This phenomenon appears to correlate with enhanced and diminished micro-exovesicle shedding from echinocytes and stomatocytes, respectively. We conclude that the rate of calcium-induced phosphatidylserine exposure (rate of lipid scrambling) in erythrocytes depends for a considerable part on the cell's ability to form microvesicles. 


\section{Introduction}

Transbilayer lipid asymmetry is a well-characterized feature of the plasma membrane of eukaryotic cells. In general, most of the choline containing lipids occupy the outer leaflet, whereas the aminophospholipids, in particular phosphatidylserine (PS), reside almost exclusively in the inner leaflet of the plasma membrane. ${ }^{1}$ In quiescent cells, this dynamic equilibrium is maintained by the activity of at least two different transport proteins: (i) aminophospholipid translocase, which rapidly translocates aminophospholipids from the outer to the inner leaflet ${ }^{2}$ and (ii) lipid floppase, which facilitates a slow outward transport of all major phospholipid classes., ${ }^{3,4} \mathrm{~A}$ candidate aminophospholipid translocase has been identified as a $\mathrm{Mg}^{2+}$-dependent P-type ATPase ${ }^{5,6}$, while floppase activity in erythrocytes has recently been ascribed to multidrug resistance associated protein, MRP1, a member of a large family of ATP-binding cassette (ABC-) proteins. ${ }^{7}$ A third transport protein, phospholipid scramblase, is inactive in resting cells but may become active under particular conditions of cellular activation or in response to apoptotic stimuli. Activation of phospholipid scramblase results in an enhanced bi-directional transmembrane migration of all membrane phospholipids, irrespective of the nature of the polar headgroup. ${ }^{8}$ Activation of the scramblase, accompanied by simultaneous inhibition of the aminophospholipid translocase causes a collapse of transmembrane lipid asymmetry. The most prominent feature of this collapse is the exposure of PS in the external leaflet of the plasma membrane. This phenomenon is of major importance for normal haemostasis since surface-exposed PS is required to promote both assembly and catalytic efficiency of several lipid-dependent coagulation reactions. ${ }^{9}$ In addition, surface-exposed PS serves a function in recognition and clearance of apoptotic cells by the reticuloendothelial system. ${ }^{10,11}$ Although a candidate phospholipid scramblase has been identified and cloned, recent data suggest that this protein may have a different function. ${ }^{12}$

Lipid scrambling and the corresponding exposure of PS are closely associated with blebbing of the plasma membrane and subsequent shedding of microvesicles. Originally, it has been suggested that transient perturbances of the bilayer structure during fusion events that accompany microvesicle shedding cause the process of lipid scrambling. ${ }^{13,14}$ Various studies using platelets and erythrocytes, however, have demonstrated that PS exposure can occur in the 
absence of microvesicle formation. ${ }^{15,16}$ This does not exclude the possibility that microvesicle formation contributes to the process of lipid scrambling. Comparison of the rates of outward and inward movement of the plasma membrane lipids during scrambling in erythrocytes and platelets reveals that the rate of inward movement of sphingomyelin is less than the rate of outward movement of the aminophospholipids. ${ }^{17,18}$ This difference in rate could lead to mass excess in the outer leaflet of the membrane that facilitates shedding of microvesicles.

The bilayer couple hypothesis, first formulated by Sheetz and Singer ${ }^{19,20}$, states that if the membrane forms a closed surface, a change in the relative surface areas of the two halves will lead to changes in the curvature of the membrane. According to this principle the building up of an excess of mass in the outer monolayer causes the membrane to bend outward and to form blebs, whereas a mass excess in the inner monolayer causes inward bending of the membrane. ${ }^{20,21}$ Therefore, it may be anticipated that compounds which incorporate in the outer leaflet (crenators) or inner leaflet (cupformers) of the plasma membrane will affect the formation of microvesicles and possibly, as a consequence, the lipid scrambling process.

Two alternatives appear possible at first sight. On the one hand, incorporation of material in the inner monolayer may drive the outward movement of PS during scrambling, whereas a surplus of material in the outer monolayer counteracts PS exposure at the outer surface. On the other hand, one may consider the formation of microvesicles to be rate limiting in the process of lipid scrambling. In this view, echinocytes treated with $\mathrm{Ca}^{2+}$-ionophore will lose lipid asymmetry more readily since they are prone to microvesicle formation; in stomatocytes this process lags behind, leading to lower rates of PS exposure. To find out which of these two alternatives is most likely, we have used various known crenators and cupformers and studied the kinetics of scramblase-catalysed surface exposure of phosphatidylserine in human erythrocytes by means of the cell's ability to stimulate prothrombinase activity. 


\section{Experimental procedures}

\section{Materials}

Lidocaine, dibucaine, chlorpromazine (CPZ), sodium oleate, 2,4dinitrophenol, 1,2-dicaproyl-sn-glycero-3-phosphocholine (dicaproylPC), 1,2-dioctanoyl-sn-glycero-3-phosphocholine (dioctanoyl-PC), octaethylene glycol monododecyl ether (C12E8) and Triton X-100 were from Sigma-Aldrich (Zwijndrecht, the Netherlands). 1-oleoyl-2[6-[(7-nitro-2-1,3-benzoxadiazol-4-yl)amino]caproyl]phosphatidylcholine (NBD-PC) and 1-oleoyl-2-[6-[(7-nitro-2-1,3-benzoxadiazol4-yl)amino]caproyl]phosphatidylserine (NBD-PS) were obtained from Avanti Polar Lipids, Inc. (Alabaster, Alabama). Other chemicals were of the highest grade available. Coagulation factors $\mathrm{Va}, \mathrm{Xa}$, and prothrombin were purified as described. ${ }^{9}$ Chromogenic substrate S2238 was from Kabi Diagnostica (Stockholm, Sweden). The methylated form of chlorpromazine ( $\mathrm{m}-\mathrm{CPZ}$ ) was prepared as described by Huang et al. ${ }^{29}$ NMR results confirmed the purity of the product.

\section{Preparation of erythrocytes}

Human blood was obtained from healthy volunteers by venepuncture and collected in acid-citrate-dextrose in a ratio of 5 to $1(\mathrm{v} / \mathrm{v})$. Erythrocytes were washed by centrifugation using a buffer composed of $120 \mathrm{mM} \mathrm{NaCl}, 50 \mathrm{mM}$ Tris, $2 \mathrm{mM} \mathrm{MgCl}$, $0.2 \mathrm{mM}$ EGTA, pH 7.4 at $37^{\circ} \mathrm{C}$ (TEMS). Cells were resuspended in TEMS to a concentration of $10^{8} / \mathrm{ml}$ and used the same day.

\section{Morphology}

For morphological studies, cells were diluted ten times in $1 \%$ glutaraldehyde in phosphate buffered saline $\left(10 \mathrm{mM} \mathrm{Na} \mathrm{HPO}_{4}\right.$ in $150 \mathrm{mM} \mathrm{NaCl}, \mathrm{pH} 7.5)$. After fixation for at least $15 \mathrm{~min}$ at $4^{\circ} \mathrm{C}$, cells were examined by light microscopy.

\section{Pre-treatment of erythrocytes and incubation with ionophore}

Unless indicated otherwise, cells were incubated with cupformers or crenators for $10 \mathrm{~min}$. The minimal concentration to produce the desired shape change was determined by observing the morphological changes of the erythrocytes. The concentration of 
each compound used is given in the legends to the figures. To compare compounds that have an opposite effect on erythrocyte shape change, but are closely alike in chemical structure, we used the quaternary ammonium derivative of chlorpromazine ( $m-\mathrm{CPZ}$ ) as described earlier ${ }^{19}$ and compared that to chlorpromazine.

Following pre-treatment with the membrane perturbing agents, cells were incubated with $5 \mu \mathrm{M}$ ionomycin and $1 \mathrm{mM} \mathrm{Ca}^{2+}$.

Exposure of PS at the outer surface of erythrocytes after activation by ionomycin was monitored by the prothrombinase activity of aliquots taken from the incubation at different time intervals. ${ }^{9}$

Microvesicles were isolated by centrifuging the erythrocyte suspension for $10 \mathrm{~min}$ at $300^{*} \mathrm{~g}$ to sediment all erythrocytes. Samples from the supernatant were considered to represent microvesicles.

\section{Measurement of prothrombinase activity}

Prothrombinase activity was measured at $37^{\circ} \mathrm{C}$ as described before. ${ }^{9}$ Briefly, the erythrocytes $\left(10^{8} / \mathrm{ml}\right)$ were diluted ten times in TEMS containing $3 \mathrm{mM} \mathrm{Ca}{ }^{2+}$ and $0.5 \mathrm{mg} / \mathrm{ml} \mathrm{BSA}$. To this suspension a mixture was added containing coagulation factors $X a$ and $V a$ to give a final concentration of $1 \mathrm{nM} \mathrm{Xa}$ and $2 \mathrm{nM} V \mathrm{Va}$. Thrombin formation was started by addition of prothrombin to a final concentration of $1 \mu \mathrm{M}$. After $60 \mathrm{sec}$, a sample from the reaction mixture was diluted in TEMS, containing $5 \mathrm{mM}$ EDTA to stop thrombin formation. The amount of thrombin formed was measured with the thrombin specific chromogenic substrate $S 2238(0.2 \mathrm{mM})$. Thrombin concentration was read from a calibration curve made with known amounts of active site titrated thrombin.

\section{Results}

Incubation of normal erythrocytes with ionophore and calcium

Erythrocytes from several healthy individuals were treated with calcium and ionophore in order to establish donor variation in response to cell stimulation. As shown in Figure 3.1, prothrombinase activity of human erythrocytes in response to stimulation by calcium and ionophore covers a wide range, despite the fact that the results are corrected for differences in cell count using the prothrombinase 
activity of a 10-fold diluted sonicated preparation for calibration. It should be emphasized that, for each individual, the day-to-day variation of the response to $\mathrm{Ca}^{2+}$-ionophore was negligible (S.D. $\pm 2.5 \%$ ) compared to the variation between individuals. Due to this large donor variation, the effects of crenators and cupformers on scramblase-catalysed exposure of PS will be shown for individual donors only, while emphasizing that there is no qualitative difference of these effects between different donors.

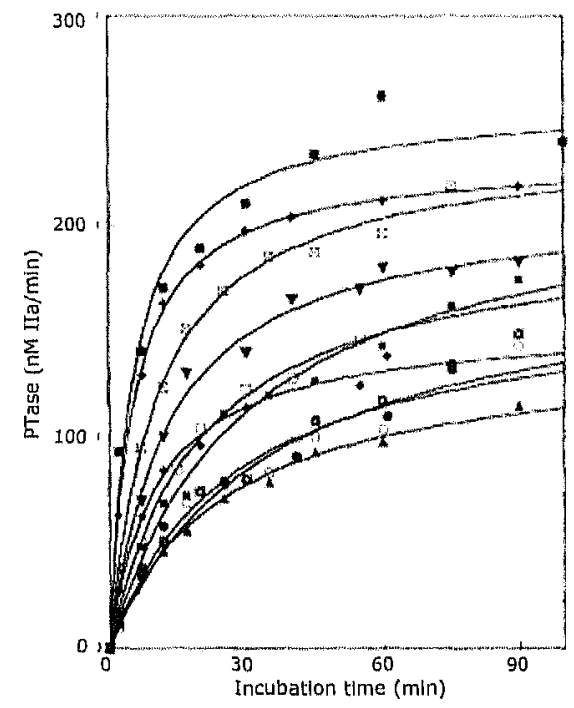

Figure 3.1 Generation of prothrombinase activity in erythrocytes of 10 healthy individuals after incubation with $5 \mu \mathrm{M}$ lonomycin and $1 \mathrm{mM}$ calcium. To correct for differences in cell numbers, prothrombinase activities of sonicated preparations were used. Prior to stimulation with ionomycin, the red cells were adjusted to a concentration that, when diluted tenfold and sonicated, gives a prothrombinase activity of $200 \mathrm{nM}$ thrombin (IIa) per minute.

\section{Morphology of pre-treated erythrocytes}

In Figure 3.2 the effect of crenators and cup-formers on the morphology of erythrocytes is shown. In agreement with the literature, the crenators dicaproyl-PC, dioctanoyl-PC, NBD-PC, sodium oleate, and 2,4-dinitrophenol produce echinocytic cells, whereas incubation of the cells with the cupformers chlorpromazine, lidocaine, and dibucaine leads to stomatocytes. The dual effect of $\mathrm{m}-\mathrm{CPZ}$ and NBD-PS is also visualised. Immediately after addition, these compounds cause echinocyte formation whereas a prolonged 
incubation period with these compounds results in stomatocyte formation.
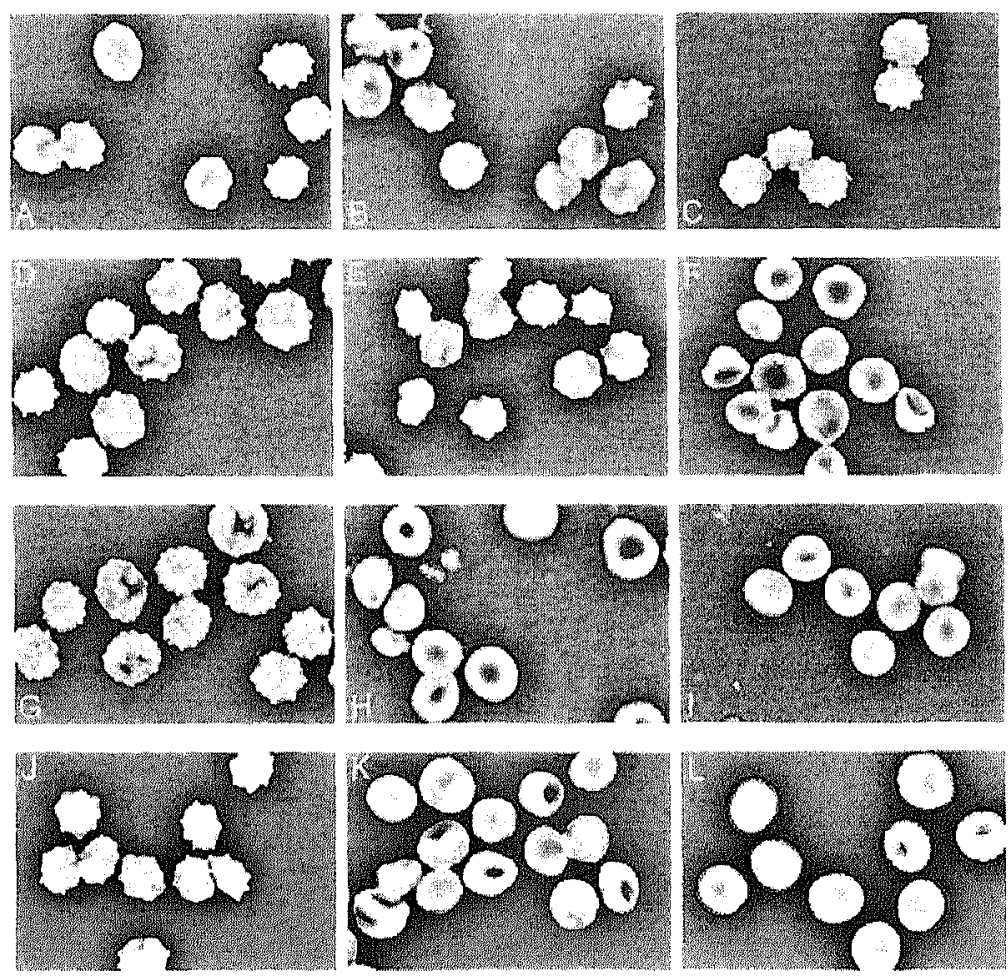

Figure 3.2 Images of differently treated erythrocytes fixed in glutaraldehyde were acquired with a microscope equipped with a video imaging system.

A: $12.5 \mu \mathrm{M}$ caproyl-PC; B: $12.5 \mu \mathrm{M}$ octanoyl-PC; C: $1 \mu \mathrm{M}$ NBD-PC; D: $100 \mu \mathrm{M}$ Na-oleate; E: $2 \mathrm{mM}$ dinitrophenol; F: $20 \mu \mathrm{M}$ chlorpromazine; G: $150 \mu \mathrm{M} \mathrm{m}-\mathrm{CPZ}$, incubated for $10 \mathrm{~min} ; \mathrm{H}: 150 \mu \mathrm{M} \mathrm{m}-\mathrm{CPZ}$, incubated for $180 \mathrm{~min}$; I: $100 \mu \mathrm{M}$ dibucaine; J: $1 \mu \mathrm{M}$ NBD-PS, incubated for $5 \mathrm{~min}$; K: $1 \mu M$ NBD-PS, incubated for $60 \mathrm{~min}$, followed by a wash with $1 \%$ BSA to remove residual NBD-PS from the outer monolayer; L: $75 \mu \mathrm{M}$ lidocaine.

Influence of crenators and cupformers on prothrombinase activity of control erythrocytes and sonicated cells

The possible influence of crenators and cupformers on the prothrombinase activity of erythrocytes was measured in a prolonged incubation at $37^{\circ} \mathrm{C}$ in the presence of calcium. In most of the pretreated cells, prothrombinase activity at 30 and $60 \mathrm{~min}$ did not show any appreciable change relative to that of control cells (data not shown). An exception should be made for cells treated with cup- 
forming polyoxyethylene detergents (see below). Also, sonicated preparations of the pre-treated erythrocytes and control cells showed no differences in prothrombinase activity (data not shown).

\section{Influence of crenators on erythrocyte prothrombinase activity}

The influence of several crenators on the time-dependent generation of prothrombinase activity of $\mathrm{Ca}^{2+}$-ionophore stimulated red cells is shown in Figure 3.3. In Figure 3.3A, prothrombinase activity curves are shown for erythrocytes pre-treated with NBD-PC, sodium oleate, and 2,4-dinitrophenol compared to control cells. While these crenators enhance the rate of exposition of PS, they do so to a different extent presumably depending on the amount of material partitioning in the membrane. Figure 3.3B shows that the increase in prothrombinase activity is very similar for dioctanoyl-PC and dicaproyl-PC, likely because of comparable membrane solubility properties of these short chain phospholipids. Also, short-term pretreatment of the cells with methyl-chlorpromazine leads to an increase in ionophore-stimulated prothrombinase activity.
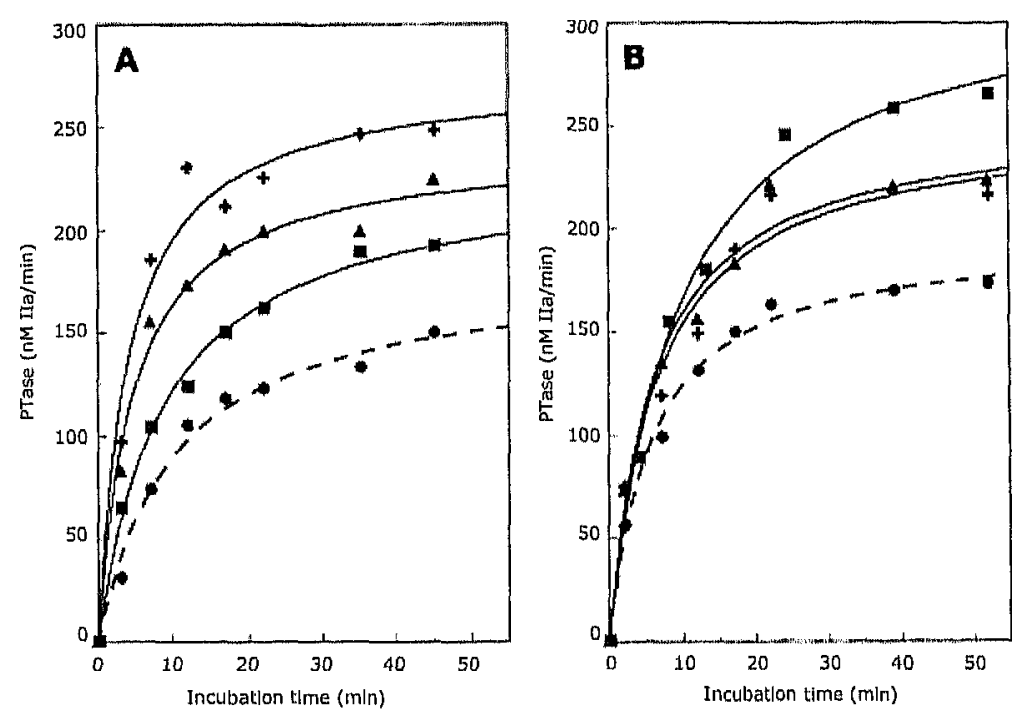

Figure 3.3 Effect of crenating agents on the generation of prothrombinase activity of erythrocytes treated with ionomycin and calcium.

Panel A: control cells; $2 \mathrm{mM}$ dinitrophenol; $100 \mu \mathrm{M} \mathrm{Na}$-oleate; + $1 \mu \mathrm{M}$ NBD-PC. Panel B: control cells; + $12.5 \mu \mathrm{M}$ dicaproyl-PC; $12.5 \mu \mathrm{M}$ dioctanoyl-PC; $150 \mu \mathrm{M}$ methyl-chlorpromazine. 


\section{Influence of cupformers on erythrocyte prothrombinase activity}

The effects of the cupformers dibucaine, lidocaine, and chlorpromazine are shown in Figure 3.4. Based on the interaction with negatively charged groups these compounds preferentially incorporate in the inner monolayer of the cells. In all cases, the resulting stomatocytes show a reduction in the rate of prothrombinase activity, i.e. a decreased rate at which PS becomes exposed at the outer surface following stimulation by $\mathrm{Ca}^{2+}$ ionophore.

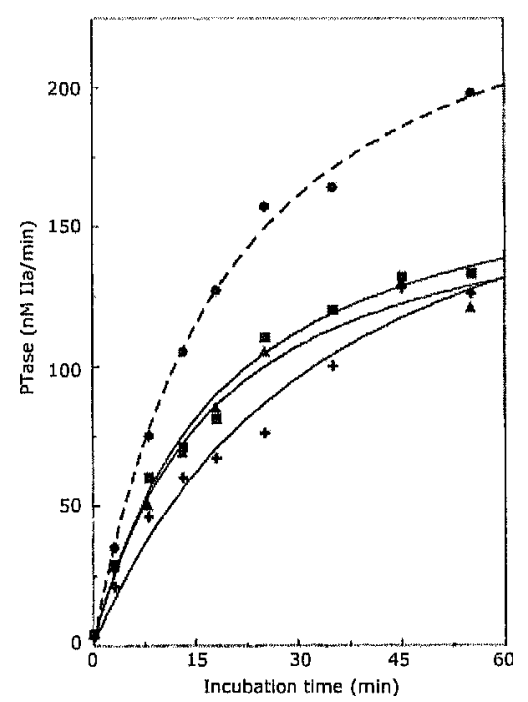

Figure 3.4 Effect of cup-forming agents on the generation of prothrombinase activity of erythrocytes treated with ionomycin and calcium.

- control cells; $50 \mu \mathrm{M}$ dibucaine; + 75 HM lidocaine; $20 \mu \mathrm{M}$ chlorpromazine.

Influence of cup-forming detergents on erythrocyte prothrombinase activity

While detergents are generally characterized by their ability to solubilize membrane lipids and proteins, low sublytic concentrations of detergents dissolve in the membrane which may lead to various perturbing effects. Sublytic concentrations of non-ionic polyoxyethylene detergents like C12E8 and Triton X-100 have been shown to induce stomatocyte formation in erythrocytes, and to cause limited $\left(\mathrm{Ca}^{2+}\right.$-independent) exposure of PS at the outer surface. ${ }^{22}$ 
The rather unexpected stomatocyte formation of these detergents has been ascribed to cation attraction of the polyoxyethylene chain via dipole-ion interactions, producing a positive charge character of C12E8 and Triton X-100 leading to a preferential incorporation in the inner monolayer of the erythrocyte membrane. ${ }^{23}$ While measuring the influence of stomatogenic concentrations of C12E8 on $\mathrm{Ca}^{2+}$ induced exposure of PS, we had to make considerable corrections for the property of this detergent to expose PS by itself, unlike the cupformers and crenators mentioned in the previous paragraphs. This was particularly evident for cells incubated with C12E8 and ionophore in the absence of calcium (Figure 3.5A).

After correction, the $\mathrm{Ca}^{2+}$-dependent PS exposure of C12E8-induced stomatocytes is reduced relative to that of normocytes (Figure 3.5B). Thus, in spite of the intrinsic PS-exposing capacity of C12E8, stomatocyte formation by this detergent has an attenuating effect on $\mathrm{Ca}^{2+}$-induced PS-exposure, similar to the cupformers mentioned in the previous paragraph. Very similar results were obtained with Triton X-100 (data not shown).

\section{NBD-PS and $\mathrm{m}-\mathrm{CPZ}$ as either crenator or cupformer}

As shown in Figure 3.2, both NBD-PS and $\mathrm{m}-\mathrm{CPZ}$ can act either as crenator or as cupformer, depending on the time of incubation. We investigated the influence of both modes of action of these compounds on the rate of $\mathrm{Ca}^{2+}$-induced scrambling of PS. Compared to control cells, both NBD-PS (Figure 3.6A) and $\mathrm{m}-\mathrm{CPZ}$ (Figure 3.6B) treated cells show an increased generation of prothrombinase activity when the stimulation with ionophore is started within 5 minutes after addition of these compounds.

In case of prolonged incubation, NBD-PS is transported to the inner monolayer by the action of the aminophospholipid translocase, while $m-C P Z$ accumulates in the inner monolayer by spontaneous diffusion with an estimated halftime of 1.5 hours, as was reported earlier by Hagerstrand et $a l^{24}$ During this prolonged incubation the cells transform from echinocytes to stomatocytes. ${ }^{25}$ When these stomatocytes are incubated with ionomycin and calcium, a reduced rate of thrombin formation is observed compared to control cells, indicating that in these cells PS becomes exposed at a lower rate. It should be noted that the low amount of NBD-PS used in these experiments does not contribute to the prothrombinase activity. 

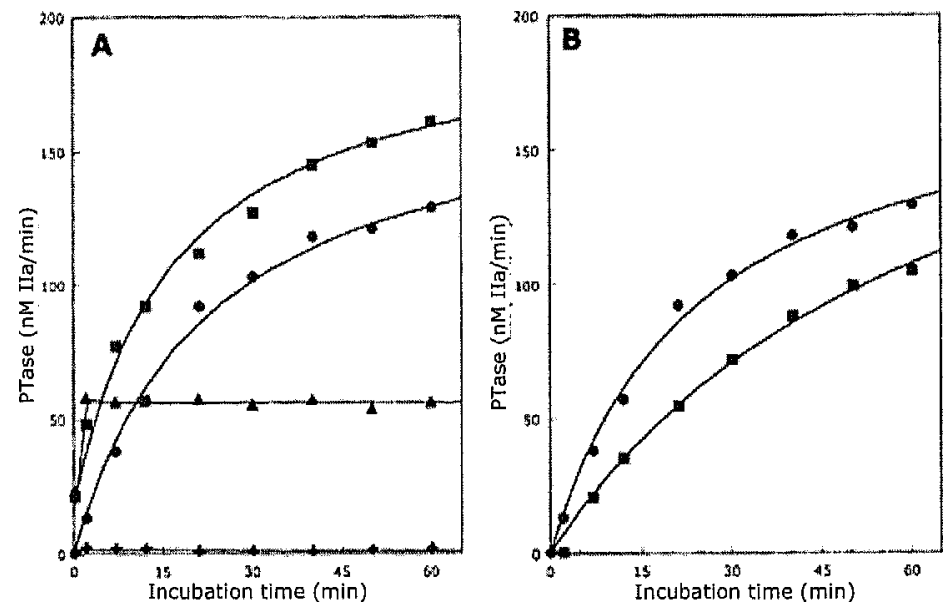

Figure 3.5 Effect of the non-ionic, cup-forming detergent C12E8 on the generation of prothrombinase activity of erythrocytes treated with ionomycin and calcium. Panel A: - cells treated with ionophore plus calcium; $\mathbf{m}$ cells pre-treated for 10 min with C12E8, followed by ionophore plus calcium; + cells treated with lonophore in absence of calcium, $\Delta$ cells preincubated for $10 \mathrm{~min}$ with C12E8, followed by ionophore without calcium. In all incubations, $t=0$ represents addition of ionophore. Note that the $\mathrm{t}=0$ value of cells pretreated with C12E8 (approx. $22 \mathrm{nM}$ thrombin/min) reflects PS-exposure induced by this detergent in the absence of calcium and ionophore.

Panel B: Generation of prothrombinase activity after correction for the effects of ionomycin and C12E8 in the absence of calcium. Values are obtained from panel A by subtracting the values from incubations without calcium from the corresponding incubations in the presence of calcium. - control cells; C12E8 pre-treated cells. Similar results were obtained using $0.002 \%(\mathrm{w} / \mathrm{V})$ Triton $\mathrm{X}-100$ although the differences were less pronounced. Incubations of cells with C12E8 alone or in the presence of calcium also showed an increase in prothrombinase activity, but to a lesser extent compared to the combination of C12E8 and ionomycin. The line showing the control cells incubated with ionophore alone is representative for all other cupformers and crenators used in this study, when incubated in the presence of ionophore.

\section{A crenator can neutralise the effect of a cupformer}

Figure 3.7 shows what happens when a crenator and a cupformer are simultaneously added to erythrocytes. The upper curve shows the rate of thrombin formation from cells treated with $m-C P Z$, while the lower curve represents cells treated with $C P Z$. When erythrocytes are incubated with both $\mathrm{m}-\mathrm{CPZ}$ and $\mathrm{CPZ}$, morphological inspection revealed that most of the cells have a near normal biconcave shape (data not shown). Treatment of these cells with calcium and 
ionophore leads to a rate of thrombin formation that closely resembles the rate observed in control cells. This suggests that the effects observed with either of the two agents alone are not due to mere perturbation of the membrane by incorporation of foreign substances.
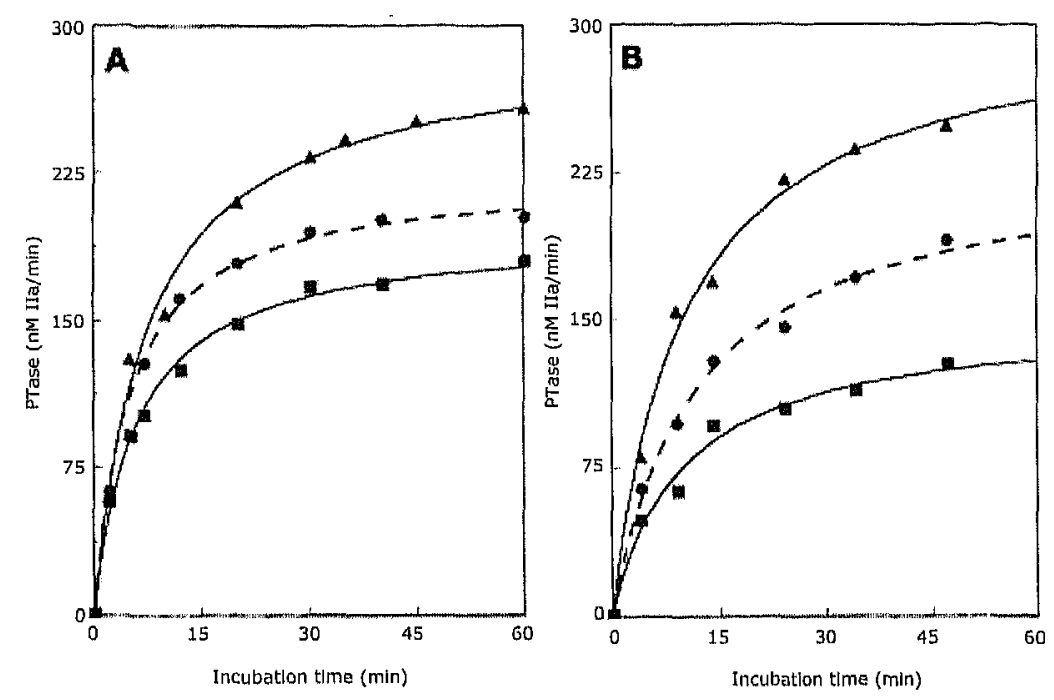

Figure 3.6 Both NBD-PS and methyl-chlorpromazine (m-CPZ) can act either as crenator or as cup-former. Prothrombinase activity after ionomycin activation is increased or reduced, corresponding to the shape change. Panel A: 1 MM NBD-PS; Panel B: $150 \mu \mathrm{M} \mathrm{m}-\mathrm{CPZ}$.

- control cells; A crenated cells; stomatocytic cells.

\section{Formation of microvesicles}

Since activation of erythrocytes, leading to exposure of PS is accompanied by formation of microvesicles, we measured the prothrombinase activity associated with microvesicles. Thereto, we used a centrifugation protocol known to sediment all the erythrocytes, leaving material in the supernatant operationally defined as microvesicles. In Figure 3.8 we compare the generation of prothrombinase activity in the total suspension (panel A) with that of the microvesicles (panel $B$ ). This shows that the increase in generation of PS exposure after treatment of erythrocytes with a crenator is also reflected in the amount of microvesicles that are shed. Also, the decreased activity of stomatocytes corresponds to a reduced formation of microvesicles compared to control cells. 


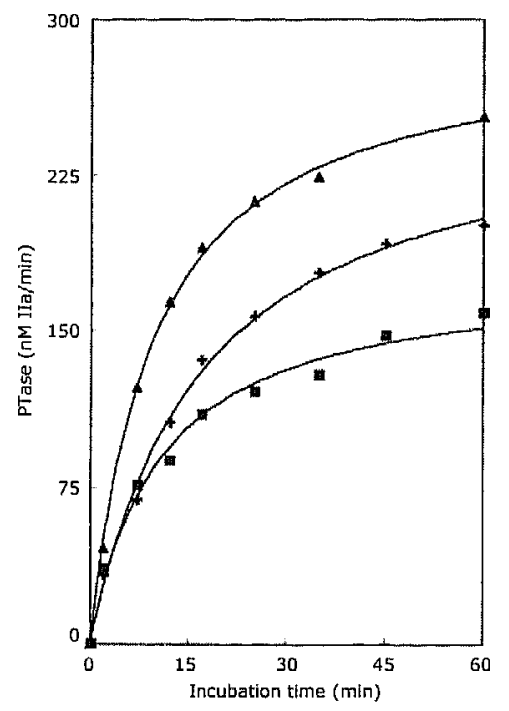

Figure 3.7 Neutralisation of the effect of CPZ on Ca-induced prothrombinase activity by its methylated derivative m-CPZ. $20 \mu \mathrm{M}$ chlorpromazine (CPZ); $+20 \mu \mathrm{M} \mathrm{CPZ}+150 \mu \mathrm{M}$ methyl-chlorpromazine (m-CPZ); A $150 \mu \mathrm{M}$ $\mathrm{m}-\mathrm{CPZ}$.
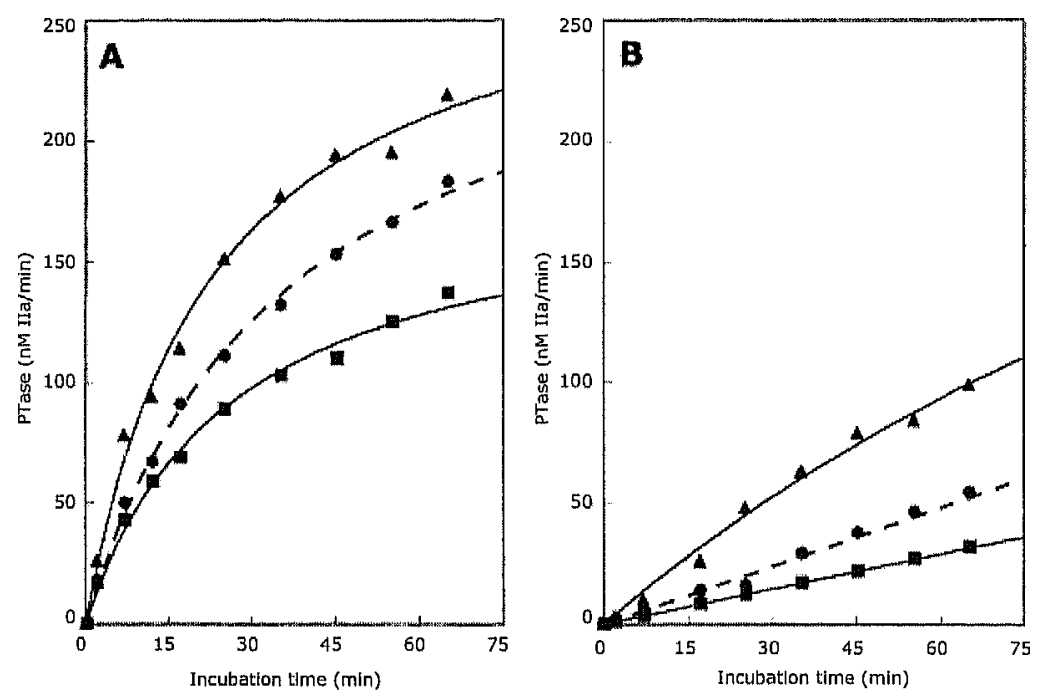

Figure 3.8 Activation of erythrocytes with calcium and ionophore, after treatment with $\mathrm{CPZ}$ or $\mathrm{m}-\mathrm{CPZ}$, or without treatment. Comparison of total prothrombinase activity versus that of the microvesicles.

Panel A: total activity; Panel B: activity associated with microvesicles. - control cells; $20 \mu \mathrm{M} \mathrm{CPZ;} \mathbf{\Delta} 150 \mu \mathrm{M} \mathrm{m}-\mathrm{CPZ}$. 


\section{Discussion}

Considering the range of the prothrombinase activities of normal biconcave erythrocytes from different individuals in response to treatment with ionophore and calcium, a large donor variation was found in both rate and extent of PS-exposure. Whether these differences, which appear reproducible within each donor, reflect variations in the number of scramblase copies per cell or in their activity is presently unclear. It should be mentioned, however, that the generation of prothrombinase activity in activated blood platelets of different healthy individuals does not vary by more than $10 \%$ (data not shown). The large variation in red cell prothrombinase activities between donors does not allow us to combine results from different donors and present average values. Therefore, we present all data as results from single individuals, stressing that other donors show the same patterns of behaviour albeit at different levels of prothrombinase activity.

The present data show that all agents that cause red cells to form echinocytes result in an increased rate of PS exposure after stimulation of the cells with $\mathrm{Ca}^{2+}$-ionophore. On the other hand, all cupformers appear to counteract the rate of PS exposure. The concentrations of the reagents that were used were based on the minimal amounts needed to cause crenation or cup-formation of 75 $80 \%$ of the cells, as examined by light microscopy. Using fluorescein isothiocyanate conjugated annexin $V$, Hagerstrand and coworkers ${ }^{22}$ demonstrated that nonionic- and anionic water-soluble amphiphiles can induce PS exposure in erythrocytes, while zwitterionic and cationic amphiphiles do not. In contrast to the present study, high, but sublytic concentrations of the lipid soluble compounds were used and no calcium ionophore was required. Moreover, cells were treated with NEM to inhibit aminophospholipid translocase to avoid PS from being pumped back to the inner leaflet, although annexin $V$ binding was not completely reduced when NEM was omitted. Similar observations were made by Pantaler et al. ${ }^{26}$ Apparently, the high sub-lytic concentrations of membrane inserted compounds may cause a perturbation of the bilayer structure facilitating movement of endogenous lipids across the membrane, although the relationship between the charge properties of the amphiphiles and their potency to cause externalisation of PS remains unclear. It should be stressed, that the concentrations of the membrane perturbing agents used in our study is far below those that were used in the studies mentioned above. Prolonged incubation of erythrocytes with the various 
compounds at these low concentrations did not result in an increase in prothrombinase activity, indicating no externalisation of PS. Also, with the exception of the non-ionic detergents C12E8 and Triton X100 , the combined presence of the lipid soluble compounds and ionomycine -in absence of $\mathrm{Ca}^{2+}$ - for one hour, followed by removal of ionophore by extraction with BSA, did not reveal PS exposure as measured by prothrombinase activity (data not shown). Moreover, a direct influence of the membrane perturbing agents on the prothrombinase reaction as such was excluded, since the prothrombinase activity of suspensions of treated and non-treated erythrocytes after sonication showed virtually identical activities. Although higher concentrations could increase the effects on the generation of prothrombinase activity, these were not used in order to avoid undesired side effects such as endo- or exo-vesiculation, or cell lysis, neither of which was observed under our experimental conditions.

The results confirm the notion that creating an imbalance in material between the two monolayers of the erythrocyte membrane will affect the subsequent activation process induced by calcium and ionophore. However, we did not find evidence in favour of the hypothesis that incorporation of material in the inner monolayer enhances externalisation of PS while incorporating material in the outer monolayer would counteract this process.

Since $\mathrm{Ca}^{2+}$-ionophore induces crenation of normal red cells, cup shaped cells first have to revert to biconcave cells before ionophoreinduced crenation followed by shedding of microvesicles can occur. Morphological inspection revealed that stomatocytes after $\mathrm{Ca}^{2+}$ ionophore treatment rapidly change via biconcave cells to echinocytes (J. Wolfs, unpublished observations). This process is completed within two minutes, which implies that prothrombinase measurements of $\mathrm{Ca}^{2+}$-ionophore treated cells were in all cases performed on cells with similar curvature. It has been shown that microvesicles are completely randomised in terms of $\mathrm{PS}^{27}$, which contributes significantly to the total prothrombinase activity of $\mathrm{Ca}^{2+}$ ionophore stimulated cells. Changing the shape of the erythrocyte before activation results in a change of the rate at which PS becomes exposed. We propose that these effects relate (at least in part) to the rate of formation of lipid-symmetric microvesicles. It could be argued that in the case of cupformers the reason for a reduced rate of PS exposure is the formation of complexes between the cupformers and PS at the inner monolayer, leading to a limited availability of this lipid for the scrambling process. However, this 
possibility is unlikely since NBD-PS, after being transported to the inner monolayer also reduces the rate of exposure of endogenous PS. Moreover, incubation of erythrocytes with the combination of CPZ and $\mathrm{m}-\mathrm{CPZ}$ results in an intermediary result compared to the effect of each of the two compounds when used alone. This would not likely occur when CPZ would contribute to restricting PS in the inner monolayer. It may be argued that pre-treatment of erythrocytes with membrane perturbing agents results in a change in membrane architecture that as such might lead to a change in measured prothrombinase activity, independent of the amount of PS exposed. This possibility, however, can be refuted by three observations: (i) the prothrombinase activity of erythrocytes (without ionomycin treatment) is not influenced by pre-treatment with crenators or cupformers in the presence of calcium, (ii) prothrombinase activities of sonicated preparations are not changed in the presence of crenators or cupformers, and (iii) the same compound (for instance $\mathrm{m}-\mathrm{CPZ}$ ) can cause either an increase or a decrease in ionomycin stimulated activity depending on incubation time, which makes it unlikely that this compound makes an a-specific contribution to prothrombinase activity.

A schematic representation of the influence of crenators and cupformers on lipid scramblase activity is given in Figure 3.9. Based on morphological studies, the progress of shape changes in time is shown, which occur after treatment of the erythrocytes with ionophore and calcium. Since crenated cells are closer to the cell shape required to shed microvesicles than stomatocytes are, this may reflect the observed differences in rate of surface exposure of PS. Nevertheless, a difference in the rate and/or amount of microvesicle formation is not fully sufficient to explain the differences in prothrombinase activity, i.e. when subtracting in Figure 3.8 the lines corresponding to the microvesicles from the respective lines of the total incubation, a difference between the three experiments, in favour of the echinocytes, is maintained. It may be speculated, however, that formation of echinocytes also leads to disruption of interactions between the lipid bilayer and the cytoskeleton ${ }^{28}$, which in itself might contribute to an increase in rate of lipid scrambling. 


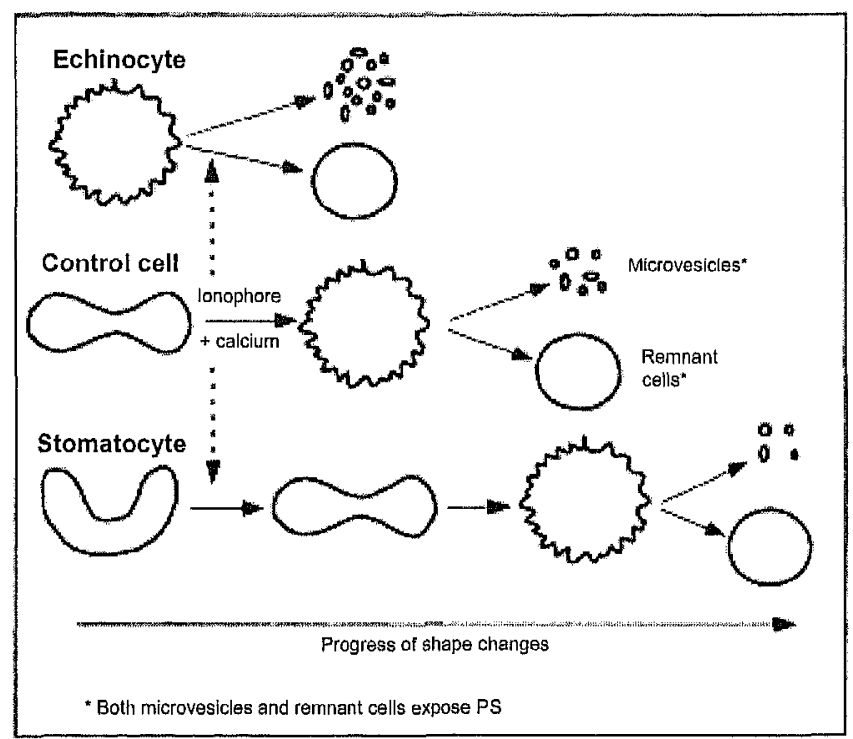

Figure 3.9 Schematic representation of the sequel of events after treatment of differently shaped erythrocytes with ionomycin and calcium.

In conclusion, we show that manipulating the shape of erythrocytes results in changes in their response to an increase in intracellular calcium. Formation of echinocytes enhances exposure of PS, whereas formation of stomatocytes leads to a reduced rate of PS exposure. As suggested by the prothrombinase measurements, this could imply that membrane-perturbing agents have an influence on blood coagulation. Whether or not these effects are also observed in other blood cells (e.g. blood platelets) is subject of future investigations. 


\section{References}

1. Schroit AJ, Zwaal RFA. Transbilayer movement of phospholipids in red cell and platelet membranes. Biochim Biophys Acta 1991; 1071: 313-29.

2. Devaux PF. Protein involvement in transmembrane lipid asymmetry. Annu Rev Biophys Biomol Struct 1992; 21: 417-39.

3. Connor J, Pak CH, Zwaal RFA, Schroit AJ. Bidirectional transbilayer movement of phospholipid analogs in human red blood cells. J Biol Chem 1992; 267: 19412-7.

4. Bitbol M, Devaux PF. Measurement of outward translocation of phospholipids across human erythrocyte membrane. Proc Natl Acad Scl U S A 1988; 85: 6783-7.

5. Morrot $G$, Zachowski A, Devaux PF. Partial purification and characterization of the

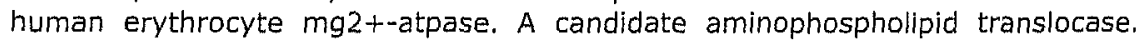
FEBS Lett 1990; 266: 29-32.

6. Daleke DL, Lyles JV. Identification and purification of aminophospholipid flippases. Biochim Biophys Acta 2000; 1486: 108-27.

7. Dekkers DWC, Comfurius P, Schroit A], Bevers EM, Zwaal RFA. Transbilayer movement of nbd-labeled phospholipids in red blood cell membranes: Outwarddirected transport by the multidrug resistance protein 1 (mrp1). Biochemistry, 1998; 37: 14833-7.

8. Williamson $P$, Bevers EM, Smeets EF, Comfurius $P$, Schlegel RA, Zwaal RF. Continuous analysis of the mechanism of activated transbilayer lipid movement in platelets. Biochemistry 1995; 34: 10448-55.

9. Rosing J, Rijn van JLML, Bevers EM, Dieijen van $G$, Comfurius P, Zwaal RFA. The role of activated human platelets in prothrombin and factor $x$ activation. Blood 1985; 65: 319-32.

10. Schroit AJ, Madsen JW, Tanaka $Y$. In vivo recognition and clearance of red blood cells containing phosphatidylserine in their plasma membranes. J Biol Chem 1985; 260: 5131-8.

11. Fadok VA, Voelker DR, Campbell PA, Cohen Jj, Bratton DL, Henson PM. Exposure of phosphatidylserine on the surface of apoptotic lymphocytes triggers specific recognition and removal by macrophages. J Immunol 1992; 148: 2207-16.

12. Zhou Q, Zhao J, Wiedmer T, Sims PJ. Normal hemostasis but defective hematopoietic response to growth factors in mice deficient in phospholipid scramblase 1. Blood 2002; 99: 4030-8.

13. Sims PJ, Wiedmer T, Esmon CT, Weiss HJ, Shattil SJ. Assembly of the platelet prothrombinase complex is linked to vesiculation of the platelet plasma membrane. Studies in scott syndrome: An isolated defect in platelet procoagulant activity. J Biol Chem 1989; 264: 17049-57.

14. Chang C-P, Zhao J, Wiedmer T, Sims PJ. Contribution of platelet microparticle formation and granule secretion to the transmembrane migration of phosphatidylserine. J Biol Chem 1993; 268: 7171-8.

15. Fox JEB, Austin CD, Reynolds CC, Steffen PK. Evidence that agonist-induced activation of calpain causes the shedding of procoagulant-containing microvesicles from the membrane of aggregating platelets. J Biol Chem 1991; 266: 13289-95.

16. Dachary-Prigent J, Pasquet JM, Freyssinet JM, Nurden AT. Calcium involvement in aminophospholipid exposure and microparticle formation during platelet activation: A study using ca2+-atpase inhibitors. Biochemistry 1995; 34: 1162534.

17. Smeets EF, Comfurius P, Bevers EM, Zwaal RF. Calcium-induced transbilayer scrambling of fluorescent phospholipid analogs in platelets and erythrocytes. Biochim Biophys Acta 1994; 1195: 281-6. 
18. Williamson P, Kulick A, Zachowski A, Schlegel RA, Devaux PF. Ca2+ induces transbilayer redistribution of all major phospholipids in human erythrocytes. Biochemistry 1992; 31: 6355-60.

19. Sheetz MP, Singer Sj. Biological membranes as bilayer couples. A molecular mechanism of drug-erythrocyte interactions. Proc Natl Acad Sci U S A 1974; 71: 4457-61.

20. Sheetz MP, Painter RG, Singer SJ. Biological membranes as bilayer couples. Iii. Compensatory shape changes induced in membranes. J Cell Biol 1976; 70: 193-203.

21. Devaux PF. Is lipid translocation involved during endo- and exocytosis? Biochimie 2000; 82: 497-509.

22. Hagerstrand $H$, Holmstrom TH, Bobrowska-Hagerstrand M, Eriksson JE, Isomaa B. Amphiphile-induced phosphatidylserine exposure in human erythrocytes. Molecular Membrane Biology 1998; 15: 89-95.

23. Hagerstrand $H$, Bobacka $]$, Bobrowska-Hagerstrand $M$, Kralj-Iglic $V$, Fosnaric $M$, Iglic A. Oxyethylene chain-cation complexation: Nonionic polyoxyethylene detergents attain a positive charge and demonstrate electrostatic head group interactions. Cell Mol Biol Lett 2001; 6: 161-5.

24. Hagerstrand $H$, Bobrowski-Hagerstrand $M$, Isomaa B. Do shape transformations in erythrocytes reflect the flip rate of amphiphilic compounds? Cellular \& Molecular Biology Letters 1996; 1: 3-14.

25. Daleke DL, Huestis WH. Erythrocyte morphology reflects the transbilayer distribution of incorporated phospholipids. J Cell Biol 1989; 108: 1375-85.

26. Pantaler E, Kamp D, Haest CW. Acceleration of phospholipid flip-flop in the erythrocyte membrane by detergents differing in polar head group and alkyl chain length. Biochim Biophys Acta 2000; 1509: 397-408.

27. Comfurius P, Senden JM, Tilly RH, Schroit AJ, Bevers EM, Zwaal RF. Loss of membrane phospholipid asymmetry in platelets and red cells may be associated with calcium-induced shedding of plasma membrane and inhibition of aminophospholipid translocase. Biochim Biophys Acta 1990; 1026: 153-60.

28. Manno S, Takakuwa $Y$, Mohandas N. Identification of a functional role for lipid asymmetry in biological membranes: Phosphatidylserine-skeletal protein interactions modulate membrane stability. Proc Natl Acad Scl U S A 2002; 99: 1943-8.

29. Huang CL, Yeh JZ, Muni IA. Comparative distribution, excretion, and metabolism of $14 \mathrm{c}$-labeled quaternary ammonium compounds of promazine, chlorpromazine, and triflupromazine. J Pharm Sci 1970; 59: 1114-8. 
Chapter 4

Reversible inhibition of the platelet procoagulant response through mamipulation of the Gardos channel

JLN Wolfs, SJH Wielders, P Comfurius, T Lindhout, JC Giddings, RFA Zwaal, EM Bevers

Blood 2006; 108: 2223-8 


\begin{abstract}
The platelet procoagulant response requires a sustained elevation of the intracellular $\mathrm{Ca}^{2+}$ concentration, $\left[\mathrm{Ca}^{2+}\right]_{1}$, causing exposure of phosphatidylserine (PS) at the outer surface of the plasma membrane. An increased $\left[\mathrm{Ca}^{2+}\right]_{1}$ also activates $\mathrm{Ca}^{2+}$-dependent $\mathrm{K}^{+}$ channels. Here, we investigated the contribution of the efflux of $\mathrm{K}^{+}$ ions on the platelet procoagulant response in collagen-thrombin activated platelets using selective $\mathrm{K}^{+}$channel blockers. The Gardos channel blockers clotrimazol, charybdotoxin and quinine caused a similar decrease in prothrombinase activity as well as in the number of PS-exposing platelets detected by fluorescence-conjugated annexin A5. Apamin and iberiotoxin, inhibitors of other $\mathrm{K}^{+}$channels, were without effect. Only clotrimazol showed a significant inhibition of the collagen plus thrombin-induced intracellular calcium response. Clotrimazol and charybdotoxin did not inhibit aggregation and release under the conditions used. Inhibition by Gardos channel blockers was reversed by valinomycin, a selective $\mathrm{K}^{+}$ionophore. The impaired procoagulant response of platelets from a patient with Scott syndrome was partially restored by pretreatment with valinomycin, suggesting a possible defect of the Gardos channel in this syndrome. Collectively, these results provide evidence for the involvement of efflux of $\mathrm{K}^{+}$ions through $\mathrm{Ca}^{2+}$-activated $\mathrm{K}^{+}$channels in the procoagulant response of platelets, opening potential strategies for therapeutic interventions.
\end{abstract}




\section{Introduction}

Blood platelets fulfill a dual role in the hemostatic process. Their adhesive and aggregating properties affirm the formation of a physical barrier required for the primary arrest of a bleeding. In addition, platelets provide a catalytic surface for the assembly of enzyme complexes of the coagulation cascade to ensure an accelerated fibrin formation. The latter function is referred to as the platelet procoagulant response, which involves a remodeling of the platelet plasma membrane. ${ }^{1}$ In quiescent platelets, phosphatidylserine (PS) is maintained in the inner leaflet of the plasma membrane mainly through the action of an aminophospholipid translocase. ${ }^{2,3}$ Stimulation of platelets causes aminophospholipid translocase activity to shut down, while simultaneously switching on the activity of a phospholipid scramblase. These events lead within minutes to a collapse of the normal asymmetric lipid distribution, resulting in surface exposure of negatively charged PS required for the binding of coagulation factor complexes. Despite several studies revealing various properties of the scramblase mechanism, the identity of the membrane protein(s) involved remains unresolved. ${ }^{2,4,5}$ A prerequisite for PS exposure in platelets appears to be a persistent elevation of $\left[\mathrm{Ca}^{2+}\right]_{1}$, a condition that is particularly accomplished using a combination of the physiological agonists collagen and thrombin. ${ }^{6}$ A prolonged rise in $\left[\mathrm{Ca}^{2+}\right]$, may also cause a collapse of lipid asymmetry in cells other than platelets. In the presence of extracellular $\mathrm{Ca}^{2+}, \mathrm{Ca}^{2+}$-ionophores such as ionomycin or A23187 have been shown to induce PS exposure in a variety of cells, including erythrocytes. Studies by Lang and coworkers ${ }^{7}$ have demonstrated that $\mathrm{Ca}^{2+}$, entering erythrocytes, not only activates the scramblase, but also stimulates the $\mathrm{Ca}^{2+}$-sensitive "Gardos" $\mathrm{K}^{+}$ channel in these cells. Subsequent loss of $\mathrm{K}^{+*}$ ions together with efflux of $\mathrm{Cl}^{-}$ions induces cell shrinkage, accompanied by shedding of microvesicles from the plasma membrane. It was further demonstrated that these events might be linked as both could be inhibited by either an increase of the extracellular $\mathrm{K}^{+}$concentration or selective Gardos $\mathrm{K}^{+}$channel blockers. Impaired cell shrinkage, microvesicle production and PS exposure upon treatment with $\mathrm{Ca}^{2+}$ ionophore are also observed in erythrocytes from patients with Scott syndrome. ${ }^{8}$ This rare hereditary bleeding disorder is caused by a defective scramblase mechanism that appears to be present in all cells of the hematological lineage. Hence, platelets from patients with 
Scott syndrome exhibit impaired PS exposure and microvesicle production in response to $\mathrm{Ca}^{2+}$-ionophore or collagen plus thrombin, despite a normal increase in $\left[\mathrm{Ca}^{2+}\right]_{1}$.

Here, we have investigated the role of the Gardos $\mathrm{K}^{+}$channel in the procoagulant response of platelets to physiological agonists such as the combined action of collagen and thrombin. To this end, we have used selective Gardos channel blockers as well as an increased extracellular $\mathrm{K}^{+}$concentration. In addition we have used valinomycin, a $\mathrm{K}^{+}$ionophore, to abolish the effect of the $\mathrm{K}^{+}$channel blockers. We demonstrate that Gardos channel blockers, but not other $\mathrm{K}^{+}$channel blockers, inhibit the platelet procoagulant response evoked by collagen and thrombin without having an appreciable effect on other platelet responses involved in the primary arrest of bleeding, such as aggregation or release. Furthermore, we present evidence that the impaired PS exposure in Scott syndrome platelets upon activation with collagen and thrombin may be partially attributed to an impaired efflux of $\mathrm{K}^{+}$ions.

\section{Materials and methods}

\section{Reagents}

Calcium ionophore ionomycin, bovine serum albumin (BSA, essentially fatty acid free), clotrimazol, quinine hydrochloride, charybdotoxin, apamin, iberiotoxin, and valinomycin were obtained from Sigma (St Louis, MO). Human thrombin was purified as previously described ${ }^{9}$ and collagen was from Horm (Nycomed, Münich, Germany). Tirofiban was obtained from MSD (Haarlem, the Netherlands). The coagulation proteins prothrombin, factor $\mathrm{Xa}$ and factor $V a$ were purified from bovine blood as described before. ${ }^{9}$ Thrombin-specific chromogenic substrate S2238 was obtained from Chromogenix (Mölndal, Sweden). Fluorescein isothiocyanate (FITC)conjugated annexin $A 5$ and Fura-2 were from Invitrogen (Leiden, the Netherlands). ATP Bioluminescence Assay Kit HS II was from Boehringer Mannheim (Germany).

\section{Platelet isolation and activation}

Platelet isolation was performed as described. ${ }^{10}$ Briefly, $10 \mathrm{ml}$ blood was collected in $2 \mathrm{ml}$ anticoagulant $A C D(80 \mathrm{mmol} / \mathrm{l}$ trisodium citrate, $52 \mathrm{mmol} / \mathrm{l}$ citric acid and $180 \mathrm{mmol} / \mathrm{l}$ glucose). Platelet rich 
plasma was obtained by centrifuging whole blood for $15 \mathrm{~min}$ at $200 \mathrm{~g}$. Platelets were spun down at $11,500 \times \mathrm{g}$ for two min using a microfuge. The platelet pellet was resuspended and washed twice with $10 \mathrm{mmol} / \mathrm{l}$ HEPES, $137 \mathrm{mmol} / \mathrm{l} \mathrm{NaCl}, 2.7 \mathrm{mmol} / \mathrm{l} \mathrm{KCl}, 2 \mathrm{mmol} / \mathrm{l}$ $\mathrm{MgCl}_{2}, 5 \mathrm{mmol} / \mathrm{l}$ glucose and $0.5 \mathrm{mg} / \mathrm{ml} \mathrm{BSA}$, adjusted at $\mathrm{pH} 6.6$ ); before each centrifugation step, $100 \mu \mathrm{ACD}$ was added to each $\mathrm{ml}$ resuspended platelets. Finally, platelets were resuspended in HEPES buffer at $\mathrm{pH} 7.4$. Platelet count was adjusted at $2 \times 10^{8}$ platelets $/ \mathrm{ml}$. For measurement of the intracellular $\mathrm{Ca}^{2+}$ concentration $\left(\left[\mathrm{Ca}^{2+}\right]_{1}\right)$, platelets were loaded with Fura-2 $(3 \mu \mathrm{mol} / \mathrm{l})$ during $45 \mathrm{~min}$ at $37^{\circ} \mathrm{C}$, prior to isolation.

Platelet activation was performed at $37^{\circ} \mathrm{C}$ at a concentration of $10^{7}$ platelets $/ \mathrm{ml}$ in a volume of $0.5 \mathrm{ml}$ under continuous stirring in the presence of $3 \mathrm{mmol} / \mathrm{l} \mathrm{CaCl}$. Platelet agonists used were thrombin $(5 \mathrm{nmol} / \mathrm{l})$ plus collagen $(10 \mu \mathrm{g} / \mathrm{ml})$ or ionomycin $(1 \mu \mathrm{mol} / \mathrm{l})$. The effect of different inhibitors was studied by pre-treatment of platelets with the various agents for 30 min before starting the activation procedure. For the effects of high extracellular $\left[\mathrm{K}^{+}\right]$, platelet suspensions were diluted 20-fold to a concentration of $10^{7}$ platelets $/ \mathrm{ml}$ in a modified HEPES buffer, referred to as $\mathrm{HEPES} / \mathrm{KCl}$ buffer (10 mmol/l HEPES, $19.7 \mathrm{mmol} / \mathrm{l} \mathrm{NaCl}, 120 \mathrm{mmol} / \mathrm{l} \mathrm{KCl}$, $2 \mathrm{mmol} / \mathrm{l} \mathrm{MgCl}_{2}, 5 \mathrm{mmol} / \mathrm{l}$ glucose and $0.5 \mathrm{mg} / \mathrm{ml} \mathrm{BSA}, \mathrm{pH} 7.4$ ), activated and assayed for thrombin generation as described before. In some experiments, HEPES buffer was used in which $120 \mathrm{mmol} / \mathrm{l}$ $\mathrm{NaCl}$ was replaced by $120 \mathrm{mmol} / \mathrm{l}$ choline chloride ( $10 \mathrm{mmol} / \mathrm{l}$ HEPES, $17 \mathrm{mmol} / \mathrm{l} \mathrm{NaCl}, 120 \mathrm{mmol} / \mathrm{l}$ choline chloride, $2.7 \mathrm{mmol} / \mathrm{l} \mathrm{KCl}$, $2 \mathrm{mmol} / \mathrm{l} \mathrm{MgCl}_{2}, 5 \mathrm{mmol} / \mathrm{l}$ glucose and $0.5 \mathrm{mg} / \mathrm{ml} \mathrm{BSA}, \mathrm{pH}$ 7.4), referred to as HEPES/Choline buffer.

For experiments with platelets from a patient with Scott syndrome, freshly obtained citrated blood from the patient and a control was shipped by airmail and platelets were isolated and used for experiments immediately upon arrival (approx 24 hours after blood donation).

\section{Platelet prothrombinase activity}

Platelet procoagulant activity was assayed as described in more detail elsewhere. ${ }^{9}$ Briefly, after activation of $10^{7}$ platelets $/ \mathrm{ml}$ with collagen $(10 \mu \mathrm{g} / \mathrm{ml})$ and thrombin $(4 \mathrm{nmol} / \mathrm{l})$ for $10 \mathrm{~min}$, samples were taken and diluted to $10^{6}$ platelets $/ \mathrm{ml}$ in HEPES buffer containing $3 \mathrm{mmol} / \mathrm{l} \mathrm{CaCl}_{2}$ and $0.5 \mathrm{mg} / \mathrm{ml} \mathrm{BSA}$. The samples were incubated with $0.2 \mathrm{nmol} / \mathrm{I}$ factor $\mathrm{Xa}$ and $2 \mathrm{nmol} / \mathrm{l}$ factor $V a$ for one min at $37^{\circ} \mathrm{C}$. 
Thrombin formation was initiated by addition of $1 \mu \mathrm{mol} / \mathrm{l}$ prothrombin and arrested after two min by addition of $10 \mathrm{mmol} / \mathrm{I}$ EDTA. Thrombin was measured using the chromogenic substrate $\mathbf{S 2 2 3 8 .}$

Separation of microparticles from remnant platelets after activation

Platelet activation has been demonstrated to be accompanied by shedding of microparticles from the plasma membrane. ${ }^{11,12}$ To evaluate the contribution of microparticles, we have used a previously described method to separate microparticles from remnant cells. ${ }^{13}$ Briefly, after activation, platelet suspensions were centrifuged at $11,500 \mathrm{~g}$; both the prothrombinase activity remaining in the supernatant and the lipid content of the supernatant approached constant values after three min centrifugation. This prothrombinase activity is operationally defined as derived from microparticles. The absence of platelets or remnant cells in the supernatant was confirmed by flow cytometry.

\section{Flow cytometry}

Samples for flow cytometry were taken simultaneously with samples for the prothrombinase assay from the platelet incubations after 10 min activation. To measure PS exposure, samples were diluted 10 -fold in HEPES buffer containing $3 \mathrm{mmol} / / \mathrm{CaCl}_{2}$ and incubated with FITC-conjugated Annexin A5 (final concentration $10 \mathrm{nmol} / \mathrm{l}$ ) for $5 \mathrm{~min}$ and analyzed for light scatter and fluorescence by a Coulter Epics XL-MLC ${ }^{T M}$ flow cytometer. Light scatter and fluorescence channels were set at logarithmic gain. Scatter parameters and fluorescence intensities were obtained from 10.000 platelets and analyzed off-line using WinMDI version 2.8 software (http://facs.scripps.edu/ software.html). Ionomycin activated platelets were used to set a marker for fluorescence intensity of annexin-positive platelets to measure the percentage of annexinpositive platelets after the various incubation procedures.

\section{Measurement of $\left[\mathrm{Ca}^{2+}\right]_{i}$ of platelets in suspension}

Platelets $\left(5 \times 10^{7} / \mathrm{ml}\right)$ were incubated with $\mathrm{K}^{+}$channel inhibitors for five $\min$, followed by the addition of tirofiban $(5 \mu \mathrm{g} / \mathrm{ml})$ and $\mathrm{Ca}^{2+}$ ( $3 \mathrm{mmol} / \mathrm{l}$ ) and incubated for an additional five $\mathrm{min}$ under stirring conditions. Collagen $(10 \mu \mathrm{g} / \mathrm{ml})$ plus thrombin $(5 \mathrm{nmol} / \mathrm{l})$ were then added simultaneously. Changes in $\left[\mathrm{Ca}^{2+}\right]_{1}$ of Fura-2-loaded platelets 
were measured under continuous stirring by dual excitation fluorometry in an SLM-Aminco 8100 spectrofluorometer (SLM Instruments). Ratio values of fluorescence at 340 and $380 \mathrm{~nm}$ excitation, obtained five min after activation with collagen plus thrombin, were converted to levels of $\left[\mathrm{Ca}^{2+}\right]_{i}$ as described. ${ }^{14}$ Experiments were performed in triplicate at $37^{\circ} \mathrm{C}$.

\section{Measurement of platelet aggregation and release}

Aggregation was measured at $37^{\circ} \mathrm{C}$ in $450 \mu \mathrm{l}$ samples of a platelet suspension of $2 \times 10^{8} / \mathrm{ml}$ using an automated model 400 Chronolog aggregometer (Chronolog Corporation, Chicago, USA). After stirring for two min at $300 \mathrm{rpm}, \mathrm{CaCl}_{2}(3 \mathrm{mmol} / \mathrm{l})$ was added, one min later followed by simultaneous addition of $10 \mathrm{ug} / \mathrm{ml}$ collagen and $4 \mathrm{nmol} / \mathrm{I}$ thrombin. The resulting aggregation was recorded for five min after which $50 \mu \mathrm{l}$ ATP-reagent (Boehringer Mannheim ATP Bioluminescence Assay Kit HS II) was added to quantify the release reaction.

\section{Statistics}

Data are expressed as mean values $\pm 1 \mathrm{SD}$. To determine the statistical significance of differences, $P$-values were calculated by Student's t-test $(* \mathrm{P}<0.05 ; * * \mathrm{P}<0.01 ; * * * \mathrm{P}<0.001)$

\section{Results}

The influence of high extracellular $\left[\mathrm{K}^{+}\right]$on the generation of procoagulant activity

Initial experiments to demonstrate the importance of an efflux of $\mathrm{K}^{+}$ ions during platelet stimulation on the procoagulant response were designed by changing the cation composition of the buffer. In these experiments, high extracellular $\left[\mathrm{K}^{+}\right]$in the $\mathrm{HEPES} / \mathrm{KCl}$ buffer was compensated by reducing $\left[\mathrm{Na}^{+}\right]$in order to maintain osmolarity. It should be emphasized, however, that a decreased $\left[\mathrm{Na}^{+}\right]$may have two major consequences: it reduces the catalytic efficiency of thrombin ${ }^{15}$ and it likely causes inhibition of the $\mathrm{Na}^{-1} / \mathrm{H}^{+}$exchanger, which may be involved in PS exposure during platelet activation. ${ }^{16}$ We therefore compared the procoagulant response induced by collagen plus thrombin in low $\left[\mathrm{Na}^{+}\right]$solutions (i.e., HEPES/Choline buffer and $\mathrm{HEPES} / \mathrm{KCl}$ buffer) with the response evoked in high [ $\left.\mathrm{Na}^{+}\right]$ solution (i.e., HEPES buffer). In these initial experiments, the 
procoagulant response was determined by the number of annexin binding platelets measured by flow cytometry. As shown in Figure 4.1 , the response in HEPES/Choline buffer decreased to $45.3 \pm 5.6 \%$ $(n=4)$ of that induced in HEPES buffer, whereas in HEPES/KCl buffer the response dropped to $31.9 \pm 4.8 \%(n=4)$. Thus, although the low $\left[\mathrm{Na}^{+}\right]$caused a decreased procoagulant response in both buffers, there appeared to be a significant additional inhibitory effect of the presence of high extracellular $\mathrm{K}^{+}$, supporting the notion that efflux of $\mathrm{K}^{+}$ions contributes to the procoagulant response. When platelets were stimulated with collagen alone, the procoagulant activity induced in Hepes/choline buffer was similar to that induced in Hepes (data not shown). This suggests that the lower response with collagen plus thrombin in Hepes/choline is more likely to be caused by a decreased activity of thrombin in low sodium buffers rather than a non-functional $\mathrm{Na}^{+} / \mathrm{H}^{+}$exchanger.

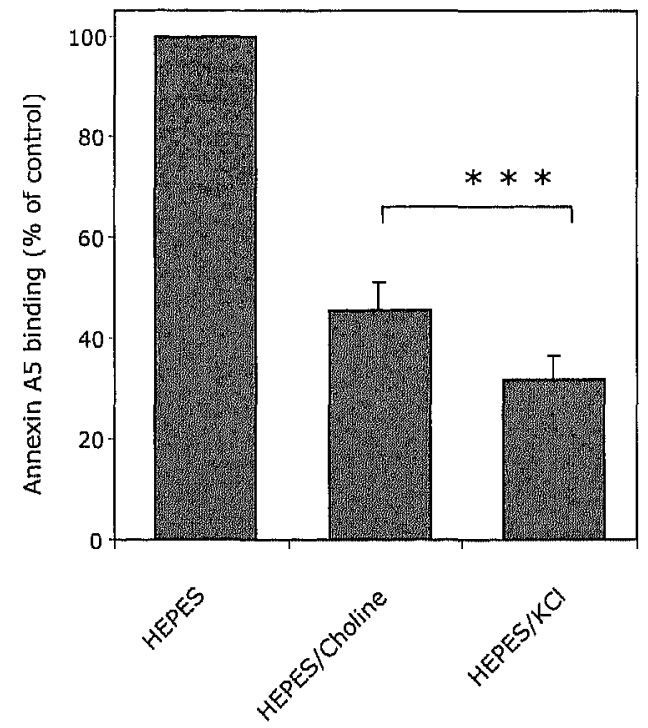

Figure 4.1 Effect of high extracellular $\left[\mathrm{K}^{+}\right]$on collagen plus thrombin induced platelet procoagulant response. Platelets at $10^{7} \mathrm{ml}^{-1}$ were activated with collagen $(10 \mu \mathrm{g} / \mathrm{ml})$ plus thrombin $(4 \mathrm{nmol} / \mathrm{l})$ for $10 \mathrm{~min}$. in HEPES, HEPES/Choline or HEPES/KCl and the procoagulant response was measured as the binding of FITC-conjugated annexin A5. Data are expressed as a percentage of the response obtained in HEPES. We emphasize that the $100 \%$ value in HEPES corresponds to approx. 20$25 \%$ of the total cell population which becomes positive for annexin binding, depending on the donor. Data are mean values \pm 1 S.D. $(n=4)$ 
Since microvesicle formation and PS exposure are closely associated events in the procoagulant response ${ }^{11-13}$, we also studied the effect of a high $\left[\mathrm{K}^{+}\right]$on microvesicle formation in collagen and thrombin activated platelets. Because of their small size, flow cytometry is not particularly suitable for quantifying platelet microparticles. Therefore, formation of microvesicles was operationally defined as residual procoagulant activity in the supernatant of a platelet suspension that was centrifuged at $11,500 \times \mathrm{g}$ for three $\min$ as was described previously. ${ }^{13,17}$ In $\mathrm{HEPES} / \mathrm{KCl}$, a $50 \%$ reduction in prothrombinase activity of both the supernatant and the total platelet incubation was found, indicating that a reduced PS exposure was accompanied by a reduced formation of microvesicles.

\section{Gardos channel blockers inhibit platelet procoagulant response}

We have tested various $\mathrm{K}^{+}$channel inhibitors for their ability to affect the collagen plus thrombin-induced platelet prothrombinase activity. The results are depicted in Figure 4.2A. The Gardos channel inhibitors clotrimazol $(10 \mu \mathrm{mol} / \mathrm{l})$ and charybdotoxin $(20 \mathrm{nmol} / \mathrm{l})$ caused $46 \pm 13 \% \quad(n=12)$ and $31 \pm 14 \% \quad(n=9)$ inhibition of the prothrombinase activity of collagen and thrombin activated platelets, respectively. The estimated $\mathrm{IC}_{50}$ for these two inhibitors on the platelet procoagulant response are $100 \mathrm{nmol} / \mathrm{l}$ and $5 \mathrm{nmol} / \mathrm{l}$, respectively, in good agreement with the estimated potencies to inhibit $\mathrm{K}^{+}$fluxes. ${ }^{18}$ Quinine, one of the first compounds demonstrated to block $\mathrm{K}^{+}$efflux in erythrocytes ${ }^{19-21}$, appeared to be the most potent inhibitor, being able to decrease the collagen plus thrombininduced procoagulant activity by $60 \pm 10 \%(n=6)$. Two other $\mathrm{K}^{+}$ channel inhibitors, iberiotoxin and apamin were without effect. Very similar findings with these inhibitors were obtained when the procoagulant response was measured as the binding of annexin A5 (Figure 4.2B). We could not demonstrate inhibition of clotrimazol, charybdotoxin or quinine on the procoagulant response induced by $\mathrm{Ca}^{2+}$-ionophore, ionomycin $(5 \mu \mathrm{mol} / \mathrm{l})$.

To investigate whether inhibition of the procoagulant response by clotrimazol, charybdotoxin and quinine was caused by a preferential effect of these inhibitors on the process of microvesicle formation, we compared the prothrombinase activity of a total suspension of activated platelets with that of its corresponding $11,500 \times \mathrm{g}$ supernatant. For each inhibitor, the decrease in prothrombinase activity of the supernatant was similar to that of the total platelet 
suspension, i.e. the prothrombinase activity of the supernatant varied between $30-35 \%$ of that of the total suspension, irrespective the presence of an inhibitor.
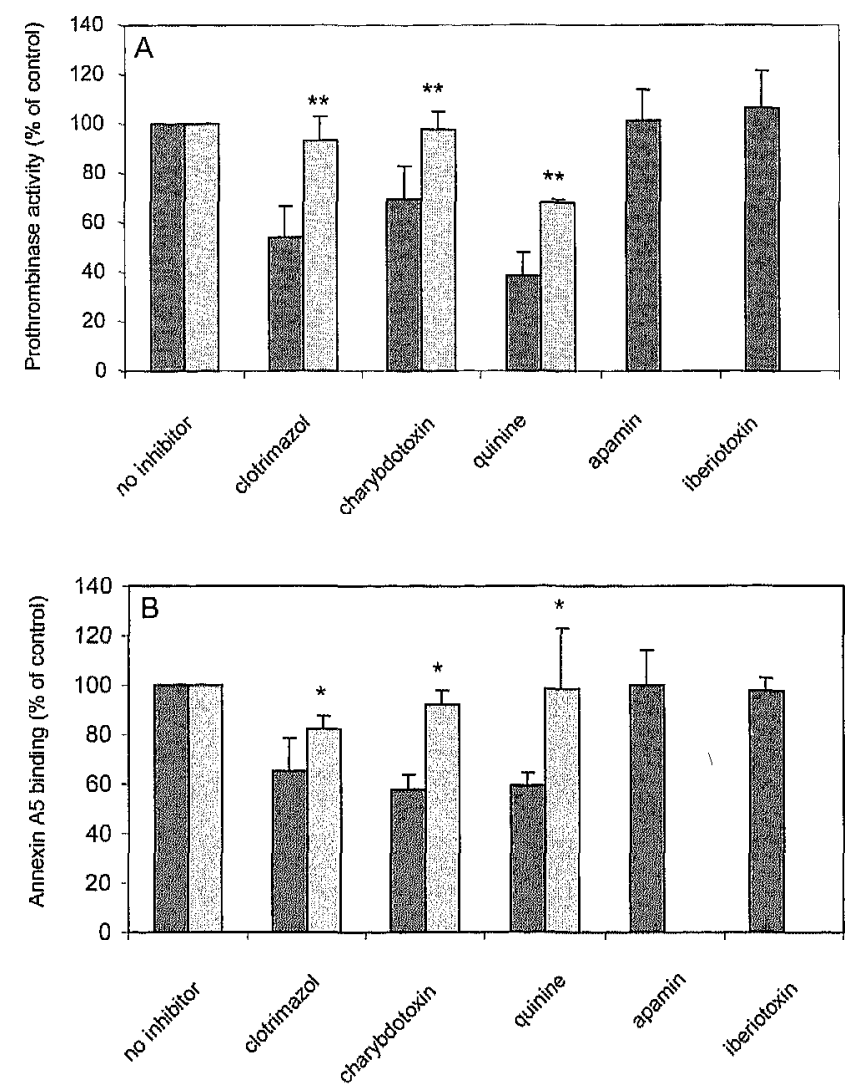

Figure 4.2 Effect of potassium channel inhibitors on collagen plus thrombin induced platelet procoagulant activity. Platelets at $10^{7} \mathrm{ml}^{-1}$ were preincubated with various inhibitors for $30 \mathrm{~min}$ followed by activation with collagen $(10 \mu \mathrm{g} / \mathrm{ml})$ plus thrombin $(4 \mathrm{nmol} / \mathrm{l})$ for $10 \mathrm{~min}$. Samples from these incubations were diluted 10 -fold in HEPES buffer containing $3 \mathrm{mmol} / \mathrm{l}$ $\mathrm{CaCl}_{2}$ and subsequently analyzed for prothrombinase activity (A) or percentage of annexin-positive cells (B) as described in the methods section. Valinomycin was added 5 min prior to activation of the platelets (to avoid long term effects of this ionophore). Black bars: absence of valinomycin; hatched bars: presence of valinomycin. Concentrations used: clotrimazol, $10 \mathrm{\mu mol} / \mathrm{l}$; charybdotoxin, $20 \mathrm{nmol} / \mathrm{l}$; quinine, $0.4 \mathrm{mmol} / \mathrm{l}$; apamin, $500 \mathrm{nmol} / \mathrm{l}$; iberiotoxin, $200 \mathrm{nmol} / \mathrm{l}$; valinomycin, $3 \mu \mathrm{mol} / \mathrm{l}$. Data are expressed as percentage of control, i.e. platelets in absence of inhibitor (mean \pm 1 S.D. $A: n>6 ; B: n>3$ ). Student's t-test was used to compare data in the presence and absence of valinomycin. 
Gardos channel blockers decrease the fraction of PSexposing platelets after collagen plus thrombin stimulation

It has been demonstrated that the procoagulant activity of platelets in suspension is caused by a fraction of the platelets showing maximal PS exposure. ${ }^{6,17,22,23}$ The level of procoagulant activity induced by various agonists is determined by the size of the subpopulation of platelets that have maximal externalized PS. To investigate whether the inhibition of procoagulant activity by the $\mathrm{K}^{+}$ channel blockers is caused by a decrease in the fraction of PSexposing platelets rather than by a decrease in the extent of PS exposure of the procoagulant platelet fraction, we used flow cytometry to measure the binding of FITC-conjugated annexin A5 on single cell level. Figure 4.3 shows a typical example of the effect of a $\mathrm{K}^{+}$channel inhibitor, clotrimazol, on the number of annexin-positive platelets after activation with collagen plus thrombin. The number of PS-exposing platelets is decreased in the presence of clotrimazol, but the extent of annexin binding (mean fluorescence intensity) of the residual PS positive platelets remains at the same level as found in the absence of inhibitor. Identical findings were obtained for the other Gardos channel blockers that inhibited the procoagulant response (data not shown).
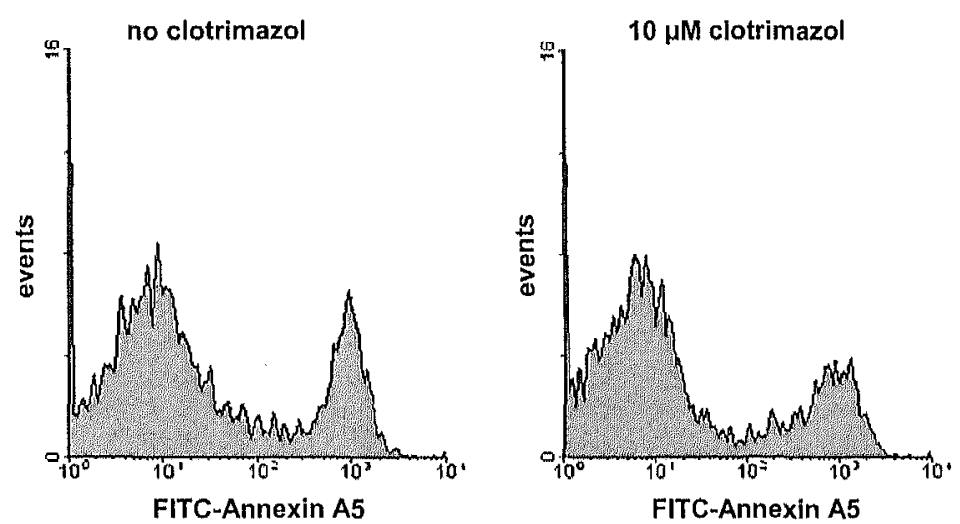

Figure 4.3 Histogram of the binding of annexin A5 to collagen plus thrombin activated platelets: effect of clotrimazol. Platelets were pre-incubated with (right histogram) or without (left histogram) clotrimazol $(10 \mu \mathrm{mol} / \mathrm{l})$ prior to activation with collagen plus thrombin. Following activation, platelet samples were diluted and FITC-conjugated annexin A5 was added. For experimental details consult the methods section. Similar results were obtained for charybdotoxin-or quinine-treated platelets. 
Besides a role in supporting blood coagulation, surface exposed PS is a hallmark of the apoptotic process, serving as 'eat me' signal for phagocyting cells. As shown previously, local anesthetics can cause PS exposure in platelets, a phenomenon associated with mitochondrial-related apoptotic-like events. ${ }^{17,24}$ Neither clotrimazol nor charybdotoxin could inhibit tetracaine-induced prothrombinase activity or binding of FITC-conjugated annexin A5 (data not shown).

No effect of Gardos channel inhibitors on collagen plus thrombin induced aggregation and release

To investigate whether or not other platelet functions were affected by the presence of $\mathrm{K}^{+}$channel inhibitors under these conditions of platelet stimulation, we studied their effect on aggregation and release of ATP. Neither high extracellular $\left[\mathrm{K}^{+}\right]$, nor the presence of clotrimazol or charybdotoxin showed an appreciable effect on aggregation or release (Table 4.1). (The diminished ATP release observed for platelets in HEPES/KCl appeared to be an apparent decrease, caused by a reduced activity of the ATP reagent (luciferine/luciferase) in this buffer). Quinine caused approx 60\% inhibition of the aggregation, but had only a minor effect on the release. It should be noted in this respect, that quinine has also been observed to inhibit phospholipase $A_{2}$, which may result in a decreased thromboxane $A_{2}$ production, a secondary stimulator of platelet aggregation. ${ }^{25}$ Since we were exclusively interested in inhibitory effects under conditions of platelet stimulation that evoke a procoagulant response, we did not perform dose-response curves for each activator separately. Hence, it cannot be excluded that these $\mathrm{K}^{+}$ channel blockers may affect the aggregation and/or release induced by collagen or thrombin at lower dose.

Table 4.1 Effect of Gardos channel inhibitors on platelet aggregation and release.

\begin{tabular}{lcc}
\hline & $\begin{array}{c}\text { aggregation } \\
\text { \% of control }( \pm \text { S.D. })\end{array}$ & $\begin{array}{c}\text { release (ATP) } \\
\text { of control }( \pm S . D .)\end{array}$ \\
\hline high $\mathrm{K}^{+}(120 \mathrm{mmol} / \mathrm{l})$ & $100.8 \pm 6.0$ & $79.4 \pm 3.3$ \\
Clotrimazol $(10 \mu \mathrm{mol} / \mathrm{l})$ & $90.0 \pm 2.8$ & $91.3 \pm 5.0$ \\
Charybdotoxin $(20 \mathrm{nmol} / \mathrm{l})$ & $108.3 \pm 10.2$ & $98.7 \pm 9.0$ \\
Quinine $(0.4 \mathrm{mmol} / \mathrm{l})$ & $40.0 \pm 3.0$ & $90.1 \pm 4.1$ \\
\hline
\end{tabular}




\section{Inhibition of the procoagulant response by Gardos} channel blockers is reversed by valinomycin

To verify that the inhibition by clotrimazol, charybdotoxin and quinine was caused by blocking the efflux of $\mathrm{K}^{+}$ions from the cell, valinomycin was used, which acts as a cage carrier selective for $\mathrm{K}^{+}$ ions. As shown in Figure 4.2A and 4.2B (hatched bars), valinomycin at a concentration of $3 \mu \mathrm{mol} / \mathrm{L}$ completely reversed the inhibition caused by clotrimazol and charybdotoxin, and partially abolished the inhibitory effect of quinine. The results depicted in Figure 4.2 were from experiments performed in HEPES buffer. Similar findings were obtained when the experiments were performed in HEPES/Choline. Moreover, also in HEPES/Choline, the inhibition by clotrimazol and charybdotoxin was virtually annihilated in the presence of valinomycin (Figure 4.4). Valinomycin itself did not cause a procoagulant response of platelets in the absence of a stimulus, nor did it affect the procoagulant response by collagen and thrombin in the absence of inhibitors. The inhibition of the procoagulant response by high extracellular $\left[\mathrm{K}^{+}\right]$was not reversed by addition of valinomycin (data not shown). Collectively, these findings strongly indicate that an efflux of $\mathrm{K}^{+}$ions through the Gardos channel augments the platelet procoagulant response induced by collagen plus thrombin.

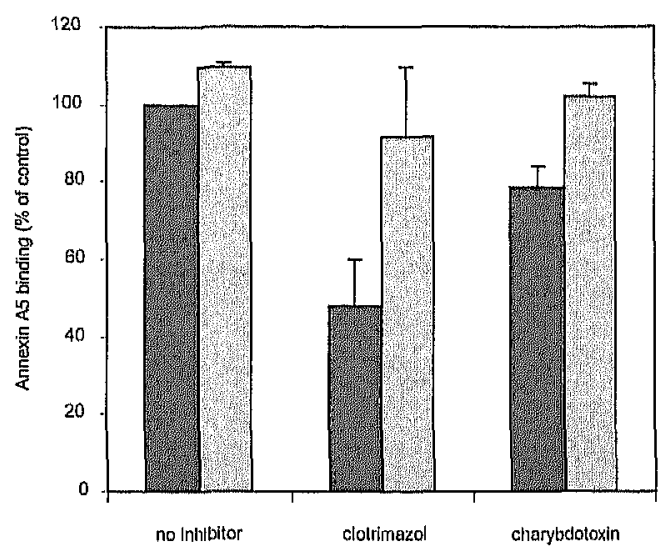

Figure 4.4 The effect of Gardos channel blockers and valinomycin on collagen plus thrombin induced procoagulant response in HEPES/Choline buffer. Platelets at $10^{7} \mathrm{ml}^{-1}$ in HEPES/Choline were preincubated with inhibitors for $30 \mathrm{~min}$ followed by activation with collagen $(10 \mu \mathrm{g} / \mathrm{ml})$ plus thrombin (4 $\mathrm{nmol} / \mathrm{l}$ ) for $10 \mathrm{~min}$. Valinomycin was added five min prior to activation. Samples from these incubations were diluted 10-fold and subsequently analyzed for binding of FITC-conjugated annexin A5. Data are expressed as a percentage of the number of annexin positive cells found upon activation in HEPES/Choline in absence of the inhibitors. Data are mean values \pm 1 S.D. $(n=4)$ 


\section{Effect of Gardos channel blockers on $\left[\mathrm{Ca}^{2+}\right]_{i}$}

It is increasingly appreciated that the procoagulant response depends on a persistent elevation of $\left[\mathrm{Ca}^{2+}\right]_{i}$. Therefore, inhibition of the procoagulant response by Gardos channel inhibitors might be due to a reduced collagen-thrombin induced change in $\left[\mathrm{Ca}^{2+}\right]_{i}$. To test this hypothesis we have conducted $\left[\mathrm{Ca}^{2+}\right]_{i}$ measurements in collagen plus thrombin activated platelets that were incubated with clotrimazol, charybdotoxin or quinine. In agreement with the notion that a sustained, threshold $\left[\mathrm{Ca}^{2+}\right]_{l}$ is of importance, $\left[\mathrm{Ca}^{2+}\right]_{1}$ levels, measured five min after stimulation with collagen plus thrombin either in the absence or presence of inhibitors, were compared. In the absence of inhibitors the change in $\left[\mathrm{Ca}^{2+}\right]$, was $364 \pm 18 \mathrm{nmol} / \mathrm{l}$. When platelets were preincubated with clotrimazol $(10 \mu \mathrm{mol} / \mathrm{I})$, the increase in $\left[\mathrm{Ca}^{2+}\right]_{i}$ was significantly lower $\left(\Delta\left[\mathrm{Ca}^{2+}\right]_{i}=275 \pm 10 \mathrm{nmol} / \mathrm{l}\right.$, $\mathrm{P}=0.01$ ). This $24 \%$ reduction could be reversed with valinomycin $\left(\Delta\left[\mathrm{Ca}^{2+}\right]_{\mathrm{l}}=326 \pm 34 \mathrm{nmol} / \mathrm{l}\right)$. With charybdotoxin $(20 \mathrm{nmol} / \mathrm{l})$, no significant change in $\left[\mathrm{Ca}^{2+}\right]_{1}$ was found $\left(\Delta\left[\mathrm{Ca}^{2+}\right]_{i}=360 \pm 23\right.$ $\mathrm{nmol} / \mathrm{l})$. The intrinsic fluorescence properties of quinine appeared to interfere with the Fura-2 signal, impeding determination of $\Delta\left[\mathrm{Ca}^{2+}\right]_{1}$ with this inhibitor.

The impaired procoagulant response of platelets from a patient with Scott syndrome can be partially corrected by valinomycin

Platelets from patients with Scott syndrome elicit a partially impaired procoagulant response when activated with collagen plus thrombin and appear to be completely defective in their response to $\mathrm{Ca}^{2+}$. ionophore. Here, we used platelets from a Welsh Scott patient, whose clinical features have been described earlier. ${ }^{26}$ Indeed, as shown in Figure 4.5, the prothrombinase activity after stimulation with collagen and thrombin was approximately $20 \%$ of that of an identically treated 'travel' control. Stimulation with collagen plus thrombin in the presence of $3 \mu \mathrm{mol} / \mathrm{I}$ valinomycin caused a significant increase in the procoagulant response of the Scott platelets, almost to the level of that observed for the control in the presence of valinomycin. 


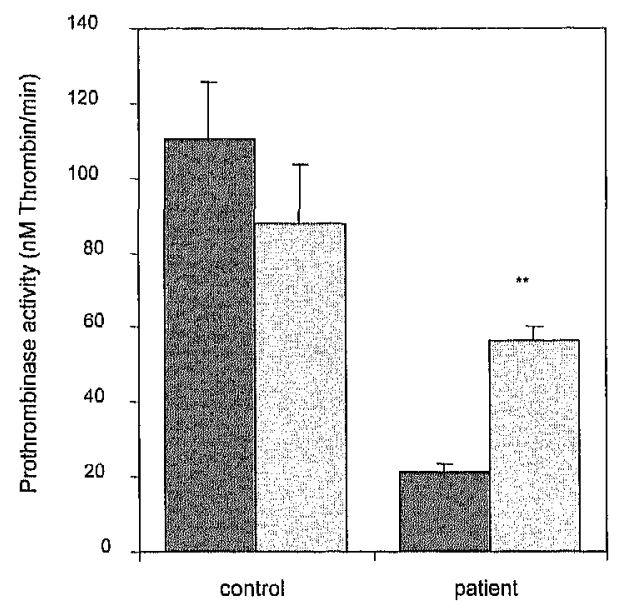

Figure 4.5 Effect of valinomycin on collagen plus thrombin induced procoagulant activity of platelets from a patient with Scott syndrome. Prothrombinase activities, expressed as nmol/l thrombin formed per min, were determined after activation with collagen $(10 \mu \mathrm{g} / \mathrm{ml})$ plus thrombin ( $4 \mathrm{nmol} / \mathrm{l}$ ) in the absence (black bars) and presence (hatched bars) of valinomycin $(3 \mu \mathrm{mol} / \mathrm{l})$. Data are mean values \pm 1 S.D. $(n=6)$

\section{Discussion}

Activation of blood platelets, particularly by the combined action of collagen and thrombin, evokes a procoagulant response, which has been attributed to surface exposure of PS in a distinct platelet population, ${ }^{17}$ thus producing a catalytic membrane surface that promotes assembly and activity of the prothrombinase and tenase complex of the blood coagulation proteins. ${ }^{9}$ In this study we wanted to investigate whether selective inhibition of $\mathrm{K}^{+}$channels present in the plasma membrane could affect the procoagulant response of platelets. A number of studies have demonstrated the presence of both voltage operated $\mathrm{K}^{+}$channels and $\mathrm{Ca}^{2+}$-induced $\mathrm{K}^{+}$channels in the plasma membrane of platelets. ${ }^{27-30}$ The latter can be subdivided in three different types, SK (small conductance-), IK (intermediate conductance-) and BK (large conductance-) channels. ${ }^{31-33}$ Whether or not all three types are present in platelets is presently unknown. Of the $\mathrm{Ca}^{2+}$-activated $\mathrm{K}^{+}$channels, the IK channel is identical to the Gardos channel, first described in erythrocytes. ${ }^{34}$ Distinction between different types of $\mathrm{K}^{+}$channels can be made based on their sensitivity to specific inhibitors. ${ }^{18,32,33}$ The anti-fungal agent clotrimazol and charybdotoxin, a high affinity peptide isolated from scorpion venom, 
specifically block the Gardos channel, although charybdotoxin can also inhibit the large-conductance $\mathrm{Ca}^{2+}$-activated $\mathrm{K}^{+}$channel. Iberiotoxin, a peptide also purified from scorpion venom and apamin, isolated from bee venom are blockers of BK and SK channels, respectively. ${ }^{18,32,33}$ The present study shows that PS exposure, microvesiculation, and prothrombinase activity of platelets stimulated with collagen plus thrombin are markedly attenuated in the presence of specific inhibitors of the Gardos $\mathrm{K}^{+}$channel, charybdotoxin, clotrimazol, and quinine, as well as in the presence of high extracellular $\mathrm{K}^{+}$. This inhibition does not occur with inhibitors of the non-Gardos $\mathrm{K}^{+}$channels (e.g. apamin and iberiotoxin), strongly suggesting that functional Gardos channels are a requisite for the process of PS externalization. Mahaut-Smith et al. ${ }^{30}$ have suggested that $\mathrm{Ca}^{2+}$-activated $\mathrm{K}^{+}$channels are important in maintaining the membrane potential during stimulated cation influx. Inhibition of these channels would be expected to cause a higher degree of membrane depolarization following platelet activation and consequently reduce the driving force for $\mathrm{Ca}^{2+}$ entry. Indeed, a significant inhibition by clotrimazol was found on the $\left[\mathrm{Ca}^{2+}\right]_{i}$ measured five min after collagen plus thrombin activation. The inhibitory effect of the Gardos-channel blockers is abolished in the presence of the $\mathrm{K}^{+}$ionophore valinomycin, in agreement with its ability to clamp the membrane potential near to the $\mathrm{K}^{+}$equilibrium potential. ${ }^{29}$ Although the effect of clotrimazol on the collagen plus thrombin induced sustained $\left[\mathrm{Ca}^{2+}\right]_{\mathrm{i}}$ (i.e., measured after five min stimulation) appeared quite small, it should be emphasized that these values represent the average of all platelets in suspension. As was shown recently, platelets are heterogeneous in the procoagulant response, i.e., the PS exposing platelets represent only a fraction of the total. ${ }^{17}$ This may explain why the inhibitory effect of charybdotoxin on the $\left[\mathrm{Ca}^{2+}\right]$, was not significant, since this inhibitor, on average, appeared less potent than clotrimazol.

Treatment of platelets with the $\mathrm{Ca}^{2+}$-ionophore ionomycin causes maximal PS exposure in all platelets and consequently evokes a maximal procoagulant response. ${ }^{17}$ Gardos channel blockers did not significantly affect ionomycin-induced PS exposure in platelets, which would be expected since in the presence of ionomycin the $\mathrm{Ca}^{2+}$ fluxes mainly depend on the $\mathrm{Ca}^{2+}$-gradients across the plasma membrane and the endoplasmic reticulum membrane and not the membrane potential. In contrast with our findings on platelets, Lang and coworkers $^{7}$ demonstrated that clotrimazol and charybdotoxin inhibit PS exposure in erythrocytes treated with $\mathrm{Ca}^{2+}$-ionophore. Also 
morphological changes, such as cell shrinkage, microvesicle production and formation of crenated spherocytes, were suppressed by these inhibitors. We found that these inhibitory effects in erythrocytes could be abolished by addition of valinomycin, indicating that diminished PS exposure was related to a decreased efflux of $\mathrm{K}^{+}$ ions (J.L.N.W. unpublished data, June 2005). We have as yet no explanation for the different effects of Gardos channel inhibitors on $\mathrm{Ca}^{2+}$-ionophore-induced responses in platelets and erythrocytes.

Interestingly, blood platelets from Scott syndrome, a rare hereditary bleeding disorder, characterized by a defective scramblase mechanism, nevertheless expose PS upon activation in the presence of valinomycin. Moreover, red cells from Scott syndrome, unlike normal red cells, have been shown to maintain their biconcave structure upon treatment with $\mathrm{Ca}^{2+}$-ionophore ${ }^{35}$, whereas normal red cells maintain their biconcave structure with $\mathrm{Ca}^{2+}$-ionophore in the presence of Gardos-channel inhibitors. ${ }^{7}$ Therefore, it can be speculated that blood cells from Scott syndrome lack, or have defective Gardos channels, preventing operation of the scramblase mechanism, and thus the formation of a procoagulant platelet membrane surface.

It is worth recalling that Scott platelets have been shown to expose PS upon treatment with local anesthetics (e.g., tetracain, propranolol) which produce mitochondria-related apoptotic events. ${ }^{24}$ These local anesthetics also produce apoptosis and concurrent PS exposure in normal platelets, but this response cannot be inhibited by the Gardos-channel blockers charybdotoxin and clotrimazol. This confirms that PS exposure during apoptosis differs from that during cell activation, as has been shown earlier. ${ }^{36}$

Finally, the Gardos-channel inhibitors do not affect platelet aggregation and release to any appreciable extent. This may open new perspectives to explore selective inhibition of the platelet procoagulant response while maintaining the platelet functions required for the primary arrest of bleeding. Also, promoting $\mathrm{K}^{+}$efflux in platelets from Scott syndrome could be a feasible strategy to correct this bleeding disorder. 


\section{References}

1. Heemskerk JW, Bevers EM, Lindhout T. Platelet activation and blood coagulation. Thromb Haemost 2002; 88: 186-93.

2. Sims PJ, Wiedmer $T$. Unraveling the mysteries of phospholipid scrambling. Thromb Haemost 2001; 86: 266-75.

3. Bevers EM, Comfurius P, Dekkers DW, Zwaal RF. Lipid translocation across the plasma membrane of mammalian cells. Biochim Biophys Acta 1999; 1439: 317-30.

4. Zhou Q, Sims PJ, Wiedmer T. Expression of proteins controlling transbilayer movement of plasma membrane phospholipids in the $B$ lymphocytes from a patient with Scott syndrome. Blood. 1998; 92: 1707-12.

5. Zhou Q, Zhao J, Wiedmer T, Sims PJ. Normal hemostasis but defective hematopoietic response to growth factors in mice deficient in phospholipid scramblase 1. Blood 2002; 99; 4030-8.

6. Keuren JF, Wielders 5J, Ulrichts $H$, Hackeng $T$, Heemskerk JW, Deckmyn $H_{\text {, }}$ Bevers EM, Lindhout T. Synergistic effect of thrombin on collagen-induced platelet procoagulant activity is mediated through protease-activated receptor-1. Arterioscler Thromb Vasc Biol 2005; 25: 1499-505.

7. Lang PA, Kaiser S, Myssina S, Wieder T, Lang F, Huber SM. Role of Caz+activated $\mathrm{K}+$ channels in human erythrocyte apoptosis. Am J Physiol Cell Physiol 2003; 285: C1553-60.

8. Zwaal RF, Comfurius P, Bevers EM. Scott syndrome, a bleeding disorder caused by defective scrambling of membrane phospholipids. Biochim Biophys Acta 2004; 1636: 119-28.

9. Rosing J, van Rijn JL, Bevers EM, van Dieijen G, Comfurius P, Zwaal RF. The role of activated human platelets in prothrombin and factor $X$ activation. Blood 1985 ; 65: 319-32.

10. Heemskerk JW, Comfurius $P$, Feijge MA, Bevers EM. Measurement of the platelet procoagulant response. Methods Mol Biol 2004; 272: 135-44.

11. Sims PJ, Wiedmer T, Esmon CT, Weiss HJ, Shattil SJ. Assembly of the platelet prothrombinase complex is linked to vesiculation of the platelet plasma membrane. Studies in Scott syndrome: an isolated defect in platelet procoagulant activity. J Biol Chem 1989; 264: 17049-57.

12. Morel $O$, Toti $F$, Hugel $B$, Freyssinet JM. Cellular microparticles: a disseminated storage pool of bioactive vascular effectors. Curr Opin Hematol 2004; 11: 156-64.

13. Comfurius P, Senden JM, Tilly RH, Schroit AJ, Bevers EM, Zwaal RF. Loss of membrane phospholipid asymmetry in platelets and red cells may be associated with calcium-induced shedding of plasma membrane and inhibition of aminophospholipid translocase. Biochim Biophys Acta 1990; 1026: 153-60.

14. Grynkiewicz G, Poenie M, Tsien RY. A new generation of $\mathrm{Ca2+}$ indicators with greatly improved fluorescence properties. J Biol Chem 1985; 260: 3440-50.

15. Di Cera E. Thrombin: a paradigm for enzymes allosterically activated by monovalent cations. C R Biol 2004; 327: 1065-76.

16. Bucki R, Pastore JJ, Giraud F, Janmey PA, Sulpice JC. Involvement of the $\mathrm{Na}(+) / \mathrm{H}(+)$ exchanger in membrane phosphatidylserine exposure during human platelet activation. Biochim Biophys Acta 2006; 1761: 195-204.

17. Wolfs JL, Comfurius $P$, Rasmussen JT, et al. Activated scramblase and inhibited aminophospholipid translocase cause phosphatidylserine exposure in a distinct platelet fraction. Cell Mol Life Sci 2005; 62: 1514-25.

18. Maher AD, Kuchel PW. The Gardos channel: a review of the Ca2+-activated K+ channel in human erythrocytes. Int I Biochem Cell Biol 2003; 35: 1182-97. 
19. Allan D, Thomas P. Ca2+-induced biochemical changes in human erythrocytes and their relation to microvesiculation. Biochem J 1981; 198: 433-40.

20. Armando-Hardy $M$, Ellory JC, Ferreira HG, Fleminger $S$, Lew VL. Inhibition of the calcium-induced increase in the potassium permeability of human red blood cells by quinine. J Physiol 1975; 250: 32P-3P.

21. Reichstein $E$, Rothstein $A$. Effects of quinine on $\mathrm{Ca}++$-induced $\mathrm{K}+$ efflux from human red blood cells. J Membr Biol 1981; 59: 57-63.

22. Dachary-Prigent J, Pasquet JM, Freyssinet JM, Nurden AT. Calcium involvement in aminophospholipid exposure and microparticle formation during platelet activation: a study using Ca2+-ATPase inhibitors. Biochemistry 1995; 34: 11625-34.

23. London FS, Marcinkiewicz M, Walsh PN. A subpopulation of platelets responds to thrombin- or SFLLRN-stimulation with binding sites for factor IXa. J Biol Chem 2004; 279: 19854-9.

24. Augereau O, Rossignol R, DeGiorgi F, Mazat JP, Letellier T, Dachary-Prigent J. Apoptotic-like mitochondrial events associated to phosphatidylserine exposure in blood platelets induced by local anaesthetics. Thromb Haemost 2004; 92: 104-13.

25. Wada A, Sakurai S, Kobayashi H, Yanagihara N, Izumi F. Suppression by phospholipase A2 inhibitors of secretion of catecholamines from isolated adrenal medullary cells by suppression of cellular calcium uptake. Biochem Pharmacol 1983; 32: 1175-8.

26. Munnix IC, Harmsma M, Giddings JC, et al. Store-mediated calcium entry in the regulation of phosphatidylserine exposure in blood cells from Scott patients. Thromb Haemost 2003; 89: 687-95.

27. Fine BP, Hansen KA, Salcedo JR, Aviv A. Calcium-activated potassium channels in human platelets. Proc Soc Exp Biol Med 1989; 192: 109-13.

28. Pipili E. Platelet membrane potential: simultaneous measurement of disC3(5) fluorescence and optical density. Thromb Haemost 1985; 54: 645-9.

29. Mahaut-Smith MP, Rink TJ, Collins SC, Sage SO. Voltage-gated potassium channels and the control of membrane potential in human platelets. J Physiol 1990; 428: 723-35.

30. Mahaut-Smith MP. Calcium-activated potassium channels in human platelets. J Physiol 1995; 484 (Pt 1): 15-24.

31. McManus OB. Calcium-activated potassium channels: regulation by calcium. J Bioenerg Biomembr 1991; 23: 537-60.

32. Castle NE. Recents advances in the biology of small conductance calciumactivated potassium channels. Perspect Drug Discov 1999; 15/16: 131-54.

33. Rodriguez de la Vega RC, Possani LD. Current views on scorpion toxins specific for Kt-channels. Toxicon 2004; 43: 865-75.

34. Gardos G. The function of calcium in the potassium permeability of human erythrocytes. Biochim Biophys Acta 1958; 30: 653-4.

35. Bevers EM, Wiedmer T, Comfurius P, Shattil SJ, Weiss HJ, Zwaal RF, Sims PJ. Defective $\mathrm{Ca}(2+)$-induced microvesiculation and deficient expression of procoagulant activity in erythrocytes from a patient with a bleeding disorder: a study of the red blood cells of Scott syndrome. Blood 1992; 79: 380-8.

36. Williamson $P$, Christie A, Kohlin T, Schlegel RA, Comfurius $P$, Harmsma M, Zwaal RF, Bevers EM. Phospholipid scramblase activation pathways in lymphocytes. Biochemistry 2001; 40: 8065-72. 


\section{Chapter 5}

\section{Direct inhibition of phospholipid scrambling activity in erythrocytes by potassium ions}

JLN Wolfs, P Comfurius, O Bekers, RFA Zwaal, K Balasubramanian, AJ Schroit, $T$ Lindhout, EM Bevers

Cell Mol Life Sci. 2009; 66: 314-23 


\section{Abstract}

The exposure of phosphatidylserine (PS) at the cell surface plays a critical role in blood coagulation and serves as a macrophage recognition moiety for the engulfment of apoptotic cells. Previous observations have shown that a high extracellular $\left[\mathrm{K}^{+}\right]$and selective $\mathrm{K}^{+}$channel blockers inhibit PS exposure in platelets and erythrocytes. Here we show that the rate of PS exposure in erythrocytes decreases by $\sim 50 \%$ when the intracellular $\left[\mathrm{K}^{+}\right]$increases from 0 to physiologic concentrations. Using resealed erythrocyte membranes, we further show that lipid scrambling is inducible by raising the intracellular $\left[\mathrm{Ca}^{2+}\right]$ and that $\mathrm{K}^{+}$ions have a direct inhibitory effect on this process. Lipid scrambling in resealed ghosts occurs in the absence of cell shrinkage and microvesicle formation, processes that are generally attributed to $\mathrm{Ca}^{2+}$-induced lipid scrambling in intact erythrocytes. Thus, opening of $\mathrm{Ca}^{2+}$-sensitive $\mathrm{K}^{+}$channels causes loss of intracellular $\mathrm{K}^{+}$that results in reduced intrinsic inhibitory effect of these ions on scramblase activity. 


\section{Introduction}

Numerous studies have revealed the involvement of several lipid transporters in the mechanisms that control transbilayer lipid distribution in eukaryotic cells. ${ }^{1,2}$ The concerted action of an inwarddirected aminophospholipid translocase and a less specific outwarddirected floppase are thought to be responsible for maintaining the dynamic equilibrium distribution of phospholipids observed in the plasma membrane of quiescent cells. Activation of a putative protein, coined phospholipid 'scramblase', dissipates normal membrane lipid asymmetry by facilitating the bidirectional transbilayer movement of all phospholipid classes irrespective of the composition of the polar head group. The most pronounced effect of the perturbed lipid asymmetry is the appearance of the negatively charged phospholipid, phosphatidylserine (PS), in the external membrane bilayer leaflet. Once externalized, PS provides a platform for the assembly of enzyme complexes that regulate the propagation of coagulation $^{3}$ and serves as a 'death signal' for the recognition and ultimate phagocytosis of apoptotic cells. ${ }^{4}$ In addition, a recently identified non-apoptotic form of PS exposure has been suggested to play a role in "inside-out" signaling in immune cells in response to pathogens. ${ }^{5}$

Vessel wall injury causes platelets to interact with collagen and thrombin, which leads to scramblase activation resulting in surface exposure of PS. This enables the assembly of the tenase- and prothrombinase complexes that ensures propagation of coagulation and rapid arrest of bleeding. ${ }^{3}$ Compromised scramblase activity results in a bleeding disorder characteristic of Scott syndrome patients. ${ }^{6}$ Although the activation pathways for scramblase activity may differ between cell types, a key downstream event for its activation seems to be sustained elevation in the intracellular $\mathrm{Ca}^{2+}$ concentration, $\left[\mathrm{Ca}^{2+}\right]_{i}$, that occurs through the release of $\mathrm{Ca}^{2+}$ from intracellular stores and/or the influx of extracellular $\mathrm{Ca}^{2+}$.

Despite considerable efforts, the identity of the scramblase has yet to be elucidated. Scramblase activity was demonstrated in proteoliposomes reconstituted from a membrane protein fraction isolated from platelets ${ }^{7}$ and erythrocytes. ${ }^{8}$ Although the protein from erythrocytes has been cloned ${ }^{9}$, an increasing body of evidence suggests that the putative human phospholipid scramblase (hPLSCR) is not responsible for the rapid transbilayer migration of lipids in apoptotic cells or in activated blood cells. ${ }^{6,10,11}$ 
We have recently obtained evidence that efflux of $\mathrm{K}^{+}$ions through $\mathrm{Ca}^{2+}$-activated $\mathrm{K}^{+}$channels plays a regulatory role in PS exposure in platelets. ${ }^{12}$ Selective $\mathrm{K}^{+}$channel blockers or increased levels of extracellular $\mathrm{K}^{+}$inhibit the procoagulant response of platelets to collagen and thrombin. Similarly, $\mathrm{Ca}^{2+}$-induced PS exposure in erythrocytes is inhibited by $\mathrm{K}^{+}$channel blockers or elevated extracellular $\left[\mathrm{K}^{+}\right]\left(\left[\mathrm{K}^{+}\right]_{\mathrm{e}}\right){ }^{13}$ While it is possible that blocking $\mathrm{K}^{+}$efflux indirectly inhibits $\mathrm{Ca}^{2+}$ influx, we have not been able to clearly demonstrate a decreased $\mathrm{Ca}^{2+}$ response in platelets treated with $\mathrm{K}^{+}$ channel blockers. ${ }^{12}$ This raised the question as to whether scramblase activity is under direct control of the intracellular $\left[\mathrm{K}^{+}\right]$, $\left[\mathrm{K}^{+}\right]_{\mathrm{i}}$.

To address this issue, we used erythrocytes and resealed erythrocyte ghosts as a model to study the relationship between $\mathrm{Ca}^{2+}$-dependent scramblase activity and $\left[\mathrm{K}^{+}\right]_{i}$. We show that $\mathrm{K}^{+}$specifically inhibits $\mathrm{Ca}^{2+}$-dependent scramblase activity by a mechanism that is independent of changes in cell morphology and the formation of microvesicles.

\section{Materials and methods}

\section{Reagents}

Ionomycin, charybdotoxin, clotrimazol and valinomycin were obtained from Sigma (St Louis, MO). The coagulation proteins prothrombin, factor $\mathrm{Xa}$ and factor $\mathrm{Va}$ were purified from bovine blood as described before. ${ }^{14}$ Thrombin-specific chromogenic substrate, S2238, was obtained from Chromogenix (Mölndal, Sweden). Fluorescein isothiocyanate (FITC)-conjugated annexin A5, Fluo-3/AM, Rhod-2/AM and Fluorescein-5 hydroxysuccinimide ester were from Invitrogen (Leiden, the Netherlands).

\section{Isolation of erythrocytes}

Human blood was obtained from healthy volunteers by venepuncture and collected in acid-citrate-dextrose in a ratio of 5 to $1(\mathrm{v} / \mathrm{v})$. Erythrocytes were washed at room temperature by centrifugation at $200 \mathrm{~g}$ for $10 \mathrm{~min}$ using buffer A (HEPES buffer: $10 \mathrm{mmol} / \mathrm{l}$ HEPES (4-(2-hydroxyethyl)-1-piperazineethane-sulfonic acid), $136 \mathrm{mmol} / \mathrm{l}$ $\mathrm{NaCl}, 2.7 \mathrm{mmol} / \mathrm{I} \mathrm{KCl}, 2 \mathrm{mmol} / \mathrm{l} \mathrm{MgCl}, 0.2 \mathrm{mmol} / \mathrm{l}$ EGTA (ethylene glycol tetraacetic acid), $5 \mathrm{mmol} / \mathrm{l}$ glucose, $\mathrm{pH}$ 7.4). Cells were 
resuspended in buffer $A$; cell count was adjusted at $10^{8} \mathrm{ml}^{-1}$ using a Coulter counter (Beckman Coulter, Miami, FL).

\section{Preparation of resealed ghosts}

Washed erythrocytes were lysed by adding $19 \mathrm{vol}$ ice-cold lysis buffer $(1 \mathrm{mmol} / \mathrm{l}$ HEPES, $14 \mathrm{mmol} / / \mathrm{NaCl}, 0.3 \mathrm{mmol} / \mathrm{l} \mathrm{KCL}, 2 \mathrm{mmol} / \mathrm{l}$ $\mathrm{MgCl}_{2}, 0.2 \mathrm{mmol} / \mathrm{l}$ EGTA, $\mathrm{pH}$ 7.4) to $1 \mathrm{vol}$ packed cells (approx. $10^{10}$ $\left.\mathrm{ml}^{-1}\right)$. After $30 \mathrm{~min}$ on ice, membranes were isolated $(30,000 \mathrm{~g}$, $15 \mathrm{~min}, 4^{\circ} \mathrm{C}$ ) and washed once with 20 vol ice cold lysis buffer. Isotonicity was restored by addition of $0.1 \mathrm{vol}$ 'reseal' buffer (100 mmol/l HEPES, $1400 \mathrm{mmol} / \mathrm{l} \mathrm{KCl}$ or $\mathrm{NaCl}, 2 \mathrm{mmol} / \mathrm{l} \mathrm{MgCl}_{2}$, $0.2 \mathrm{mmol} / \mathrm{l}$ EGTA, $50 \mathrm{mmol} / \mathrm{l}$ glucose, $\mathrm{pH}$ 7.4). After $30 \mathrm{~min}$ incubation at $37^{\circ} \mathrm{C}$, resealed ghosts were collected by centrifugation at $2,200 \mathrm{~g}$ for $10 \mathrm{~min}$ and subsequently washed $3 \mathrm{x}$ in isotonic HEPES buffer with either $\mathrm{Na}^{+}$or $\mathrm{K}^{+}$or, when indicated, mixtures of both cations. The concentration of resealed ghosts was adjusted with buffer $A$ to $10^{8} \mathrm{ml}^{-1}$ using a Coulter counter (Beckman Coulter, Miami, FL). Ghosts were kept on ice until use.

\section{Prothrombinase assay and rate of lipid scrambling (scramblase activity)}

The rate of conversion of prothrombin to thrombin by the enzyme complex factor Xa-factor $V a$ has been shown to be a convenient, rapid and sensitivity method to monitor in a semi-quantitative manner the extent of exposure of PS at the outer cell surface. ${ }^{15}$ Briefly, samples taken from $10^{8} \mathrm{ml}^{-1}$ erythrocytes or resealed ghosts were 10 -fold diluted in buffer $A$ and incubated at $37^{\circ} \mathrm{C}$ with factor $\mathrm{Xa}$ and factor $\mathrm{Va}$ at $\mathrm{a}$ final concentration of 0.2 and $2 \mathrm{nmol} / \mathrm{l}$, respectively, for two $\mathrm{min}$ in the presence of $3 \mathrm{mmol} / \mathrm{l} \mathrm{CaCl}$. The reaction was started by addition of prothrombin (final concentration $1 \mu \mathrm{mol} / \mathrm{l})$; two min after addition of prothrombin, a sample from the incubation mixture was transferred to a cuvette containing $1 \mathrm{ml}$ buffer composed of $50 \mathrm{mmol} / \mathrm{I}$ TRIS, $120 \mathrm{mmol} / \mathrm{l} \mathrm{NaCL}$ and $2 \mathrm{mmol} / \mathrm{I}$ EDTA ( $\mathrm{pH} \mathrm{7.4).} \mathrm{The} \mathrm{amount} \mathrm{of} \mathrm{thrombin} \mathrm{formed} \mathrm{was} \mathrm{determined} \mathrm{by}$ measuring the change in absorbance at $405 \mathrm{~nm}$ caused by proteolysis of $\mathrm{S} 2238(0.2 \mathrm{mmol} / \mathrm{l})$.

The time course of PS exposure (lipid scrambling) in erythrocytes or erythrocyte ghosts was determined by analyzing samples taken at different times and assaying for prothrombinase activity. As shown by Wolfs et $a /{ }^{16}$, the scramblase activity in blood cells from different donors varies significantly. Therefore, the time courses presented in 
the figures are from single experiments that are representative of at least three identical experiments with erythrocytes obtained from different donors. Prothrombinase activity of erythrocytes from various healthy donors demonstrated that maximal activity required $\sim$ 40-60 minutes treatment with ionomycin. Therefore, activity measured after a 15 min ionomycin treatment was chosen to reflect the rate of PS exposure, i.e., the scramblase activity.

\section{Mean cellular volume and intracellular $\mathrm{K}^{+}$content}

Mean cellular volume of erythrocytes and ghosts was determined using a Coulter ${ }^{R} A^{C}$.T diff ${ }^{T M}$ Analyzer (Beckman Coulter, Miami, FL). $\left[\mathrm{K}^{+}\right]$of various buffers used in the experiments was determined using an IL 943 Flame photometer (Instrumentation Laboratory, Ramsey, MN). Osmolarity measurements were performed with a

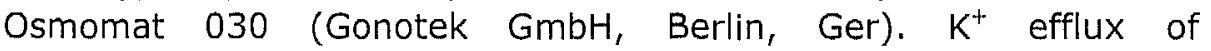
erythrocytes was determined by analyzing the $\left[\mathrm{K}^{+}\right]$in the supernatant of $10^{8}$ erythrocytes $/ \mathrm{ml}$.

\section{Measurement of cytosolic $\mathrm{Ca}^{2+}$}

RBCs (1\% hct) were incubated for one hour at $37^{\circ} \mathrm{C}$ with Rhod-2/am (5 $\mu \mathrm{mol} / \mathrm{l}$ ). The cells were then washed with buffer $A$ and resuspended in the same buffer. $2 \mathrm{ml}$ of the RBC suspension was transferred to a fluorometer cuvette and incubated for the indicated time with ionophore $(5 \mu \mathrm{mol} / \mathrm{l})$. Briefly, Rhod-2 fluorescence $\left(\lambda_{E x}=552 \mathrm{~nm}, \lambda_{E m}=581 \mathrm{~nm}\right.$ ) was monitored following the addition of increasing $\left[\mathrm{CaCl}_{2}\right]$ from a $100 \mathrm{mmol} / \mathrm{l}$ stock solution. The increase in relative fluorescent intensity was recorded 5 min after each addition.

Assessment of ionophore/ $\mathrm{Ca}^{2+}$ induced vesiculation in intact $\mathrm{RBC}$ and resealed $\mathrm{RBC}$ ghosts

Intact RBCs were labeled for two hours at $4^{\circ} \mathrm{C}$ with the $\mathrm{N}$-hydroxysuccinimide ester of fluorescein-5 $(250 \mu \mathrm{mol} / \mathrm{l})$. The cells were then washed with $2 \%$ BSA in buffer $A$ to remove unlabeled reagent and resuspended in buffer $\mathrm{A}$ without $\mathrm{BSA}$. Intact $R B C$. Fluorescein labeled $\mathrm{RBC}$ ( $2 \% \mathrm{hct}$ ) were incubated for $1 \mathrm{~h}$ at $37^{\circ} \mathrm{C}$ with $1 \mathrm{mmol} / / \mathrm{Ca}^{2+}$ in the absence (control) or presence of ionophore. The cells were then centrifuged at $2,500 \mathrm{~g}$ for five min and residual fluorescence in the supernatant was measured $\left(\lambda_{\mathrm{Ex}}=488\right.$ $\left.\mathrm{nm} / \lambda_{\mathrm{Em}}=525 \mathrm{~nm}\right)$. Data is expressed as the fraction of total fluorescence in the suspension before centrifugation. Resealed RBC 
Ghosts. Fluorescein labeled RBCs were lysed with hypotonic buffer (1:10 diluted buffer $A$ ), centrifuged at $30,000 \mathrm{~g}$ for $15 \mathrm{~min}$ at $4^{\circ} \mathrm{C}$ and washed twice with the same buffer. The ghosts were then resealed by bringing the suspension to iso-osmolarity by adding 0.1 volume of 'reseal' buffer followed by incubation for $30 \mathrm{~min}$ at $37^{\circ} \mathrm{C}$. Resealed ghosts were collected by centrifugation at $2,500 \mathrm{~g}$ for five min. The resealed ghosts were then incubated with $\mathrm{Ca}^{2+}$ in the absence or presence of ionophore, and the fluorescence in the supernatants assessed as described for intact RBC.

\section{Morphology}

For morphological analysis, cells or ghosts were diluted ten times in $1 \%$ glutaraldehyde in buffer A. After fixation for $15 \mathrm{~min}$ at $4^{\circ} \mathrm{C}$, the cells were washed in distilled water and subsequently taken through a graded series of ethanol and finally resuspended in absolute ethanol. Cells were deposited on plastic cover slips, air dried and sputter-coated with gold. Scanning electron micrographs were made using a Phillips CM-12 electron microscope at $15 \mathrm{kV}$ (Phillips, Eindhoven, the Netherlands)

\section{Results}

\section{Lipid scrambling in intact erythrocytes: effect of $\left[\mathrm{K}^{+}\right] \mathrm{i}$}

Figure 5.1A shows that lipid scrambling can be induced in erythrocytes by treatment with the calcium ionophore, ionomycin, in the presence of extracellular $\mathrm{Ca}^{2+}$. Scrambling is accompanied by an efflux of $\mathrm{K}^{+}$(Figure 5.1B) and concomitant loss of $\mathrm{Cl}^{-}$and water. ${ }^{13}$ Charybdotoxin, isolated from the venom of the scorpion Leiuris quinquestriatus, blocks the Gardos channel, the intermediate conductance $\mathrm{Ca}^{2+}$-activated $\mathrm{K}^{+}$channel. ${ }^{17-19}$ This inhibitor reduced the efflux rate of $\mathrm{K}^{+}$ions (Figure 5.1B, open circles) and the rate at which cells become PS positive as measured by the development of prothrombinase activity (Figure $5.1 \mathrm{~A}$, open circles). Similar results were obtained with the antifungal agent, clotrimazol, another blocker of the Gardos channel ${ }^{18,19}$ (data not shown). Inhibition of scramblase activity achieved by blocking $\mathrm{K}^{+}$efflux was rescued by allowing $\mathrm{K}^{+}$ efflux through the addition of valinomycin (Figure 5.1, open squares). In the presence of valinomycin, the rate of PS exposure induced by ionomycin is enhanced and, as expected, the efflux of $\mathrm{K}^{+}$ 
ions is nearly instantaneous (Figure $5.1 \mathrm{~A}$ and $5.1 \mathrm{~B}$, closed squares). Importantly, treatment of erythrocytes with valinomycin in absence of ionomycin does not lead to the generation of PS positive cells (open triangles), underscoring the essential requirement for $\mathrm{Ca}^{2+}$. To confirm that varying levels of intracellular $\mathrm{K}^{+}$and/or valinomycin did not affect ionophore/ $\mathrm{Ca}^{2+}$-mediated increase in $\left[\mathrm{Ca}^{2+}\right]_{i}$, thus causing changes in scramblase activity, $\mathrm{Ca}^{2+}$ levels were monitored with Rhod-2 in the presence and absence of valinomycin.
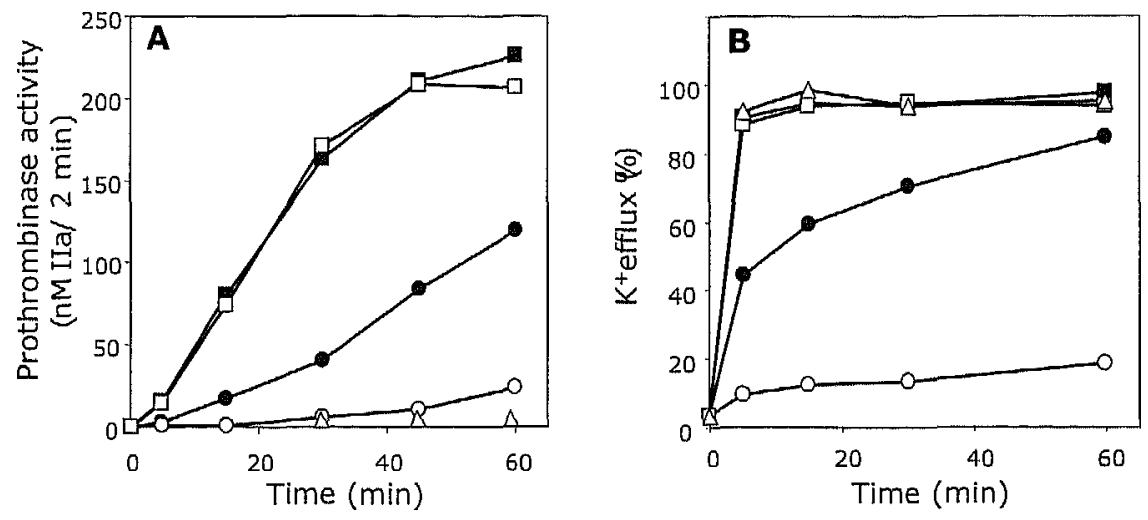

Figure 5.1 Ionomycin induced PS exposure and $\mathrm{K}^{+}$efflux in intact erythrocytes: inhibition by the $\mathrm{K}^{+}$channel blocker charybdotoxin and stimulation by the $\mathrm{K}^{+}$ionophore valinomycin. (A) Erythrocytes $\left(10^{8} \mathrm{ml}^{-1}\right)$ were preincubated with charybdotoxin $(20 \mathrm{nmol} / \mathrm{l})$ and/or valinomycin $(3 \mu \mathrm{mol} / \mathrm{l})$ for $15 \mathrm{~min}$ prior to treatment with ionomycin $(5 \mu \mathrm{mol} / / \mathrm{l})$ in the presence of $\mathrm{CaCl}_{2}$ $(1 \mathrm{mmol} / \mathrm{l})$ in buffer $\mathrm{A}\left(\left[\mathrm{K}^{+}\right] 2.7 \mathrm{mmol} / \mathrm{l}\right)$. At different times, samples were analyzed for prothrombinase activity to evaluate the extent of PS exposure. (B) Ionomycin induced $\mathrm{K}^{+}$efflux in intact erythrocytes was measured by analyzing the $\mathrm{K}^{+}$content of the supernatant using a flame photometer. Under the experimental conditions used, $\left[\mathrm{K}^{+}\right]$in the supernatant appeared constant after $15 \mathrm{~min}$ pre-incubation with valinomycin $(3 \mu \mathrm{mol} / \mathrm{l})$; this value was set at $100 \%$. Symbols indicate: - no additions; o charybdotoxin; valinomycin; a charybdotoxin + valinomycin; $\Delta$ valinomycin without ionomycin. Data presented are from a single representative experiment out of three identical experiments performed with cells obtained from different donors.

Figure 5.2 shows that ionomycin-induced increases in $\left[\mathrm{Ca}^{2+}\right]_{1}$ were identical in the presence or absence of valinomycin. Similar results were obtained in the presence of high $\left[\mathrm{K}^{+}\right]_{\mathrm{e}}$ or $\mathrm{K}^{+}$channel blockers (data not shown). These results indicate that scramblase activity is directly dependent on $\left[\mathrm{Ca}^{2+}\right]_{i}$ and strongly suggest that an association exists between the rate of $\mathrm{Ca}^{2+}$-dependent PS exposure 
and $\left[\mathrm{K}^{+}\right]_{1}$. Support for this relationship is provided by the data shown in Figure 5.3, where the rate of scrambling was determined as a function of $\left[\mathrm{K}^{+}\right]_{1}$. This was done by equilibrating erythrocytes for 15 min in buffers containing varying $\left[\mathrm{K}^{+}\right]$in the presence of valinomycin, prior to treatment with $\mathrm{Ca}^{2+}$-ionophore. The results (Figure 5.3A) indicate that scramblase activity, determined as the fraction prothrombinase activity developed after $15 \mathrm{~min}$ treatment with ionomycin, decreases with increasing $\left[\mathrm{K}^{+}\right]$up to $\sim 0$ to $30 \mathrm{mmol} / \mathrm{l} \mathrm{K}$. Similar conclusions were reached when the effect of high $\mathrm{K}^{+}$on the scramblase process was assessed with fluorescentlabeled annexin A5 instead of the prothrombinase assay (data not shown).

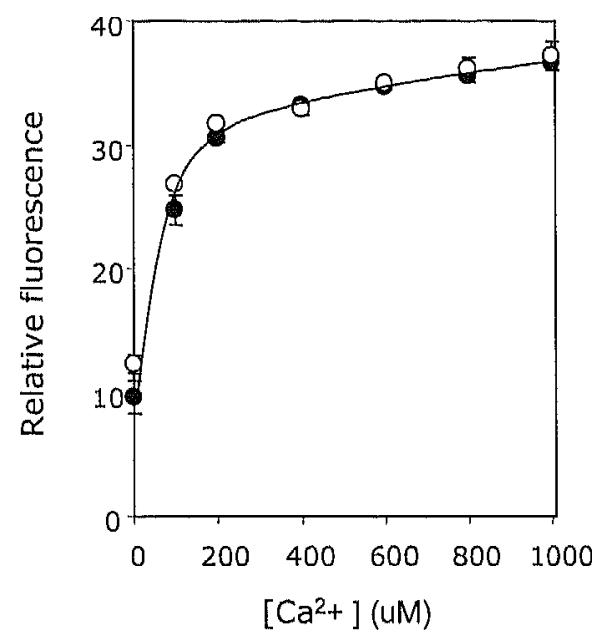

Figure 5.2 Effect of intracellular $\mathrm{K}^{+}$on ionophore-dependent $\mathrm{Ca}^{2 \cdot 1}$ influx. Rhod-2 labeled RBC in buffer A (low K+) were incubated with ionomycin alone (•) or with ionomycin and valinomycin $(0)$ as described in the experimental procedures section. The cells were then incubated with increasing amounts of $\mathrm{Ca}^{2+}$ and the change in fluorescence intensity was assessed after five min.

Lipid scrambling in intact erythrocytes: effect of swelling and shrinkage

Depending on the $\left[\mathrm{K}^{+}\right]_{\mathrm{e}}$, loss or uptake of $\mathrm{K}^{+}$ions is likely accompanied by loss or uptake of $\mathrm{Cl}^{-}$ions and subsequent water transport causing cell shrinkage or cell swelling, respectively. As shown in Figure 5.3A (inset), the mean cellular volume of the erythrocytes varies from 71 to $94 \mathrm{fL}$ when the cells are incubated with valinomycin at $\left[\mathrm{K}^{+}\right]_{\mathrm{e}}$ from 0 to $140 \mathrm{mmol} / \mathrm{l}$. In the absence of valinomycin, the mean cellular volume is $87 \mathrm{fL}$, irrespective the 
$\left[\mathrm{K}^{+}\right]_{\mathrm{e}}$. Considering that a change in cellular volume could affect the physical properties of the membrane and as a result the scrambling process, the rate of lipid scrambling was measured as a function of the mean cellular volume. This was done by preincubating cells in buffers of different osmolarity prior to inducing lipid scrambling with ionomycin and $\mathrm{Ca}^{2+}$. Osmolarity was altered by changing only the $[\mathrm{NaCl}]$, keeping the concentration of the other buffer components constant. The results presented in Figure 5.3B illustrate that for cells in hypotonic medium (cell lysis was always $<1 \%$ ), i.e. in swollen cells, the rate of PS exposure is significantly enhanced compared to that of cells in isotonic medium; conversely in hypertonic medium, scramblase activity is reduced. This observation is particularly interesting since it suggests that cell size alone dramatically influences scrambling activity. Because of this, accurate determination of the relationship between PS exposure (prothrombinase activity at $15 \mathrm{~min}$ ) and intracellular $\mathrm{K}^{+}$(as depicted in Figure 5.3A) needs to be corrected for MCV. Thus, cells incubated with valinomycin at low $\left[\mathrm{K}^{+}\right]_{\mathrm{e}}$, will lose $\mathrm{K}^{+}$and, as a consequence, water that will lead to cell shrinkage. Under these conditions, the rate of ionomycin-induced lipid scrambling is suppressed. On the other hand, at high $\left[\mathrm{K}^{+}\right]_{\mathrm{e}}$, uptake of $\mathrm{K}^{+}$and water will cause the cells to swell and lipid scrambling will be enhanced. Taking into consideration $\mathrm{MCV}$, this suggests that the prothrombinase activity at zero $\mathrm{K}^{+}$is underestimated by approx $50 \%$, and the prothrombinase activity at $140 \mathrm{mM} \mathrm{K} \mathrm{K}^{+}$is overestimated by approx $50 \%$. Taken together, these data suggest a much stronger dependence of scrambling activity on $\left[\mathrm{K}^{+}\right]_{i}$ than actually shown in Figure 5.3. 

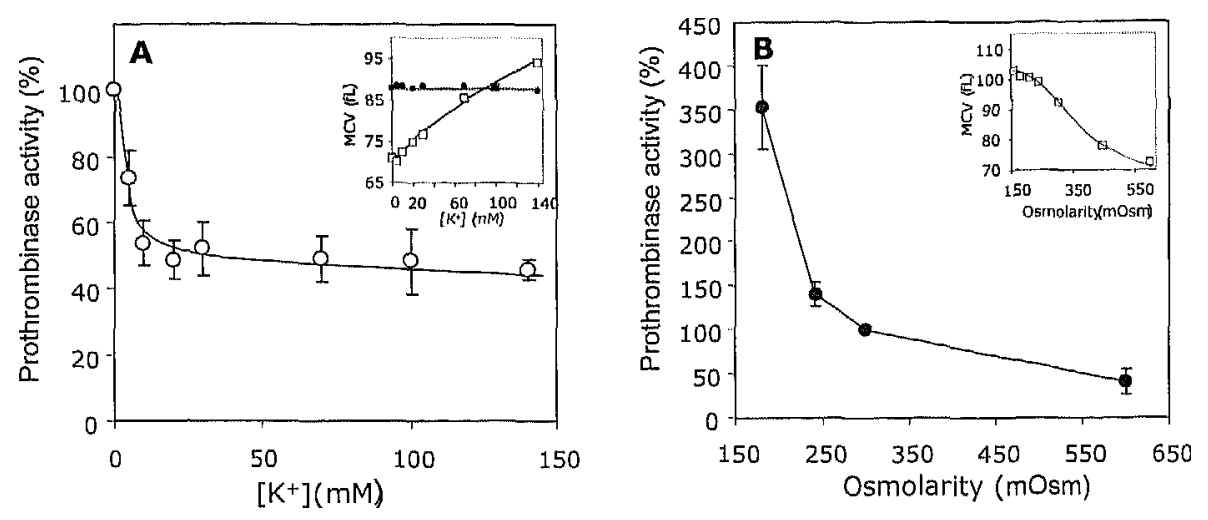

Figure 5.3 Ionomycin-induced PS exposure (scramblase activity) in intact erythrocytes as a function of the $\left[\mathrm{K}^{+}\right]_{i}$ and the osmolarity. A. $\left[\mathrm{K}^{+}\right]_{1}$ was modulated by equilibrating cells $\left(10^{8} \mathrm{~m}^{-1}\right)$ in buffers containing graded $\left[\mathrm{K}^{+}\right]$in the presence of valinomycin $(3 \mu \mathrm{mol} / \mathrm{l})$ for $15 \mathrm{~min}$ prior to treatment with ionomycin $(5 \mu \mathrm{mol} / \mathrm{l})$ and $\mathrm{CaCl}_{2}(1 \mathrm{mmol} / \mathrm{l})$. Scramblase activity was assessed by measuring prothrombinase activity 15 min after the addition of ionomycin. The prothrombinase activity measured at zero $\mathrm{K}^{+}$was set at $100 \%$. Inset: mean cellular volume as a function of the $\left[\mathrm{K}^{+}\right]$, determined before ( $\left.{ }^{-}\right)$and $15 \mathrm{~min}$ after equilibration with valinomycin ( $\square$ ). B. Different osmolarities were obtained by changing $[\mathrm{NaCl}]$ in buffer $\mathrm{A}$. The $\left[\mathrm{K}^{+}\right]$was maintained at $3 \mathrm{mmol} / \mathrm{l}$. Scramblase activity was induced with ionomycin and $\mathrm{CaCl}_{2}$ and measured as described for Figure 5.3A. The scramblase activity determined at $300 \mathrm{mosm}$ was set at $100 \%$. Inset: mean cellular volume as a function of the osmolarity. For both insets, mean cellular volumes were determined before treatment with ionomycin/ $/ \mathrm{Ca}^{2+}$. Error bars represent S.D. $(n=3)$

\section{Lipid scrambling in resealed erythrocyte ghosts: effect of} $\mathrm{K}^{+}$and $\mathrm{Na}^{+}$ions

The $\mathrm{K}^{*}$ content of intact erythrocytes affects the intracellular $\mathrm{pH}^{20}{ }^{20} \mathrm{To}$ explore the relationship between $\left[\mathrm{K}^{+}\right]$and scramblase activity in a $\mathrm{pH}$-independent system, we built upon earlier observations with resealed erythrocyte ghosts. These studies showed that as long as the original membrane lipid asymmetry is maintained (by ensuring that the free $\left[\mathrm{Ca}^{2+}\right]$ is kept low during the lysis and resealing procedures), $\mathrm{Ca}^{2+}$-dependent scramblase activity can be demonstrated in resealed erythrocyte ghosts. ${ }^{21}$ The rates of PS exposure induced by ionomycin and $\mathrm{Ca}^{2+}$ in ghosts resealed in high $\mathrm{K}^{+\cdot}$ or in high $\mathrm{Na}^{+}$medium are shown in Figure $5.4 \mathrm{~A}$. The prothrombinase assay shows that the initial rate of PS exposure for $\mathrm{Na}^{+}$ghosts is at least twofold higher than that for $\mathrm{K}^{+}$ghosts. Ghosts prepared in choline chloride display kinetics of PS exposure similar to 
the $\mathrm{Na}^{+}$ghosts (Figure 5.4A, dashed line), indicating that $\mathrm{K}^{+}$ions inhibit scramblase as opposed to $\mathrm{Na}^{+}$ions stimulating scramblase. The effect of $\mathrm{K}^{+}$ions was further detailed by determining the rate of scramblase activity as a function of the $\left[\mathrm{K}^{+}\right]$. Figure $5.4 \mathrm{~B}$ shows the prothrombinase activity induced by $15 \mathrm{~min}$ ionomycin treatment of ghosts prepared in buffers containing graded concentrations of $\mathrm{Na}^{+}$ and $\mathrm{K}^{+}$. The inhibitory effect is observed over the whole range of $\mathrm{K}^{+}$ concentrations. It should be noted that unlike the results obtained for intact erythrocytes, the electrolyte concentrations inside and outside the ghosts are identical. The observed effects, therefore, are not related to cellular volume changes due to ion fluxes across the membrane.
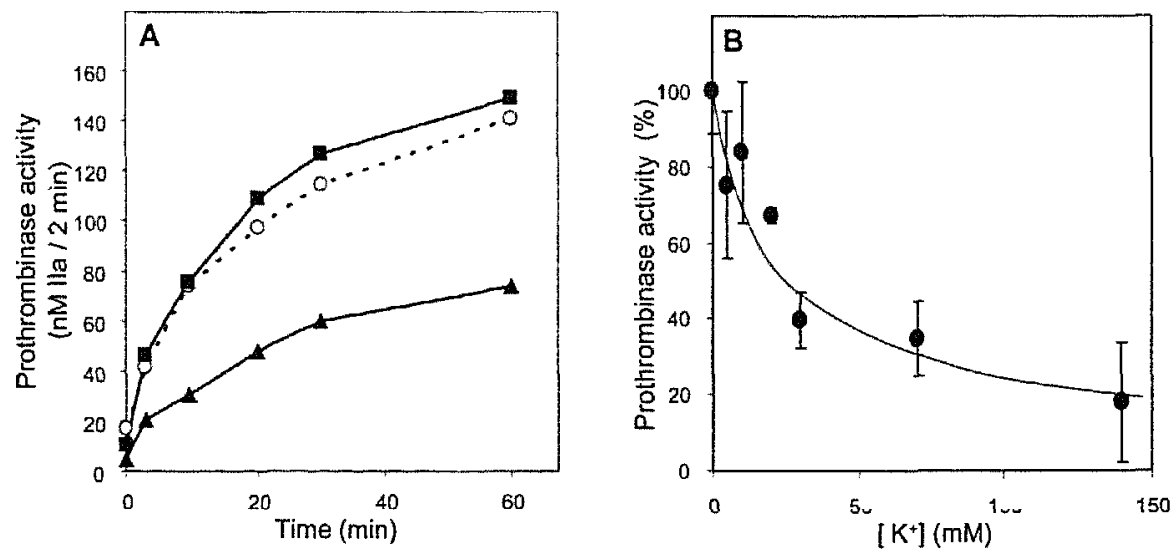

Figure 5.4 Ionomycin-induced prothrombinase activity in resealed erythrocyte ghosts: effect of monovalent cations. A. Ghosts $\left(10^{8} \mathrm{ml}^{-1}\right)$, resealed in the presence of HEPES buffer containing $140 \mathrm{mmol} / 1 \mathrm{Na}^{+}-, \mathrm{K}^{+}-$or CholCl (choline chloride), were treated with ionomycin $(3 \mu \mathrm{M})$ in the presence of $\mathrm{CaCl}_{2}$ (1 mmol/and prothrombinase activity (i.e. PS exposure) was monitored in time. ॥ ghosts resealed in $\mathrm{Na}^{+}$buffer; $\Delta$ resealed in $\mathrm{K}^{+}$ buffer; o resealed in CholCl buffer. Data presented are from a single representative experiment out of three identical experiments performed with erythrocytes obtained from different donors. B. Ghosts were resealed in HEPES buffers with varying $\left[\mathrm{K}^{+}\right]$, in which osmolarity was kept constant at 300 mOsm by compensating with $\mathrm{NaCl}$. Scramblase activity was assessed by measuring prothrombinase activity after $15 \mathrm{~min}$ treatment with ionomycin in the presence of $1 \mathrm{mmol} / \mathrm{l} \mathrm{CaCl}$. Error bars represent S.D. $(n=3)$

To rule out the possibility that a high $\left[\mathrm{K}^{+}\right]$or $\left[\mathrm{Na}^{+}\right]$indirectly influenced the differences in scrambling activity by affecting the final $\left[\mathrm{Ca}^{2+}\right]_{i}$ induced by ionomycin, an experiment was designed to avoid movement of $\mathrm{Ca}^{2+}$ ions across the membrane. To accomplish this, 
erythrocyte ghosts were resealed at $0^{\circ} \mathrm{C}$ in the presence of $1 \mathrm{mmol} / \mathrm{l}$ $\mathrm{Ca}^{2+}$ together with $\mathrm{KCl}$ or $\mathrm{NaCl}$ to restore osmolarity to 300 mOsm (although the reseal process is enhanced at $37^{\circ} \mathrm{C}$, resealing also occurs upon prolonged incubation $\left(120 \mathrm{~min}\right.$ ) at $0^{\circ} \mathrm{C}$ ). Figure 5.5 shows, that membrane lipid asymmetry in both ghost preparations is preserved when kept at $0^{\circ} \mathrm{C}$ (time zero). Upon incubation at $37^{\circ} \mathrm{C}$, however, prothrombinase activity increases with time indicating activation of scramblase. The results show that the rate of PS exposure in $\mathrm{Ca}^{2+}$-containing ghosts resealed with $\mathrm{K}^{+}$is significantly lower (approx 50\%) than in ghosts resealed with $\mathrm{Na}^{+}$.

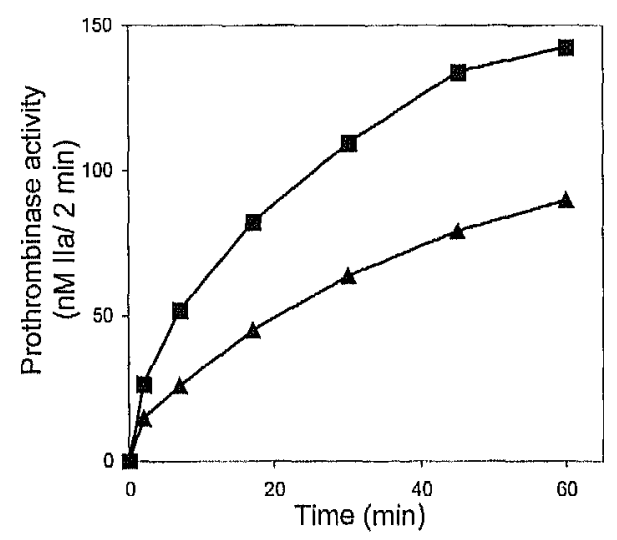

Figure 5.5 Time course of development of prothrombinase activity in ghosts resealed in the presence of $\mathrm{Ca}^{2+}$ and either $\mathrm{K}^{++}$or $\mathrm{Na}^{+}$. Ghosts were resealed in HEPES buffer with $140 \mathrm{mmol} / / \mathrm{K}^{+}(\Delta)$ or $\mathrm{Na}^{+}(\mathbf{m})$, both in the presence of $\mathrm{CaCl}_{2}(1 \mathrm{mmol} / \mathrm{l})$ at $0^{\circ} \mathrm{C}$. Scramblase activity was started by increasing the temperature to $37^{\circ} \mathrm{C}$ and monitored by prothrombinase activity. For details, see 'Materials and methods'. Data presented are from a single representative experiment out of three identical experiments performed with erythrocytes obtained from different donors.

\section{Morphology of erythrocyte ghosts during the process of lipid scrambling}

It is well known, that treatment of erythrocytes with $\mathrm{Ca}^{2+}$-ionophore causes shedding of membrane vesicles and concomitant cell shrinkage that results in the formation of spherocytes. Increase of the $\left[\mathrm{Ca}^{2+}\right]_{1}$ will cause opening of $\mathrm{Ca}^{2+}$-dependent $\mathrm{K}^{+}$channels which, depending on its concentration gradient, will result in efflux or influx of $\mathrm{K}^{+}$ions accompanied with efflux or influx of $\mathrm{Cl}^{-}$ions and water. Indeed, we could confirm cell shrinkage by measuring the mean cellular volume of intact erythrocytes treated with $\mathrm{Ca}^{2+}$-jonophore in the presence of $5 \mathrm{mmol} / \mathrm{l}$ extracellular $\mathrm{K}^{+}$(Figure $5.6 \mathrm{~A}$ ); 
alternatively, swelling occurs when cells are treated with $\mathrm{Ca}^{2+}$ ionophore in the presence of $140 \mathrm{mmol} / \mathrm{l}$ extracellular $\mathrm{K}^{+}$(see Figure $5.3 \mathrm{~A}$ inset). Under conditions where ion fluxes across the membrane are excluded (as described in Figure 5.5), ghosts show no significant change in mean cellular volume upon scramblase activation (Figure $5.6 \mathrm{~A}$ ). These findings were confirmed by comparing the morphology of intact erythrocytes and resealed ghosts before and $60 \mathrm{~min}$ after treatment with $\mathrm{Ca}^{2+}$-ionophore (Figure 5.6B). Clearly, intact erythrocytes shrink and shed microvesicles that results in the formation of spherocytes with an approximate diameter of 5 micron. In contrast, for both $\mathrm{K}^{+}$and $\mathrm{Na}^{+}$ghosts, the morphology is virtually unaffected by treatment with $\mathrm{Ca}^{2+}$-ionophore. The majority of the resealed ghosts retain the biconcave shape of the original erythrocyte, although they are smaller in size.
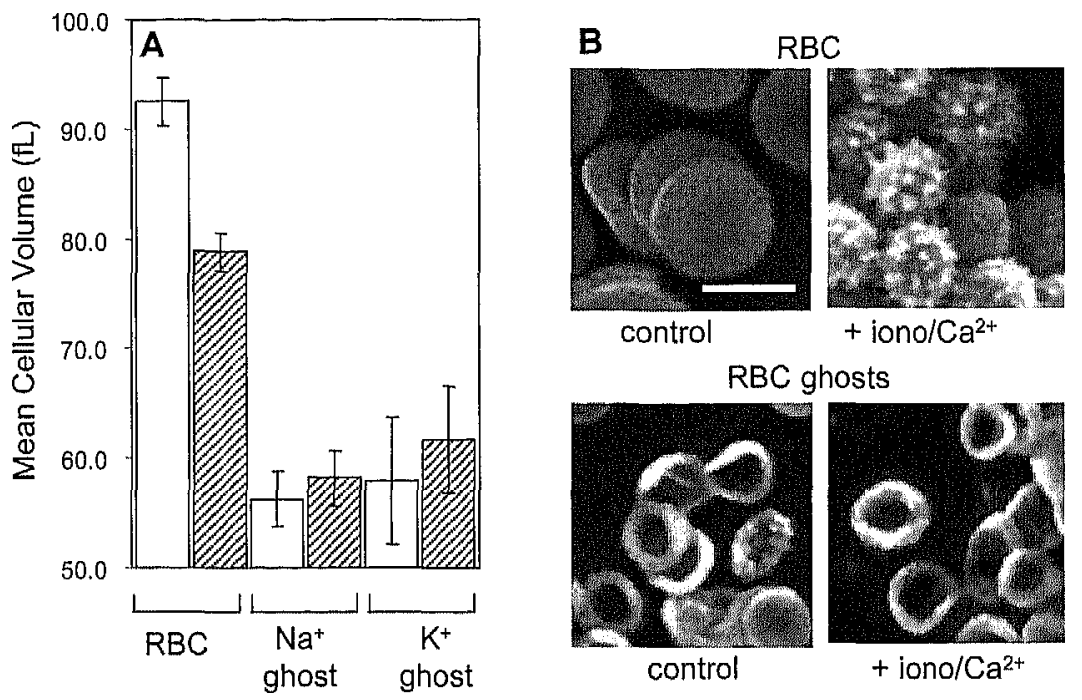

Figure 5.6 Morphological changes in erythrocytes and resealed ghosts upon treatment with $\mathrm{Ca}^{2+}$ ionomycin. A. Mean cellular volume of erythrocytes and erythrocyte ghosts before (white bars) and after (hatched bars) treatment with ionomycin (iono) in the presence of $\mathrm{Ca}^{2+}(1 \mathrm{mmol} / \mathrm{I})$. Ghosts were resealed in HEPES buffer with $140 \mathrm{mmol} / / \mathrm{Na}^{+}$or $140 \mathrm{mM}$ $\mathrm{K}^{+}$, and subsequently washed and resuspended in the same high $\mathrm{Na}^{+}$and $\mathrm{K}^{+}$containing HEPES buffer, respectively, thus excluding monovalent cation fluxes resulting from ionomycin treatment. For details see 'Materials and methods'. Presented are mean values \pm S.D. from three independent experiments. B. Scanning micrographs of erythrocytes and erythrocyte ghosts before and after treatment with ionomycin. All micrographs are at the same magnification. Bar represents $5 \mu \mathrm{m}$. 


\section{Microvesicle formation by erythrocyte ghosts during the process of lipid scrambling}

Two independent experiments were carried out to determine whether $\mathrm{Ca}^{2+}$-ionophore treated erythrocytes and ghosts produce microvesicles. First, approximately $25 \%$ of the prothrombinase activity was found in the supernatant of erythrocytes after 60 min incubation with ionomycin (Figure 5.7A), in agreement with previous estimates of the amount of plasma membrane shed under these conditions. ${ }^{22}$ In contrast, when ghosts were challenged with $\mathrm{Ca}^{2+}$-ionophore, the activity remaining in the supernatant was less than $5 \%$. These results indicate that the supernatants did not contain procoagulant lipids suggesting that microvesicles were not produced. To rule out the possibility that vesicles lacking PS were formed, ghosts labeled with $\mathrm{N}$-hydroxysuccinimide-fluorescein were treated with $\mathrm{Ca}^{2+}$ ionophore and residual fluorescence in the supernatants was determined. Figure 5.7B shows that, in contrast to erythrocytes that released a significant fraction of fluorescein-labeled membrane, fluorescent membrane was not detected in ionomycin-treated ghosts. Taken together, these results indicate that lipid scrambling occurs through a mechanism that is independent of cell morphology, cell size and microvesicle formation.
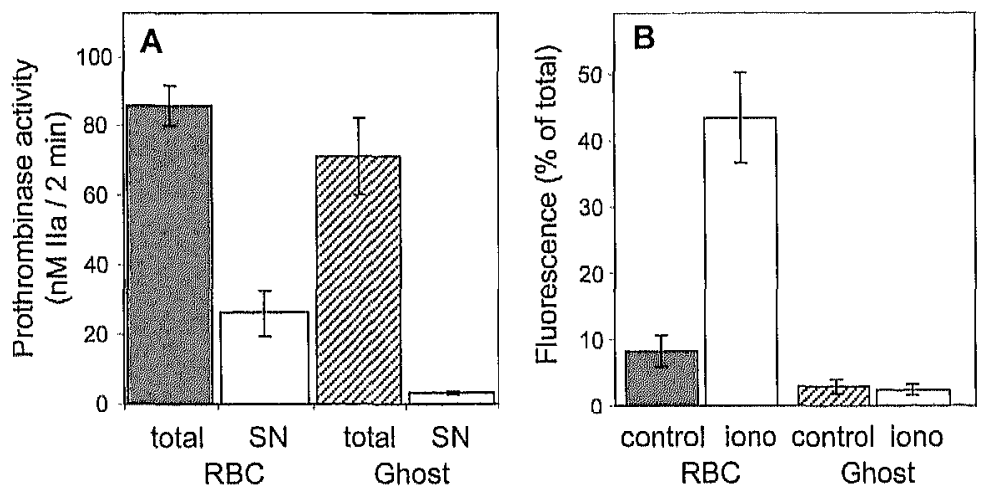

Figure 5.7 Microvesicle production in ionomycin-treated erythrocytes and erythrocyte ghosts. A. Prothrombinase activity in erythrocytes (solid bar) and erythrocyte ghosts (hatched bar) after 60 min incubation with ionomycin in the presence of $1 \mathrm{mmol} / / \mathrm{Ca}^{2+}$. Contribution of microvesicles was estimated by measuring the prothrombinase activity of the supernatant (white bars) obtained after centrifugation. Presented are mean values \pm S.D. from three independent experiments. B. RBC ghosts do not vesiculate following incubation with ionophore/Ca ${ }^{2 \cdot t}$. Fluorescein-labeled-RBC (solid bar) or resealed ghosts (hatched bar) were incubated with $\mathrm{Ca}^{2+}$ in the absence or presence of ionomycin (open bars) as described in the section experimental procedures. The RBC and ghosts were then centrifuged and the residual fluorescence in the supernatant measured. Data are expressed as the fraction of total fluorescence in the supernatant (SN). 


\section{Discussion}

Increased intracellular $\mathrm{Ca}^{2+}$, efflux of $\mathrm{K}^{+}$ions, cell shrinkage, shedding of membrane vesicles and collapse of lipid asymmetry are features typical of nucleated cells undergoing apoptosis. Similar phenomena also occur in anucleated cells such as platelets and red blood cells under conditions that result in a persistent elevation of $\left[\mathrm{Ca}^{2+}\right]_{i \cdot}{ }^{3,13}$ Together with elevated $\mathrm{Ca}^{2+}$, intracellular $\mathrm{K}^{+}$also plays an important role in apoptosis since preventing loss of $\mathrm{K}^{+}$by manipulating the $\left[\mathrm{K}^{+}\right]_{\mathrm{e}}$ or treatment with $\mathrm{K}^{+}$channel blockers blocks apoptosis. ${ }^{23-26}$ We have previously observed inhibition of PS exposure in collagen/thrombin-activated platelets by high extracellular $\mathrm{K}^{+}$and blockers of the $\mathrm{Ca}^{2+}$-activated $\mathrm{K}^{+}$channel (Gardos channel). ${ }^{12}$ Similarly, blockade of $\mathrm{K}^{+}$channels or high extracellular $\left[\mathrm{K}^{+}\right]$inhibits $\mathrm{Ca}^{2+}$-ionophore induced PS exposure in red blood cells. ${ }^{13}$ Valinomycin abolishes the inhibitory effect of the $\mathrm{K}^{+}$channel blockers. Using the red blood cell membrane as a model to study the relationship between intracellular $\mathrm{K}^{+}$and exposure of PS during lipid scrambling, the present study shows that the $\left[\mathrm{K}^{+}\right]_{\mathrm{i}}$ directly affects the rate at which membrane lipid asymmetry is lost when erythrocytes are challenged with high $\left[\mathrm{Ca}^{2+}\right]_{1}$.

A possible explanation for the inhibitory effect of $\mathrm{K}^{+}$on scrambling could be the hyperpolarisation following activation of $\mathrm{Ca}^{2+}$-sensitive $\mathrm{K}^{+}$channels, which drives additional $\mathrm{Ca}^{2+}$ into the cell augmenting cytosolic $\left[\mathrm{Ca}^{2+}\right] .{ }^{13}$ The results presented in Figure 5.2, however, suggest that the $\left[\mathrm{K}^{+}\right]_{\mathrm{i}}$ does not influence ionophore-dependent $\left[\mathrm{Ca}^{2+}\right]_{i}$. Conversely, elevation of cytosolic $\mathrm{Ca}^{2+}$ achieved with ionophore $/ \mathrm{Ca}^{2+}$ in erythrocytes did not facilitate complete efflux of $\mathrm{K}^{+}$ through opening of the $\mathrm{Ca}^{2+}$-sensitive $\mathrm{K}^{+}$channels since the addition of valinomycin resulted in increased scramblase activity (Figure $5.1 \mathrm{~A})$. Interestingly, Schneider et al. ${ }^{27}$ recently showed that valinomycin-mediated loss of $\mathrm{K}^{+}$can induce PS exposure in erythrocytes in the absence of ionomycin. The inability of valinomycin alone to induce PS exposure in the present study is likely due to differences in the experimental conditions; the result by Schneider et al., required long incubation times ( $24 \mathrm{hr}$ ) and is likely similar to the (unexplored) mechanism that is responsible for the exposure of PS upon in vitro aging that requires incubation for 4 days in the absence of $\mathrm{Ca}^{2+} \cdot 28$

Comparison of the effect of $\mathrm{K}^{+}$on intact erythrocytes and erythrocyte ghosts (Figure 5.3A and 5.4B) shows that the inhibitory effect of $\mathrm{K}^{+}$ is significantly stronger in the ghosts. As explained in the results 
section, because of the osmolarity (size)-dependent effects on scramblase activity, the changes in the mean cellular volume of intact erythrocytes at different $\left[\mathrm{K}^{+}\right]$likely cause under- and overestimates of scramblase activity at low and high $\left[\mathrm{K}^{+}\right]$, respectively. Moreover, it should be emphasized that $\left[\mathrm{K}^{+}\right]_{i}$ in the intact erythrocytes treated with valinomycin is not necessarily identical to $\left[\mathrm{K}^{+}\right]_{\mathrm{e}}$. At electrochemical equilibrium in a dehydrating cell with a hyperpolarized membrane, $\left[\mathrm{K}^{+}\right]_{\mathrm{i}}$ is likely to exceed $\left[\mathrm{K}^{+}\right]_{\mathrm{e}}$. Thus, the $\mathrm{K}^{+}$titration in ghosts (Figure 5.4B) more likely reflects the true inhibitory effect of $\mathrm{K}^{+}$on the rate of scrambling.

Efflux of $\mathrm{K}^{+}$is likely accompanied by acidification of the intracellular content. While we cannot exclude the possibility that this will affect the scrambling process in intact cells, the experiments with resealed erythrocyte ghosts (Figure 5.4 and 5.5) clearly demonstrate that lipid scrambling is directly modulated by $\left[\mathrm{K}^{+}\right]_{\mathrm{i}}$. Indeed, metal ions are known to alter the activity of various enzymes ${ }^{29}$ and many enzymes are allosterically affected by $\mathrm{Na}^{+}$or $\mathrm{K}^{+}$ions, often in tandem with bivalent cations such as $\mathrm{Mg}^{2+}$ or $\mathrm{Ca}^{2+}$. Inhibition of lipid scrambling by $\mathrm{K}^{+}$ions rather than a stimulation by $\mathrm{Na}^{+}$ions occurs since replacement of $\mathrm{Na}^{+}$with choline ${ }^{+}$had no effect on scrambling activity, whereas substitution with $\mathrm{K}^{+}$decreased the rate of lipid scrambling. The mechanism responsible for $\mathrm{K}^{+}$suppression of scramblase activity awaits identification of the scramblase protein(s). Considering that $\left[\mathrm{K}^{+}\right]_{1}$ in human erythrocytes is normally high (100$140 \mathrm{mmol} / \mathrm{l})$, scramblase activity in resting cells is likely suppressed. Thus, triggering scramblase activity by increasing intracellular $\mathrm{Ca}^{2+}$ will open $\mathrm{Ca}^{2+}$-sensitive $\mathrm{K}^{+}$channels resulting in loss of intracellular $\mathrm{K}^{+}$that further enhances the $\mathrm{Ca}^{2+}$-dependent scrambling activity.

A recent publication by Elliott et al. raised the possibility that cell shrinkage-associated alterations in membrane lipid packing at the base and the apex of membrane blebs might be responsible for a scramblase-independent mechanism for PS externalization. ${ }^{30}$ This conclusion is based on the results of temporal labeling of lymphocytes with merocyanine 540 (a lipid packing-dependent dye) and annexin A5. Although PS exposure is known to be closely associated with membrane curvature ${ }^{16}$, cell shrinkage ${ }^{27}$, membrane blebbing and shedding of microvesicles ${ }^{21,31}$ in intact red blood cells, we show here that lipid scrambling in ghosts occurs in the absence of volume changes and microvesicle formation (Figure 5.6 and 5.7). Indeed, using spermine-containing ghosts, Bucki et al. ${ }^{31}$ demonstrated that PS exposure and microvesicle formation are distinct and separable processes. Thus, while scrambling might be 
concurrent to cell shrinkage and microvesicle formation in intact cells, these phenomena are unrelated and mechanistically distinct.

Our observations on the inverse relationship between $\left[\mathrm{K}^{+}\right]_{1}$ and $\mathrm{Ca}^{2+}$ dependent lipid scrambling may provide some insight into the physiology and mechanism(s) involved in erythrocyte aging. Similar to the data reported here, RBC senescence is associated with reduced plasma membrane $\mathrm{Ca}^{2+}$-ATPase activity that leads to the intracellular accumulation of the cation and concomitant loss of $\left[\mathrm{K}^{+}\right]_{1}$ to less than $10 \mathrm{mM} .^{32}$ In addition, some pathological conditions, such as sickle cell anaemia, are accompanied by an increased number of cells with substantial amounts of surface exposed PS, which may be partially related to changes in $\mathrm{K}^{+}$content of the cells (reviewed in Zwaal et $\left.a .^{6}\right)$. Moreover, the inverse correlation between $\left[\mathrm{K}^{+}\right]$and PS asymmetry in erythrocytes is in agreement with recent data demonstrating inhibition of agonist (collagen and thrombin)-induced PS exposure at the platelet surface by $\mathrm{K}^{+}$channel blockers and their subsequent reversal with valinomycin. ${ }^{12}$ While it is unclear whether loss of intracellular $\mathrm{K}^{+}$is critical for apoptosis regulated activation of scramblase activity in nucleated cells, there are reports which show an inhibitory role for intracellular $\mathrm{K}^{+}$on caspase and nuclease activity $^{33}$ and apoptosome activation ${ }^{34,35}$ suggesting a physiological role for intracellular $\mathrm{K}^{+}$as a negative regulator of several key events in apoptosis including PS externalization.

In conclusion, we have shown that lipid scrambling can occur in isolated red blood cell membranes and that the activity of the scramblase is directly influenced by $\left[\mathrm{K}^{+}\right]$. While cell shrinkage and changes in morphology affect the rates of lipid scrambling, they do not appear to be the driving force behind this process. Because of its significance in blood coagulation and in the removal of apoptotic cells, modulation of PS exposure by selective manipulation of the $\left[\mathrm{K}^{+}\right]_{\mathrm{i}}$ in $\mathrm{Ca}^{2+}$-dependent lipid scrambling may offer new strategies to control this important physiologic process. 


\section{References}

1 Daleke DL. Regulation of transbilayer plasma membrane phospholipid asymmetry. J Lipid Res 2003; 44: 233-42

2 Pomorski T, Menon AK. Lipid flippases and their biological functions. Cell Mol Life Sci 2006; 63: 2908-21

3 Heemskerk JW, Bevers EM, Lindhout T. Platelet activation and blood coagulation. Thromb Haemost 2002; 88; 186-93

4 Schlegel RA, Williamson P. Phosphatidylserine, a death knell. Cell Death Differ $2001 ; 8: 551-63$

5 Smrz D, Draberova L, Draber P. Non-apoptotic phosphatidy/serine externalization induced by engagement of glycosylphosphatidylinositol-anchored proteins. 3 Blol Chem 2007; 282: 10487-97

6 Zwaal RF, Comfurius P, Bevers EM. Surface exposure of phosphatidylserine in pathological celis. Cell Mol Life Sci 2005; 62: 971-88

7 Comfurius $P$, Williamson P, Smeets EF, Schlegel RA, Bevers EM, Zwaal RF. Reconstitution of phospholipid scramblase activity from human blood platelets. Biochemistry 1996; 35: 7631-4

8 Basse $F$, Stout JG, Sims PJ, Wiedmer T. Isolation of an erythrocyte membrane protein that mediates $\mathrm{Ca}^{2+}$-dependent transbilayer movement of phospholipid. $]$ Biol Chem 1996; 271: 17205-10

9 Zhou Q, Zhao J, Stout JG, Luhm RA, Wiedmer T, Sims PJ. Molecular cloning of human plasma membrane phospholipid scramblase. A protein mediating transbilayer movement of plasma membrane phospholipids. J Blol Chem 1997; 272: $18240-4$

10 Sahu SK, Gummadi SN, Manoj N, Aradhyam GK. Phospholipid scramblases: an overview. Arch Biochem Biophys 2007; 462: 103-14

11 Sims PJ, Wiedmer T. Unraveling the mysteries of phospholipid scrambling. Thromb Haemost 2001; 86: 266-75

12 Wolfs JL, Wielders SJ, Comfurius P, Lindhout T, Giddings JC, Zwaal RF, Bevers EM. Reversible inhibition of the platelet procoagulant response through manipulation of the Gardos channel. Blood 2006; 108: 2223-8

13 Lang PA, Kaiser S, Myssina S, Wieder T, Lang F, Huber SM. Role of $\mathrm{Ca}^{2+}$-activated $\mathrm{K}^{+}$channels in human erythrocyte apoptosis. Am J Physiol Cell Physiol 2003; 285: C1553-60

14 Rosing J, van Rijn JL, Bevers EM, van Dieijen G, Comfurius P, Zwaal RF. The role of activated human platelets in prothrombin and factor $X$ activation. Blood 1985; 65: 319-32

15 Bevers EM, Comfurius $\mathrm{P}$, Zwaal RF. Changes in membrane phospholipid distribution during platelet activation. Biochim Biophys Acta 1983; 736:, 57-66

16 Wolfs JL, Comfurius P, Bevers EM, Zwaal RF. Influence of erythrocyte shape on the rate of $\mathrm{Ca}^{2+-}$-induced scrambling of phosphatidylserine. Mol Membr Biol 2003; 20: $83-91$

17 Gardos G. The function of calcium in the potassium permeability of human erythrocytes. Biochim Biophys Acta 1958: 30: 653-4

18 Maher AD, Kuchel PW. The Gardos channel: a review of the $\mathrm{Ca}^{2+}$-activated $\mathrm{K}^{\text {t }}$ channel in human erythrocytes. Int I Biochem Cell Biol 2003; 35: 1182-97

19 Rodriguez de la Vega RC, Possani LD. Current views on scorpion toxins specific for $\mathrm{K}^{+}$-channels. Toxicon 2004; 43: 865-75

20 Lew VL, Bookchin RM. Ion transport pathology in the mechanism of sickle cell dehydration. Physiol Rev 2005; 85: 179-200 
21 Bevers EM, Wiedmer T, Comfurius P, Shattil SJ, Weiss HJ, Zwaal RF, Sims PJ. Defective $\mathrm{Ca}^{2+}$-induced microvesiculation and deficient expression of procoagulant activity in erythrocytes from a patient with a bleeding disorder: a study of the red blood cells of Scott syndrome. Blood 1992; 79: 380-8

22 Allan D, Thomas P. Ca ${ }^{2+}$-induced biochemical changes in human erythrocytes and their relation to microvesiculation. Blochem J 1981; 198: 433-40

23 Hughes FM Jr, Cidlowski JA. Potassium is a critical regulator of apoptotic enzymes in vitro and in vivo. Adv Enzyme Regul 1999; 39: 157-71

24 Lang F, Foller M, Lang KS, Lang PA, Ritter M, Gulbins E, Vereninov A, Huber SM. Ion channels in cell proliferation and apoptotic cell death. J. Membr. Biol. 2005; 205: $147-57$

25 Park IS, Kim JE. Potassium efflux during apoptosis. J Biochem Mol Biol 2002; 35: 41-6

26 Yu SP, Canzoniero LM, Choi DW. Ion homeostasis and apoptosis. Curr. Opin. Cell Biol. 2001; 13: 405-11

27 Schneider J, Nicolay JP, Foller M, Wieder T, Lang F. Suicidal erythrocyte death following cellular $\mathrm{K}^{+}$loss. Cell Physiol Blochem 2007; 20: 35-44

28 Oka K, Sawamura T, Kikuta K, Itokawa S, Kume N, Kita T, Masaki T. Lectin-like oxidized low-density lipoprotein receptor 1 mediates phagocytosis of aged/apoptotic cells in endothelial cells. Proc Natl Acad Sci USA 1998; 95: $9535-$ 40

29 Page MJ, Di Cera E. Role of $\mathrm{Na}^{+}$and $\mathrm{K}^{+}$in enzyme function. Physiol Rev 2006; 86: 1049-92

30 Elliott JI, Sardini A, Cooper JC, Alexander DR, Davanture S, Chimini G, Higgins CF. Phosphatidylserine exposure in B lymphocytes: a role for lipid packing. Blood 2006; 108: 1611-7

31 Bucki R, Bachelot-Loza C, Zachowski A, Giraud F, Sulpice JC. Calcium induces phospholipid redistribution and microvesicle release in human erythrocyte membranes by independent pathways. Biochemistry 1998; 37: 15383-91

32 Bookchin RM, Etzion Z, Sorette M, Mohandas N, Skepper JN, Lew VL. Identification and characterization of a newly recognized population of high- $\mathrm{Na}^{+}$, low- $\mathrm{K}^{+}$, low-density sickle and normal red cells. Proc Natl Acad Sci USA 2000; 97: 8045-50

33 El Kebir D, Jozsef $L$, Khreiss T, Filep JG. Inhibition of $\mathrm{K}^{+}$efflux prevents mitochondrial dysfunction, and suppresses caspase-3-, apoptosis-inducing factor, and endonuclease G-mediated constitutive apoptosis in human neutrophils. Cell Signal 2006; 18: 2302-13

34 Cain K, Langlais C, Sun XM, Brown DG, Cohen GM. Physiological concentrations of $\mathrm{K}^{+}$inhibit cytochrome c-dependent formation of the apoptosome. ] Biol Chem 2001; 276: 41985-90

35 Karki P, Seong C, Kim JE, Hur K, Shin 5Y, Lee JS, Cho B, Park IS. Intracellular K ${ }^{+}$ inhibits apoptosis by suppressing the Apaf-1 apoptosome formation and subsequent downstream pathways but not cytochrome c release. Cell Death Differ 2007; 14: 2068-75 


\section{Chapter 6}

Generall discussion 


\section{General discussion}

It is generally accepted that the lipid composition of the outer- and inner monolayer of the plasma membrane are different. The outer monolayer consists primarily of choline-containing phospholipids, phosphatidylcholine (PC) and sphingomyelin (SM), whereas the aminophospholipids, phosphatidylserine (PS) and phosphatidylethanolamine (PE), dominate the composition of the inner leaflet of the membrane. Generation and maintenance of this asymmetric lipid distribution is mainly controlled by a specific lipid transporter, the aminophospholipid translocase; ${ }^{1}$ this enzyme catalyses an ATPdependent transport of PS and PE from the outer to the inner leaflet of the plasma membrane. In addition to this transporter, evidence was obtained for the presence of a non-selective, ATP-dependent transport of phospholipids in opposite direction, catalyzed by $A B C C 1$ (previously called MRP1), ${ }^{2,3}$ Transport by $A B C C 1$ is much slower than that of the aminophospholipid translocase (half time in the order of hours in comparison to minutes for the translocase) and has as yet only been demonstrated for fluorescent labeled phospholipid probes. Indirect evidence has shown that also endogenous lipids are transported, because prolonged incubation with inhibitors of $A B C C 1$ causes a shift in the distribution of $P C$ and $S M$, judged from a diminished susceptibility of these lipids for extracellular added phospholipases. ${ }^{2}$ A concerted action of these two transporters was proposed to be responsible for a dynamic equilibrium in which the various phospholipid classes are asymmetrically distributed over both halves of the membrane bilayer.

Spontaneous transbilayer movement of phospholipids is very slow with half times varying from hours to days ${ }^{4-7}$, meaning that the asymmetric lipid distribution is relatively stabile and translocation is mainly required to restore lipid asymmetry, compromised by fusion processes occurring during endo- and exocytosis. However, cellular activation may give rise to a collapse of lipid asymmetry which is of significant physiological importance like for instance in the process of hemostasis and in the removal of apoptotic cells during tissue development. Loss of lipid asymmetry is not simply caused by inactivation of the aminophospholipid translocase. ${ }^{8-10}$ In the past decennia, an increasing amount of evidence has been generated for the existence of one or more proteins that, activated by $\mathrm{Ca}^{2+}$ ions, facilitate a non-selective, bidirectional migration of lipids across the membrane. Because activation of this mechanism results in randomization or 'scrambling' of the different phospholipid classes 
over both halves of the plasma membrane, the term 'scramblase' was coined to indicate the protein(s) that mediate this process.

The most prominent feature of collapse of lipid asymmetry is the appearance of negatively-charged PS in the outer leaflet of the plasma membrane of the cell. Surface exposed PS serves various functions, one of which is to catalyze assembly of several enzyme complexes of the blood coagulation cascade, required for a rapid fibrin formation (reviewed in ${ }^{11}$ ). In particular blood platelets are equipped with an active scrambling mechanism and the formation of a PS-exposing, procoagulant surface, the so-called procoagulant response, plays, next to adhesion and aggregation, a pivotal role in the hemostatic process. Experimentally, the procoagulant response is mainly determined in platelet-rich plasma or in suspensions of washed platelets. Maximal procoagulant response, measured as prothrombinase activity, is observed within one minute after platelets are activated with ionomycin in the presence of extracellular $\mathrm{Ca}^{2+}$. With physiologic agonists, such as the combination of collagen and thrombin, procoagulant activity develops in a period of 10-15 minutes before reaching a plateau level. In this thesis (chapter 2), flow cytometric analysis revealed that in a suspension of collagen plus thrombin activated platelets, a fraction of the platelets exposes PS to an extent comparable with that obtained after ionomycin treatment; in time, this fraction increases to reach a final level of $20-30 \%$ of the total number of platelets after approximately 15 minutes. Similar indications for fractional activation have been described earlier by Dachary-Prigent et al. ${ }^{12}$

In addition, we determined aminophospholipid translocase and scramblase activities in single cells by FACS analysis, using fluorescent labeled phospholipid probes. The results of these experiments revealed that in the fraction of PS positive platelets scramblase activity is fully activated while aminophospholipid translocase is blocked; in contrast, in the PS negative population of platelets scramblase is inactive and translocase activity was found to be enhanced in comparison to non-activated platelets. A time course of PS exposure in platelets activated with ionomycin in the presence of extracellular $\mathrm{Ca}^{2+}$ shows an increasing fraction of platelets in which PS exposure is maximal (chapter 2). Platelets with an intermediate extent of PS exposure (in between control and ionomycin activated platelets) were not found, suggesting an all or none effect after a threshold for activation has been reached. This makes an earlier model proposed by Diaz and Schroit ${ }^{13}$, in which, 
depending on the $\mathrm{Ca}^{2+}$ concentration, the concerted action of a partially activated scramblase and a partially inactivated translocase can accommodate variable amounts of surface exposed PS, less likely. These observations of heterogeneity in cellular response emphasize that bulk measures of PS exposure, such as procoagulant activity or transbilayer movement of lipid analogs in cell populations, do not allow distinguishing the rate of lipid movement from the rate and efficiency of activation of this movement.

Previous studies on platelets but also erythrocytes showed that loss of lipid asymmetry is associated with an increased concentration of intracellular $\mathrm{Ca}^{2+}\left(\left[\mathrm{Ca}^{2+}\right]_{1}\right)$, while lowering the intracellular $\mathrm{Ca}^{2+}$ causes an arrest of the lipid scrambling process. ${ }^{14-19}$ Using a continuous assay based on fluorescent lipid analogs to monitor lipid scrambling, it was demonstrated that intracellular $\mathrm{Ca}^{2+}$ acts as a switch for the scrambling machinery; ionomycin-mediated influx and efflux of $\mathrm{Ca}^{2+}$ in platelets allowed multiple cycles of activation and inactivation of the scrambling process. ${ }^{19}$ Studies on blood platelets demonstrated that a transient elevation of $\left[\mathrm{Ca}^{2+}\right]_{i}$ is insufficient to activate the lipid scrambling process, as illustrated by a comparison of the procoagulant response after activation with thrombin or the combined action of collagen plus thrombin. ${ }^{16,17}$ Although activation with thrombin produces $\left[\mathrm{Ca}^{2+}\right]_{i}$ in the micromolar range, it does not cause an appreciable activation of the scramblase and even results in an enhanced translocase activity. ${ }^{20}$ Elevation of $\left[\mathrm{Ca}^{2+}\right]_{1}$ with this agonist is transient because of rapid sequestration of $\mathrm{Ca}^{2+}$ ions in intracellular stores and removal of $\mathrm{Ca}^{2+}$ by the $\mathrm{Ca}^{2+}$. ATPase pump in the plasma membrane. In contrast, activation of platelets with collagen plus thrombin causes a sustained elevation of $\left[\mathrm{Ca}^{2+}\right]_{i}$ resulting in PS exposure. ${ }^{16,17}$ Also, when analyzed in single cells, the PS exposing platelet fraction showed a sustained elevation of $\left[\mathrm{Ca}^{2+}\right]_{\mathrm{i} .}{ }^{12,21}$ Studies on red blood cells revealed that the minimal extracellular $\left[\mathrm{Ca}^{2+}\right]$ which is required to activate the scrambling process is around 50 en $100 \mu \mathrm{M}^{22-24}$ This concentration exceeds the concentration to cause half maximal inhibition of the translocase activity with at least an order of magnitude (IC $50 \sim 0.2-2 \mu \mathrm{M}^{25}$ ), suggesting that under conditions in which scramblase is activated, translocase activity is completely inhibited. Whether or not this is also true for platelets is presently unknown.

This leaves open the question why only a fraction of the platelets in a suspension activated with collagen and thrombin reaches the threshold for activating the scramblase, whereas under the same conditions the release reaction takes place in all platelets as judged 
from the expression of P-selectin (CD62). Clearly, a transient elevation of $\left[\mathrm{Ca}^{2+}\right]_{1}$ is sufficient to activate the secretory event, which can be induced by thrombin alone in the entire platelet population. $A$ sustained elevation of $\left[\mathrm{Ca}^{2+}\right]_{i}$ requires the presence of both agonists, collagen and thrombin. Heterogeneity in this response could be caused by a heterogeneous activation process; only platelets that come into contact with collagen (and thrombin) will be effectively activated to obtain a sustained high $\left[\mathrm{Ca}^{2+}\right]_{1}$ required for lipid scrambling. Aggregation, caused by ADP released from activated platelets, could restrict the number of platelets that come into contact with collagen. However, studies by Alberio et al. showed that also upon activation with convulxin (a soluble GPVI agonist) and thrombin, under conditions preventing platelet aggregation, only a fraction of the platelets becomes PS positive, the so-called 'coat platelets' (collagen (or convulxin) and thrombin activated platelets). ${ }^{26,27} \mathrm{~A}$ plausible explanation could be found in age-related differences between platelets in a population. A diminished $\mathrm{Ca}^{2+}$ homeostasis in senescent platelets (diminished $\mathrm{Ca}^{2+}$ sequestrating potential) could lead to sustained levels of increased $\left[\mathrm{Ca}^{2+}\right]_{1}$ following stimulation, with subsequent PS exposure. On the other hand, evidence has been obtained for a decreased platelet function upon aging as shown by Alberio et al. for the response of canine platelets to collagen. They suggested that this decreased response originates from a decreased receptor density for collagen (GP VI) upon ageing ${ }^{26}$, which is in line with the observation that 'coat' platelets concern mainly young platelets. Heterogeneity in platelet response with respect to PS exposure has also been reported by other groups. ${ }^{12,28,29}$ Experiments with platelets under flow, in which both PS exposure and binding of fibrinogen was studied, have demonstrated that during thrombus formation on a collagen coated surface, two different platelet fractions are visualized: platelets which are PS positive, showing no fibrinogen binding next to platelets that do bind fibrinogen and that do not expose PS. ${ }^{29}$ It is unclear to what extent this heterogeneous response coincides with that observed for platelets in suspensions stimulated with collagen and thrombin. Further studies are required to clarify this heterogeneous behavior of platelets.

Another aspect that originated from our studies, in particular with red blood cells, is the association between lipid scrambling and morphology, i.c. membrane morphology (chapter 3). Since Sheetz and Singer first proposed their bilayer couple theory ${ }^{30}$, it is well 
appreciated and experimentally confirmed that very small changes in lipid mass between the two leaflets of a membrane lead to membrane bending and could thus support processes such as endocytosis, exocytosis and shedding of membrane derived microparticles (reviewed $\mathrm{in}^{31}$ ). Originally, the strong correlation between lipid scrambling and the shedding of membrane microvesicles led Sims and co-workers to propose that vesicle shedding itself might provide a mechanism for the loss of lipid asymmetry. ${ }^{32,33}$ Shedding of microvesicles from the plasma membrane requires fusion between opposing segments of cytoplasmic membrane surfaces and transient formation of nonbilayer structures at the point of fusion might provide a pathway for local collapse of transbilayer lipid asymmetry.

Several observations make the above described model to be less plausible. Conditions which suppress microvesicle formation in both platelets and erythrocytes did not reduce PS exposure. ${ }^{10,34-38}$ Moreover, microvesicle shedding induced by incorporation of dimyristoylphosphatidylcholine (DMPC) into the outer leaflet of the erythrocyte membrane is not accompanied by loss of lipid asymmetric lipid. When DMPC-induced microvesicles are treated with $\mathrm{Ca}^{2+}$-ionophore, lipid asymmetry is rapidly lost, but morphology (size) is unchanged. ${ }^{39,40}$ Studies, aimed to measure rates of lipid scrambling, revealed that the outward movement of PS exceeds the rate of inward movement of SM. The resulting mass imbalance, according to the coupled bilayer hypothesis, could lead to exfoliation of the plasma membrane with subsequent shedding of membrane microvesicles..$^{40-42}$ The hypothesis that lipid scrambling forms the driving force of microvesicle formation is supported by the observation that microvesicle formation in patients with Scott syndrome is impaired.

Both PS exposure and cell shrinkage are hallmarks of apoptosis. ${ }^{40-42}$ Differences in surface tension between the two leaflets of the plasma membrane may provide the driving force for volume-related changes in lipid asymmetry. $\mathrm{Ca}^{2+}$-induced lipid scrambling in B-lymphocytes causes externalization of PS; this phenomenon appears to be preceded by and to be dependent on a decrease in packing density of the membrane lipids as can be visualized by an increased binding of merocyanin $540 .{ }^{43}$ In a hypothetical model, Elliott et al. have postulated that cell shrinkage-induced membrane deformation creates domains with high and low packing density in the apex and the base of membrane blebs, respectively. ${ }^{43}$ They argued that this promotes outward movement of lipids in the apex and inward 
movement at the base, entirely in agreement with the characteristics of the scrambling process, including bi-directional movement of all phospholipid classes. They even speculated that in this model, lipid scrambling may be independent of a protein mediator. In support of this 'shrinkage' model, Schneider et al recently demonstrated a reciprocal correlation between forward scatter (cell volume) and annexin A5 binding (PS exposure) in erythrocytes, irrespective of the conditions by which the cell volume was manipulated (changing osmolarity or causing influx or efflux of $\mathrm{K}^{+}$ions). ${ }^{44}$ From our studies described in chapter 4 , where we have determined the effect of intracellular $\mathrm{K}^{+}$ions on lipid scrambling, it appeared that this proposed shrinkage model seems less likely. In these experiments, we have used resealed erythrocyte ghosts, in which isolated red cell membranes are closed to intact membrane structures while keeping the original membrane lipid distribution intact. Lipid scrambling can be induced in these resealed membranes without appreciable changes in cell morphology or cell volume and without production of microvesicles.

Although our studies revealed that lipid scrambling can occur in absence of morphological changes, this does not exclude that membrane morphology can influence the scrambling process as illustrated by the experiments described in chapter 3. Erythrocyte morphology can be manipulated by incorporation of various anionic or cationic lipid soluble amphipatic compounds, which because of their charge incorporate in the outer- and inner leaflet of the membrane, respectively. Incorporation in the outer leaflet will cause crenation in which the normal biconcave shape of the red cell changes into an echinocyte shape. Alternatively, compounds that intercalate in the inner monolayer will give rise to stomatocytosis (cup formation). We found that upon treatment of these shapemanipulated erythrocytes with $\mathrm{Ca}^{2+}$ ionophore, the process of lipid scrambling in echinocytes is accelerated, while that in stomatocytes is decelerated in comparison to normocytes. Apparently, the shedding of membrane vesicles facilitates the process of lipid scrambling; however, accumulation of a mass excess in the outer leaflet due to different rates of inward and outward movement of lipids during lipid scrambling will take more time starting from stomatocytes than from echinocytes.

In addition to the pivotal role of $\mathrm{Ca}^{2+}$ ions in the activation of the scramblase in hematopoietic cells, evidence has been obtained for a modulating effect by monovalent cations or their gradients on the 
process of lipid scrambling. For instance, PS exposure in platelets activated by collagen in combination with a thrombin receptor agonist (TRAP, SFLLRN) was reported to be impaired in a $\mathrm{Na}^{+}$-free medium. ${ }^{34}$ Inhibitors of the $\mathrm{Na}^{+} / \mathrm{H}^{+}$exchanger inhibit the procoagulant response of platelets. ${ }^{34,45}$ It is however unclear to what extent these ions have a direct modulating effect on the scrambling process as such or are essential for an efficient signal transduction required to activate the scramblase. The studies described in chapters 4 and 5 provide evidence for a direct effect of $\mathrm{K}^{+}$ions on the rate of lipid scrambling. Decreasing $\mathrm{K}^{+}$efflux by increasing extracellular $\left[\mathrm{K}^{+}\right]$or using specific $\mathrm{K}^{+}$channel blockers causes a diminished PS exposure induced by $\mathrm{Ca}^{2+}$ ionophore in both platelets (chapter 4 ) and erythrocytes (chapter 5 and refs ${ }^{46,47}$ ). Valinomycin, a $\mathrm{K}^{+}$ionophore, increases the rate of $\mathrm{Ca}^{2+}$-induced lipid scrambling in erythrocytes and abolished the inhibitory effect of $\mathrm{K}^{+}$channel blockers. Although manipulation of the extracellular $\mathrm{K}^{+}$concentration could affect lipid scrambling indirectly through changes in morphology and volume of the cell, our studies with resealed erythrocyte ghosts provide evidence that the inhibitory effect of $\mathrm{K}^{+}$ ions on the scramblase is direct (chapter 5). The rate of lipid scrambling in intact erythrocytes is suppressed by a high intracellular $\mathrm{K}^{+}$concentration and is accelerated by the efflux of $\mathrm{K}^{+}$ions through $\mathrm{Ca}^{2+}$-activated Gardos channels. The number of Gardos channels per cell varies significantly between different individuals. ${ }^{48,49}$ This suggests that the individual variability in rate of lipid scrambling observed for erythrocytes obtained from healthy donors as described in chapter 3, may be due to differences in the number of Gardos channels. However, this explanation was disproven since the presence of valinomycin did not abolish these differences (Wolfs, 2007, unpublished observations). An alternative explanation for the variation in scrambling activity between different donors could be a difference in efficiency of protein sorting at the enucleation step of erythropoiesis. At this step, the cell remnant containing the nucleus is engulfed by macrophages in a process related to the PS-dependent recognition of apoptotic cells ${ }^{50,51}$; restricting scramblase to the nucleated remnant cell would promote its PS-dependent recognition and engulfment by macrophages, whereas its exclusion from membrane surrounding the newborn reticulocyte would allow its escape from this engulfment and entry into the circulation. The result would be a low level of scramblase in the red cell membrane; how low it finally reaches would reflect the efficiency of the scramblase segregation process at the point of creation of the reticulocyte. In 
this context it is tempting to speculate that the absence of scramble activity in porcine erythrocytes (but not platelets) may reflect a very efficient protein sorting process.

In erythrocytes, $\mathrm{Ca}^{2+}$-ionophore induces a large variety of simultaneous biochemical changes among which are microvesicle formation, $\mathrm{K}^{+}$efflux, cell shrinkage, degradation of polyphosphoinositides, production of diacylglycerol (DAG) and phosphatidic acid (PA) and changes in the pattern of membrane proteins. These various events and there mutual relationship have been studied extensively by Allan and collaborators in the eighties of the last century..$^{5-56}$ Unfortunately, data about lipid scrambling are lacking from these studies as this event was not yet generally recognized in that time. Nevertheless, an overview of the most relevant data from these studies combined with current knowledge of lipid scrambling in erythrocytes reveals some interesting aspects (Table 6.1).

Table $6.1 \mathrm{Ca}^{2+}$-stimulated events in mammalian eythrocytes and erythrocyte ghosts $\left({ }^{52-56}\right)$

\begin{tabular}{lccccccc}
\hline & $\begin{array}{c}\text { K+ } \\
\text { efflux }\end{array}$ & $\begin{array}{c}\text { Cell } \\
\text { shrinkage }\end{array}$ & $\begin{array}{c}\text { Echinocyte } \\
\text { formation }\end{array}$ & $\begin{array}{c}\text { Micro- } \\
\text { vesicle } \\
\text { formation }\end{array}$ & $\begin{array}{c}\text { DAG } \\
\text { production }\end{array}$ & $\begin{array}{c}\text { PA } \\
\text { production }\end{array}$ & $\begin{array}{c}\text { Lipid } \\
\text { scrambling }\end{array}$ \\
\hline human & + & + & + & + & + & + & + \\
rat & + & + & + & + & + & + & + \\
guinea pig & + & + & + & + & + & + & N.D. \\
rabbit & + & + & + & + & + & + & N.D. \\
plg & + & N.D. & $-(?)$ & - & - & - & - \\
ox & - & - & - & - & - & - & - \\
Sheep (high K+) & - & - & - & - & - & - & - \\
human ery ghost & - & - & - & - & + & $-*$ & + \\
Scott syndrome & + & $+(?)$ & - & - & N.D. & N.D. & - \\
\hline
\end{tabular}

*PA is formed only when ATP is incorporated; N.D. is not determined

Allan et al. demonstrated that $\mathrm{Ca}^{2+}$-induced microvesicle production is not related to changes in membrane protein patterns and DAG or PA production. ${ }^{54,55}$ They also demonstrated that $\mathrm{K}^{+}$efflux and cell shrinkage are essential but not sufficient for the production of microvesicles and they conclude that an additional $\mathrm{Ca}^{2+}$-dependent process is required; we speculate that this is likely the process of lipid scrambling. Unlike valinomycin, abolishing the $\mathrm{K}^{+}$gradient by 
gramicidin (exchange between $\mathrm{Na}^{+}$and $\mathrm{K}^{+}$) or nigericin (exchange between $\mathrm{H}^{+}$and $\mathrm{K}^{+}$) is not accompanied by changes in cell volume; under these conditions $\mathrm{Ca}^{2+}$-induced microvesicle formation is absent. Whether lipid scrambling is impaired under these conditions has not been investigated, but is not likely considering the findings described in chapter 5 .

A most remarkable finding comparing the data in Table 6.1 is the correlation between lipid scrambling and DAG production, suggesting the latter might be a prerequisite for scrambling. In this respect it is worth to mention previous observations showing that treatment of platelets with phospholipase $C$ results in increased PS exposure. ${ }^{57,58}$ Unfortunately, no data are available about the DAG production in erythrocytes from Scott patients after treatment with $\mathrm{Ca}^{2+}$ ionophore, although it has been established that the PIP $\mathrm{P}_{2}$ content, the major source of DAG production, and the $\mathrm{Ca}^{2+}$-induced hydrolysis of $\mathrm{PIP}_{2}$ is not appreciable different from that of healthy controls. ${ }^{59}$

In contrast to aminophospholipid translocase, scramblase-mediated migration of lipids across the membrane does not require ATP hydrolysis. This is best illustrated by the fact that $\mathrm{Ca}^{2+}$-induced lipid scrambling can still occur in resealed 'white'erythrocyte ghosts, lacking cellular ATP. ${ }^{15,18,60}$ However, prolonged incubation of erythrocytes in glucose-free medium or the presence of metabolic inhibitors, resulting in severe ATP depletion, causes a gradual loss of $\mathrm{Ca}^{2+}$-induced lipid scrambling. ${ }^{61,62}$ Loss of scrambling activity was prevented when the phosphatase inhibitors, vanadate or okadaic acid, were present during ATP depletion ${ }^{61}$ and scramblase activity could be restored upon ATP repletion. ${ }^{63}$ Also, the experiments with erythrocyte ghosts described in chapter 5 , indicate that scramblase activity is dependent on the concentration of incorporated ATP during the reseal procedure (Wolfs, unpublished data). Moreover, artificial increase of the intracellular ATP content in intact erythrocytes through incubation in high glucose medium resulted in enhanced $\mathrm{Ca}^{2+}$-induced lipid scrambling. These observations suggest that the scramblase protein(s) might be phosphorylated and that the degree of phosphorylation determines its activity. Because the presence of staurosporine during treatment of erythrocytes with $\mathrm{Ca}^{2+}$-ionophore does not affect the scrambling in these cells ${ }^{64}$, we further postulate that at least a fraction of the scramblase protein(s) are constitutively phosphorylated. Interestingly, $\mathrm{Ca}^{2+}$-induced lipid scrambling in erythrocytes is accompanied by an increased phosphorylation of 
band 3 protein (anion transporter) ${ }^{65}$, and Dekkers et al. have found that this phosphorylation is virtually absent in patients with Scott syndrome. ${ }^{64}$ An impaired tyrosine phosphorylation, albeit less pronounced, was also found after activation of platelets from these patients. ${ }^{64,66-68}$ Although it was tempting to speculate that the phosphorylation defect in Scott patients was underlying the impaired lipid scrambling process, subsequent experiments by Dekkers et al. led to a different conclusion. To find out whether the phosphorylation defect in Scott syndrome was caused by an impaired kinase or an overactive phosphatase, Dekkers et al. studied the tyrosine phosphorylation patterns of unsealed erythrocyte ghosts upon incubation with ATP ${ }^{64}$. No differences in phosphorylation patterns between Scott cells and erythrocytes from healthy controls were observed. Unfortunately, scramblase activity of ghosts from Scott erythrocytes, resealed in the presence of ATP, was not measured. However, when this experiment was performed as part of the studies in this thesis, it appeared that even after incorporation of ATP in Scott resealed ghosts, $\mathrm{Ca}^{2+}$-induced lipid scrambling could not be restored (Wolfs et al. unpublished observations). Therefore, a plausible explanation for the observed phosphorylation defect in Scott erythrocytes is that it concerns an epiphenomenon that could be related to a defective lipid scrambling (downstream), but is not causal to this defect. This does, however, not exclude the existence of one or more phosphorylated components as part of the scramblase machinery.

\section{Concluding remarks}

Lipid scrambling, with surface exposed PS as one of its major consequences, forms an important part of various physiological and pathophysiological processes. There are more pathways that lead to collapse of lipid asymmetry, but little is known about the actual scrambling mechanism. Many characteristics of the 'putative' scramblase have been documented during the past decennia, but the few attempts to identify protein(s) which directly or indirectly could act as a scramblase have been as yet unsuccessful. It is important in future research, to focus on identification of specific protein(s) involved in the scramblase mechanism. A possible approach that deserves attention is the use of modern proteomic tools in experiments in which Scott cells are compared with cells of healthy controls to identify the protein encoded by the gene involved in the disease. In the end, concentrating on the identity of responsible 
proteins will resolve the mechanism of lipid scrambling. Understanding this mechanism will undoubtedly provide ways to manage pathophysiological consequences of PS exposure in the clinic. 


\section{References}

1. Daleke DL. Phospholipid flippases. J Biol Chem 2007; 282: 821-5.

2. Dekkers DW, Comfurius P, van Gool RG, Bevers EM, Zwaal RF. Multidrug resistance protein 1 regulates lipid asymmetry in erythrocyte membranes. Blochem J 2000; 350 Pt 2: 531-5.

3. Sohnius A, Kamp D, Haest CW. ATP and GSH dependence of MRP1-mediated outward translocation of phospholipid analogs in the human erythrocyte membrane. Mol Membr Biol 2003; 20: 299-305.

4. Bai J, Pagano RE. Measurement of spontaneous transfer and transbilayer movement of BODIPY-labeled lipids in lipid vesicles. Biochemistry 1997; 36: 8840-8.

5. de Kruijff B, van Zoelen EJ, van Deenen LL. Glycophorin facilitates the transbilayer movement of phosphatidylcholine in vesicles. Biochim Biophys Acta 1978; 509: 537-42.

6. Kornberg RD, McConnell HM. Inside-outside transitions of phospholipids in vesicle membranes. Biochemistry 1971; 10: 1111-20.

7. Papadopulos A, Vehring S, Lopez-Montero I, et al. Flippase activity detected with unlabeled lipids by shape changes of giant unilamellar vesicles. $\mathrm{J}$ Biol Chem 2007; 282: 15559-68.

8. Comfurius P, Senden JM, Tilly RH, Schroit AJ, Bevers EM, Zwaal RF. Loss of membrane phospholipid asymmetry in platelets and red cells may be associated with calcium-induced shedding of plasma membrane and inhibition of aminophospholipid translocase. Biochim Biophys Acta 1990; 1026: 153-60.

9. Tilley L, Cribier S, Roelofsen B, Op den Kamp JA, van Deenen LL. ATP-dependent translocation of amino phospholipids across the human erythrocyte membrane. FEBS Lett $1986 ; 194: 21-7$.

10. Verhoven $B$, Schlegel RA, Williamson P. Rapid loss and restoration of lipid asymmetry by different pathways in resealed erythrocyte ghosts. Biochim Biophys Acta 1992; 1104: 15-23.

11. Zwaal RF, Comfurius P, Bevers EM. Lipid-protein interactions in blood coagulation. Biochim Biophys Acta 1998; 1376: 433-53.

12. Dachary-Prigent J, Pasquet JM, Nurden AT. Simultaneous detection of changes in cytoplasmic $\mathrm{Ca}(2+)$, aminophospholipid exposure and micro-vesiculation in activated platelets. Platelets 1997; 8: 405-12.

13. Diaz $C$, Schroit AJ. Role of translocases in the generation of phosphatidylserine asymmetry. J Membr Biol 1996; 151: 1-9.

14. Chandra R, Joshi PC, Bajpai VK, Gupta CM. Membrane phospholipid organization in calcium-loaded human erythrocytes. Blochim Biophys Acta 1987; 902: 253-62.

15. Connor J, Gillum K, Schroit AJ. Maintenance of lipid asymmetry in red blood cells and ghosts: effect of divalent cations and serum albumin on the transbilayer distribution of phosphatidylserine. Biochim Blophys Acta 1990; 1025: 82-6.

16. Munnix IC, Harmsma M, Giddings $\mathrm{JC}$, et al. Store-mediated calcium entry in the regulation of phosphatidylserine exposure in blood cells from Scott patients. Thromb Haemost 2003; 89: 687-95.

17. Smeets $E F$, Heemskerk JW, Comfurius P, Bevers EM, Zwaal RF. Thapsigargin amplifies the platelet procoagulant response caused by thrombin. Thromb Haemost 1993; 70: 1024-9.

18. Williamson P, Algarin L, Bateman J, Choe HR, Schlegel RA. Phospholipid asymmetry in human erythrocyte ghosts. J Cell Physiol 1985; 123: 209-14.

19. Williamson $P$, Bevers EM, Smeets EF, Comfurius P, Schlegel RA, Zwaal RF. Continuous analysis of the mechanism of activated transbilayer lipid movement in platelets. Blochemistry 1995; 34: 10448-55. 
20. Tilly RH, Senden JM, Comfurius P, Bevers EM, Zwaal RF. Increased aminophospholipid translocase activity in human platelets during secretion. Biochim Biophys Acta 1990; 1029: 188-90.

21. Keuren JF, Wielders S], Ulrichts $H$, Hackeng T, Heemskerk JW, Deckmyn $H$, Bevers EM, Lindhout T. Synergistic effect of thrombin on collagen-induced platelet procoagulant activity is mediated through protease-activated receptor-1. Arterioscler Thromb Vasc Biol 2005; 25: 1499-505.

22. de Jong $K$, Kuypers FA. Sulphydryl modifications alter scramblase activity in murine sickle cell disease. Br J Haematol 2006; 133: 427-32.

23. Williamson P, Kulick A, Zachowski A, Schlegel RA, Devaux PF. Ca2+ induces transbilayer redistribution of all major phospholipids in human erythrocytes. Biochemistry 1992; 31: 6355-60.

24. Woon LA, Holland JW, Kable EP, Roufogalis BD. Ca2+ sensitivity of phospholipid scrambling in human red cell ghosts. Cell Calcium 1999; 25: 313-20.

25. Bitbol M, Fellmann P, Zachowski $A$, Devaux PF. Ion regulation of phosphatidylserine and phosphatidylethanolamine outside-inside translocation in human erythrocytes. Biochim Biophys Acta 1987; 904: 268-82.

26. Alberio L, Friese $P$, Clemetson KJ, Dale GL. Collagen response and glycoprotein VI function decline progressively as canine platelets age in vivo. Thromb Haemost 2002; 88: 510-6.

27. Dale GL, Friese $\mathrm{P}$, Batar P, Hamilton SF, Reed GL, Jackson KW, Clemetson KJ, Alberio $\mathrm{L}$. Stimulated platelets use serotonin to enhance their retention of procoagulant proteins on the cell surface. Nature 2002; 415: 175-9.

28. London FS, Marcinkiewicz M, Walsh PN. A subpopulation of platelets responds to thrombin- or SFLLRN-stimulation with binding sites for factor IXa. J Biol Chem 2004; 279: 19854-9.

29. Munnix IC, Kuijpers MJ, Auger J, Thomassen CM, PanizzI $P$, van Zandvoort MA, Rosing J, Bock PE, Watson SP, Heemskerk JW. Segregation of platelet aggregatory and procoagulant microdomains in thrombus formation: regulation by transient integrin activation. Arterioscler Thromb Vasc Biol 2007; 27: 2484-90.

30. Sheetz MP, Singer SJ. Biological membranes as bilayer couples. A molecular mechanism of drug-erythrocyte interactions. Proc Natl Acad Sci U S A 1974; 71: 4457-61.

31. Devaux PF, Herrmann A, Ohlwein N, Kozlov MM. How lipid flippases can modulate membrane structure. Biochim Biophys Acta 2008; 1778: 1591-600.

32. Chang $\mathrm{CP}$, Zhao J, Wiedmer T, Sims PJ. Contribution of platelet microparticle formation and granule secretion to the transmembrane migration of phosphatidylserine. J Biol Chem 1993; 268: 7171-8.

33. Sims PJ, Wiedmer T, Esmon CT, Weiss $\mathrm{HJ}$, Shattil SJ. Assembly of the platelet prothrombinase complex is linked to vesiculation of the platelet plasma membrane. Studies in Scott syndrome: an isolated defect in platelet procoagulant activity. J Biol Chem 1989; 264: 17049-57.

34. Bucki $R$, Bachelot-Loza $C$, Zachowski A, Giraud F, Sulpice JC. Calcium induces phospholipid redistribution and microvesicle release in human erythrocyte membranes by independent pathways. Biochemistry 1998; 37: 15383-91.

35. Dachary-Prigent J, Pasquet JM, Freyssinet JM, Nurden AT. Calcium involvement in aminophospholipid exposure and microparticle formation during platelet activation: a study using Ca2+-ATPase inhibitors. Biochemistry 1995; 34 : 11625-34.

36. Gaffet $P$, Bettache N, Bienvenue A. Phosphatidylserine exposure on the platelet plasma membrane during A23187-induced activation is independent of cytoskeleton reorganization. Eur J Cell Biol 1995; 67: 336-45.

37. Henseleit $U$, Plasa $G$, Haest C. Effects of divalent cations on lipid flip-flop in the human erythrocyte membrane. Biochim Biophys Acta 1990; 1029: 127-35. 
38. Williamson P, Bateman J, Kozarsky K, Mattocks $K$, Hermanowicz N, Choe HR, Schlegel RA. Involvement of spectrin in the maintenance of phase-state asymmetry in the erythrocyte membrane. Cell 1982; 30:725-33.

39. Beleznay $Z$, Zachowski A, Devaux PF, Ott P. Characterization of the correlation between ATP-dependent aminophospholipid translocation and Mg2+-ATPase activity in red blood cell membranes. Eur J Biochem 1997; 243: 58-65.

40. Zwaal RF, Comfurius P, Bevers EM. Mechanism and function of changes in membrane-phospholipid asymmetry in platelets and erythrocytes. Biochem Soc Trans $1993 ; 21: 248 \% 53$.

41. Basse F, Gaffet P, Rendu F, Bienvenue A. Translocation of spin-labeled phospholipids through plasma membrane during thrombin- and ionophore A23187-induced platelet activation. Biochemistry 1993; 32: 2337-44.

42. Smeets EF, Comfurius P, Bevers EM, Zwaal RF, Calcium-induced transbilayer scrambling of fluorescent phospholipid analogs in platelets and erythrocytes. Biochim Biophys Acta 1994; 1195: 281-6.

43. Elliott JI, Sardini A, Cooper JC, et al. Phosphatidylserine exposure in B lymphocytes: a role for lipid packing. Blood 2006; 108: 1611-7.

44. Schneider J, Nicolay JP, Foller M, Wieder T, Lang F. Suicidal erythrocyte death following cellular $\mathrm{K}+$ loss. Cell Physiol Biochem 2007; 20: 35-44.

45. Samson J, Stelmach $\mathrm{H}$, Tomasiak M. The importance of $\mathrm{Na} / \mathrm{H}+$ exchanger for the generation of procoagulant activity by porcine blood platelets. Platelets 2001; 12: 436-42.

46. de Jong K, Larkin SK, Styles LA, Bookchin RM, Kuypers FA. Characterization of the phosphatidylserine-exposing subpopulation of sickle cells. Blood 2001; 98 : 860-7.

47. Lang PA, Kaiser S, Myssina S, Wieder T, Lang F, Huber SM. Role of Ca2+activated $\mathrm{K}+$ channels in human erythrocyte apoptosis. Am J Physiol Cell Physiol 2003; 285: C1553-60.

48. Alvarez J, Garcia-Sancho J. An estimate of the number of Ca2+-dependent K+ channels in the human red cell. Biochim Biophys Acta 1987; 903: 543-6.

49. Lew VL, Tiffert $T$, Etzion $Z$, et al. Distribution of dehydration rates generated by maximal Gardos-channel activation in normal and sickle red blood cells. Blood 2005; 105: 361-7.

50. Williamson PL, Massey WA, Phelps BM, Schlegel RA. Membrane phase state and the rearrangement of hematopoietic cell surface receptors. Mol Cell Biol 1981; 1 : 128-35.

51. Yoshida $H$, Kawane $K$, Kolke $M$, Mori $Y$, Uchiyama $Y$, Nagata $S$. Phosphatidylserine-dependent engulfment by macrophages of nuclei from erythroid precursor cells. Nature 2005; 437: 754-8.

52. Allan D, Michell RH. Accumulation of 1,2-diacylglycerol in the plasma membrane may lead to echinocyte transformation of erythrocytes. Nature 1975; 258: 348-9.

53. Allan D, Michell RH. Production of 1,2-diacyiglycerol in human erythrocyte membranes exposed to low concentrations of calcium ions. Biochim Blophys Acta 1976; 455: 824-30.

54. Allan D, Michell RH. Calcium ion-dependent diacylglycerol accumulation in erythrocytes is associated with microvesiculation but not with efflux of potassium ions. Biochem J 1977; 166: 495-9.

55. Allan D, Thomas P. Ca2t-induced biochemical changes in human erythrocytes and their relation to microvesiculation. Biochem 3 1981; 198: 433-40.

56. Allan $D$, Thomas $P$. The effects of $\mathrm{Ca} 2+$ and $\mathrm{Sr} 2+$ on $\mathrm{Ca} 2+-$-sensitive biochemical changes in human erythrocytes and their membranes. Biochem J 1981; 198: 441-5.

57. Bevers $E M$, Comfurius $P, Z$ waal RF. The nature of the binding for prothrombinase at the platelet surface as revealed by lipolytic enzymes. Eur J Biochem 1982; 122: $81-5$. 
58. Comfurius $P$, Bevers EM, Zwaal RF. Stimulation of prothrombinase activity of platelets and erythrocytes by sub-lytic treatment with phospholipase $C$ from Clostridium welchii. Biochem Biophys Res Commun 1983; 117: 803-8.

59. Bevers EM, Wiedmer $T$, Comfurius $P$, et al. The complex of phosphatidylinositol 4,5-bisphosphate and calcium ions is not responsible for Ca2+-induced loss of phospholipid asymmetry in the human erythrocyte: a study in Scott syndrome, a disorder of calcium-induced phospholipid scrambling. Blood 1995; 86: 1983-91.

60. Bevers EM, Wiedmer $T$, Comfurius $P$, et al. Defective $\mathrm{Ca}(2+)$-induced microvesiculation and deficient expression of procoagulant activity in erythrocytes from a patient with a bleeding disorder: a study of the red blood cells of Scott syndrome. Blood 1992; 79: 380-8.

61. Martin DW, Jesty $\mathrm{J}$. Calcium stimulation of procoagulant activity in human erythrocytes. ATP dependence and the effects of modifiers of stimulation and recovery. J Biol Chem 1995; 270: 10468-74.

62. Sulpice JC, Zachowski A, Devaux PF, Giraud $F$. Requirement for phosphatidylinositol 4,5-bisphosphate in the $\mathrm{Ca}(2+)$-induced phospholipid redistribution in the human erythrocyte membrane. J Biol Chem 1994; 269: 6347-54.

63. Bevers EM, Comfurius P, Dekkers DW, Zwaal RF. Lipid translocation across the plasma membrane of mammalian cells. Biochim Biophys Acta 1999; 1439: 317-30.

64. Dekkers DW, Comfurius $P$, Vuist $W M$, et al. Impaired $\mathrm{Ca} 2+$-induced tyrosine phosphorylation and defective lipid scrambling in erythrocytes from a patient with Scott syndrome: a study using an inhibitor for scramblase that mimics the defect in Scott syndrome. Blood 1998; $91: 2133-8$.

65. Minetti G, Piccinini G, Balduini C, Seppi C, Brovelli A. Tyrosine phosphorylation of band 3 protein in Ca2+/A23187-treated human erythrocytes. Biochem J 1996; 320 ( Pt 2): 445-50.

66. Dachary-Prigent J, Pasquet JM, Fressinaud E, Toti F, Freyssinet JM, Nurden AT. Aminophospholipid exposure, microvesiculation and abnormal protein tyrosine phosphorylation in the platelets of a patient with Scott syndrome: a study using physiologic agonists and local anaesthetics. Br J Haematol 1997; 99: 959-67.

67. Imam-Sghiouar N, Laude-Lemaire I, Labas $V$, et al. Subproteomics analysis of phosphorylated proteins: application to the study of B-lymphoblasts from a patient with Scott syndrome. Proteomics 2002; 2: 828-38.

68. Martinez MC, Martin S, Toti F, et al. Significance of capacitative Ca2+ entry in the regulation of phosphatidylserine expression at the surface of stimulated cells. Biochemistry 1999; 38: 10092-8. 
Summary 


\section{Summary}

The plasma membrane of eukaryotic cells consists of two monolayers that differ in phospholipid composition. The outer leaflet comprises the majority of the choline-containing phospholipids, phosphatidylcholine (PC) and sphingomyelin (SM), whereas the aminophospholipids, phosphatidylserine (PS) and phosphatidylethanolamine (PE) are almost exclusively present in the inner leaflet. The importance of this asymmetric lipid distribution can be deduced from the fact that the cell spends energy for its maintenance, since changes in the lipid composition of the membrane surface may have important physiological consequences. Lipid asymmetry is maintained by at least two different transport proteins: 1 . the aminophospholipid translocase, responsible for a specific inward directed transport of the aminophospholipids, PS and PE, and 2. the so-called floppase, a protein that facilitates outward directed lipid transport. The latter is not selective with respect to the polar headgroup of the lipids and transport occurs with a much longer $t_{1 / 2}$ than that of the aminophospholipid translocase. Spontaneous transbilayer movement of phospholipids is extremely slow with a $t_{1 / 2}$ ranging from hours to days. As a consequence, lipid asymmetry is relatively stabile and the activity of the aminophospholipid translocase is mainly required to restore lipid asymmetry that is compromised by membrane fusion processes during exo- and endocytosis. Another protein, called scramblase, facilitates migration of lipids across the plasma membrane in both directions, irrespective the polar headgroup of the lipid molecule. Phospholipid scramblase is inactive in quiescent cells. Calcium ions play a pivotal role in collapse of membrane lipid asymmetry: scramblase is activated by a sustained elevation of the intracellular $\mathrm{Ca}^{2+}$ concentration, whereas the aminophospholipid translocase under these conditions is inhibited.

The most prominent feature of a collapse of transbilayer lipid asymmetry is the exposure of PS at the exofacial surface of the plasma membrane. Surface-exposed PS, in particular in blood platelets, is crucial for normal haemostasis. PS-containing membranes provide a catalytic surface (procoagulant surface) for the assembly of enzyme complexes (a.o. the prothrombinase complex) of the coagulation cascade, thus accelerating fibrin formation to ensure a localised control of the haemostatic process. In addition to this important physiological function restricted to blood coagulation, surface exposed PS serves a broader function as a recognition signal 
for the removal of apoptotic cells and in facilitating cell-cell interactions as part of fusion processes developing tissues.

Because of its critical dependence on the presence of PS, and its convenience to measure, the prothrombinase activity (procoagulant activity) is routinely used to detect PS exposure. However, the prothrombinase assay measures PS exposure in total cell suspensions. This implies that an increased prothrombinase activity may be caused either by an increased PS exposure in each cell of the suspension or by an increase in the number of cells that expose PS (or a combination of both). In chapter 2, we have studied the platelet procoagulant response in more detail with respect to the level of PS exposure per platelet using flow cytometry. The results of these studies indicate that after activation with various agonists, two platelet fractions can be distinguished, a PS-positive fraction and a PS-negative fraction. The extent of PS exposure in the PS-positive fraction is comparable to that of platelets activated with $\mathrm{Ca}^{2+}$ ionophore (i.e. maximal PS-exposition). The size of the PS-exposing fraction appears to be dependent on the type of agonist. This size increases with time and is proportional to the procoagulant activity of the total suspension. Our studies also revealed that in the subfraction of PS-exposing platelets, scramblase is fully active whereas translocase activity is completely inhibited. Translocase activity was only present in the platelet fraction that did not expose PS. Platelets with an intermediate PS exposure, positioned between that of control and $\mathrm{Ca}^{2+}$-ionophore stimulated platelets, could not be observed. These observations do not support the hypothesis that a gradual shift in the balance between translocase and scramblase activity is responsible for the extent of PS exposure and consequently the platelet procoagulant activity. In chapter 3 we describe the influence of erythrocyte morphology on the scrambling process. Simultaneous to lipid scrambling, treatment of erythrocytes with $\mathrm{Ca}^{2+}$-ionophore initiates a number of other phenomena such as cell shrinkage, morphological changes, membrane blebbing and shedding of microvesicles, small cell fragments surrounded by plasma membrane. The morphological changes involve a transition from a biconcave shape to an echinocyte shape, characterized by spiculated protrusions. A possible explanation for this change in shape is based on the 'coupled bilayer hypothesis' proposed by Sheetz and Singer, stating that a change in lipid mass between the two leaflets of a membrane induces bending of the membrane. According to this principle, a mass excess in the outer leaflet causes the membrane to exfoliate resulting in formation of spikes 
(echinocyte), whereas a mass excess in the inner leaflet results in invagination of the membrane leading to formation of stomatocytes. Previous studies, in which the rates of inward and outward movement of various lipids during the scrambling process were measured, have demonstrated that the rate of outward movement of aminophospholipids exceeds that of the inward movement of sphingomyelin. This difference in rate of inward and outward lipid migration leads to a mass excess in the outer leaflet of the membrane resulting in formation of echinocytes and subsequent shedding of microvesicles. Based on the foregoing, it was hypothesized that compounds (pharmaca) which incorporate in the outer leaflet (so-called crenators) or in the inner leaflet (cup formers) may affect the scrambling process. Two possibilities seem likely: on the one hand, incorporation of material in the inner leaflet may generate a driving force accelerating aminophospholipids to migrate outward, wheras an excess of mass in the outer leaflet may inhibit aminophospholipids to gain access to the outer leaflet. On the other hand, shedding of microvesicles could be rate limiting to the scrambling process; in this view, echinocytes treated with $\mathrm{Ca}^{2+}$ ionophore will lose lipid asymmetry more readily because of their 'natural ability' to form microvesicles, whereas in stomatocytes this process will be delayed due to the mass excess in the inner leaflet. To investigate which of these two alternatives is the most probable, we have used various crenators and cupformers and studied the rate of scrambling measured as development of a procoagulant surface. It was found that in comparison to normocytes, rate of lipid scrambling was enhanced in echinocytes and decreased in stomatocytes. We conclude that the process of microvesicle formation rather than a mass imbalance between the monolayers of the plasma membrane determines the rate of lipid scrambling.

$\mathrm{Ca}^{2+}$ uptake in erythrocytes not only activates the scrambling process, but also causes opening of $\mathrm{Ca}^{2+}$-sensitive $\mathrm{K}^{+}$channels, the so-called Gardos channels. In chapter 4 we investigated the possible role of intracellular $\mathrm{K}^{+}$ions on the scramblase activity and the corresponding procoagulant response. Activation of the scramblase in platelets requires a sustained elevation of the intracellular $\mathrm{Ca}^{2+}$ concentration. It was demonstrated that inhibition of the $\mathrm{K}^{+}$efflux by means of a high extracellular $\mathrm{K}^{+}$concentration or the presence of selective blockers of the Gardos channel, caused a significant decrease $(30-50 \%)$ of the procoagulant response of platelets stimulated with collagen and thrombin. This inhibition could be abolished by addition of valinomycin, a $\mathrm{K}^{+}$ionophore, which 
makes the plasmamembrane permeable for $\mathrm{K}^{+}$ions. Interestingly, the impaired procoagulant response of platelets from a patient with Scott syndrome was partially restored upon incubation with valinomycin.

Chapter 5 continues on the importance of $\mathrm{K}^{+}$efflux on the scrambling activity. Simultaneous measurement of the $\mathrm{K}^{+}$efflux and the rate of lipid scrambling in erythrocytes in the presence and absence of Gardos channel blockers, suggest a direct modulating effect of $\mathrm{K}^{+}$ions on the scramblase activity. Valinomycin enhances the $\mathrm{Ca}^{2+}$-induced lipid scrambling and abolishes the inhibition by $\mathrm{K}^{+}$ channel blockers. Experiments in which the intracellular $\mathrm{K}^{+}$ concentration was manipulated by means of valinomycin show a clear correlation between the intracellular $\mathrm{K}^{+}$concentration and the rate of lipid scrambling. When varying the intracellular $\mathrm{K}^{+}$ concentration from $0-140 \mathrm{mM}$, the rate of lipid scrambling decreases by approximately $50 \%$. In addition, studies with closed isolated erythrocyte membranes, so-called resealed ghosts, revealed that this inhibitory effect of $\mathrm{K}^{+}$ions is direct and significantly stronger than in intact erythrocytes. Moreover, the results described in chapter 5 showed that lipid scrambling in resealed erythrocyte ghosts can occur independent of cell shrinkage and formation of microvesicles, processes which appear to be strongly associated in intact red blood cells. Summarizing, we conclude that the high intracellular $\mathrm{K}^{+}$ concentration in non-stimulated cells suppresses the scramblase activity. Elevation of intracellular $\mathrm{Ca}^{2+}$ upon stimulation not only activates the scramblase, but also opens Gardos channels resulting in $\mathrm{K}^{+}$efflux and subsequent loss of the intrinsic inhibitory effect of this ion of the scramblase activity.

Finally, chapter 6 discusses the results described in this thesis in the broader context of the current literature on this subject. 
Samenvatting 


\section{Samenvatting}

De plasmamembraan van eukaryote cellen is opgebouwd uit twee monolagen die van elkaar verschillen in lipidensamenstelling. De buitenste monolaag bestaat voornamelijk uit de choline- houdende fosfolipiden, fosfatidylcholine (PC) en sphingomyeline (SM), terwijl de aminofosfolipiden, fosfatidylserine, (PS) uitsluitend en fosfatidylethanolamine (PE), grotendeels voorkomen in de binnenste monolaag. Het belang van deze asymmetrische lipidenverdeling is af te leiden uit het feit dat de cel energie besteedt aan het handhaven hiervan en zeker, omdat veranderingen in lipidensamenstelling van het membraanoppervlak gevolgen hebben voor het functioneren van verschillende fysiologische processen. De asymmetrische lipidenverdeling wordt in stand gehouden door minstens twee transporteiwitten: 1. een translocase, verantwoordelijk voor een specifiek naar binnen gericht transport van de aminofosfolipiden, PS en $P E$, en 2 . een zogenaamd floppase, een eiwit dat transport van lipiden van binnen naar buiten faciliteert. Dit transport is niet specifiek met betrekking tot het soort lipide en verloopt veel langzamer dan dat door de aminofosfolipidentranslocase. Spontane transbilaag beweging van fosfolipiden verloopt zeer traag met halfwaardetijden uiteenlopend van uren tot dagen. Als gevolg hiervan is de asymmetrische lipidenverdeling relatief stabiel en is de aminofosfolipiden translocatie voornamelijk bedoeld om de verdeling te herstellen wanneer deze verstoord is, bijvoorbeeld als gevolg van fusieprocessen tijdens exo- en endocytose. Een ander eiwit, scramblase genaamd, faciliteert migratie van lipiden in beide richtingen over de membraan. Het fosfolipiden scramblase is in rustende cellen inactief. Calcium ionen spelen een centrale rol in het opheffen van de normale lipidenverdeling: scramblase wordt geactiveerd door een blijvend hoge intracellulaire $\mathrm{Ca}^{2+}$ concentratie, terwijl aminofosfolipidentranslocase onder zulke condities wordt geremd.

Het meest opvallende kenmerk van het instorten van de asymmetrische lipidenverdeling is het beschikbaar komen van PS in de buitenste monolaag van de plasmamembraan. Oppervlaktegeexposeerd PS, met name in bloedplaatjes speelt een belangrijke rol in de bloedstolling, omdat PS-houdende membranen een katalytisch oppervlak (procoagulant oppervlak) vormen, waarop verschillende enzymcomplexen (o.a. het protrombinasecomplex) uit de bloedstollingscascade kunnen worden geassembleerd, waardoor een snelle fibrinevorming wordt gegarandeerd. Hierdoor wordt een 
plaats-gebonden controle van het hemostase proces gewaarborgd. Daarnaast dient oppervlakte-geëxposeerd PS als herkenningssignaal voor het verwijderen van apoptotische cellen en vormt het onderdeel van cel-cel interacties tijdens fusieprocessen. Omdat de activiteit van het protrombinasecomplex eenvoudig te meten is en in hoge mate afhankelijk is van de aanwezigheid van PS, wordt deze activiteit (procoagulant activiteit) veelal gebruikt om PS expositie te detecteren. Echter, de protrombinase activiteitsmeting betreft een zogenaamde 'bulk'-meting. Dat betekent dat een verhoogde activiteit veroorzaakt kan worden zowel door een toename van de hoeveelheid geëxposeerd PS per cel als door een toename van de hoeveelheid PS-exposerende cellen. In hoofdstuk 2 hebben wij de procoagulante respons van bloedplaatjes nader bestudeerd op het niveau van PSexpositie per bloedplaatje. Dit werd gedaan met behulp van flow cytometrie. Uit ons onderzoek blijkt dat na activatie met de diverse agonisten er twee plaatjesfracties kunnen worden onderscheiden: een PS-positieve fractie en een PS-negatieve fractie. De mate van PS-expositie in de PS-positieve fractie komt overeen met die welke wordt waargenomen na activatie van plaatjes met $\mathrm{Ca}^{2+}$-ionofoor (i.e. maximale PS-expositie). De grootte van de PS-exposerende fractie blijkt afhankelijk te zijn van de gebruikte agonist. De omvang van de PS-exposerende fractie neemt toe in de tijd en is evenredig met de procoagulant activiteit van de plaatjessuspensie.

Voorts blijkt uit ons onderzoek dat, in de plaatjesfractie die PS exposeert, scramblase volledig aangeschakeld is en de translocase volledig uitgeschakeld is. Translocase activiteit werd uitsluitend waargenomen in die fractie die geen PS exposeert. Er werden geen plaatjes waargenomen met een intermediaire PS expositie, gelegen tussen die van de controle en van $\mathrm{Ca}^{2+}$-ionofoor gestimuleerde plaatjes. Op grond van deze bevindingen moet de hypothese, dat een graduele verschuiving in de balans tussen scramble- en translocase activiteit bepalend is voor de mate van PS-expositie en daarmee de procoagulante activiteit van het plaatje, worden verworpen. In hoofdstuk 3 wordt de invloed van de morfologie van erythrocyten op het scramble-proces bestudeerd. Wanneer erythrocyten met $\mathrm{Ca}^{2+}$-ionofoor worden behandeld treden tegelijk met lipidenscrambling en PS-expositie een aantal andere processen op zoals celkrimp, vormverandering, en membraanblebbing, i.e. het afsnoeren van microvesikels, kleine, door plasmamembraan omgeven, celfragmenten. Deze vormverandering betreft de overgang van biconcaaf naar echinocyt, waarbij de cel gekenmerkt wordt door 
stekelvormige uitstulpingen. Een mogelijke verklaring voor deze vormverandering is gebaseerd op een hypothese van Sheets en Singer, de zogenaamde 'coupled bilayer hypothesis', die stelt dat verandering in lipidenmassa tussen beide helften van de bilaag leidt tot verandering in membraankromming. Volgens dit principe veroorzaakt het opbouwen van een massa-overmaat in de buitenste monolaag uitstulping van de membraan en de vorming van 'spikes' (echinocyt-vorming), terwijl een massa-overmaat in de binnenste monolaag zorgt voor instulping (stomatocyt-vorming). Eerdere studies van de snelheden van uitwaartse en inwaartse bewegingen van de plasmamembraanlipiden, tijdens het scramble-proces in erythrocyten (en bloedplaatjes), lieten zien dat de snelheid van inwaartse beweging van sphingomyeline kleiner is dan de snelheid van uitwaartse beweging van aminofosfolipiden.

Dit snelheidsverschil leidt tot massa-overschot in de buitenste monolaag van de membraan met als gevolg vorming van echinocyten en afsnoeren van microvesikels. Op grond hiervan werd verondersteld dat farmaca die in de buitenste monolaag (crenators) of binnenste monolaag (cupformers) van de plasmamembraan worden geïncorporeerd, het scramble-proces zouden kunnen beïnvloeden. Hierbij lijken er twee mogelijkheden te bestaan, enerzijds kan incorporatie van materiaal in de binnenste monolaag de uitgaande beweging van PS bevorderen, terwijl een surplus aan materiaal in de buitenste monolaag de migratie van PS van binnen naar buiten tegen werkt. Anderzijds bestaat de mogelijkheid dat de vorming van microvesikels tijdens het scramble-proces snelheidslimiterend is. In deze optiek zullen echinocyten, behandeld met $\mathrm{Ca}^{2+}$ -ionofoor, hun lipiden-asymmetrie gemakkelijker verliezen aangezien zij 'aanleg' hebben tot microvesikel-vorming, terwijl in stomatocyten dit proces vertaagd zal zijn als gevolg van massa-overschot in de binnenste monolaag. Om te weten te komen welke van deze twee alternatieven het waarschijnlijkst is, hebben we diverse bekende crenators en cupformers gebruikt. De snelheid van scrambling werd bepaald aan de hand van de ontwikkeling van een procoagulantoppervlak, gemeten met behulp van de protrombinase reactie. Aangetoond werd dat, in vergelijking met normocyten, echinocyten een verhoogde scramble-snelheid vertonen, terwijl stomatocyten een verlaagde scramble-snelheid laten zien. Concluderend kunnen we zeggen dat de snelheid van lipidenscrambling meer bepaald wordt door het vermogen tot microvesikel-vorming dan door een massaimbalans tussen de twee monolagen van de membraan. Bekend is dat $\mathrm{Ca}^{2+}$ opname in erythrocyten, niet alleen scramblase activeert, 
maar ook $\mathrm{Ca}^{2^{+}}$-gevoelige $\mathrm{K}^{+}$kanalen (Gardoskanalen) in deze cellen stimuleert. In hoofdstuk 4 onderzochten we de mogelijke rol van intracellulaire $\mathrm{K}^{+}$ionen op de scramblase activiteit en daarmee de ontwikkeling van de procoagulant respons. Bij plaatjes vereist het activeren van de scramblase een blijvende verhoging van de intracellulaire $\mathrm{Ca}^{2}$ concentratie. Aangetoond werd dat bij plaatjes remming van de $\mathrm{K}^{+}$efflux door hoog extracellulair kalium of door selectieve Gardoskanaalblokkers tijdens activatie met collageen/trombine gepaard gaat met een duidelijke afname (30$50 \%$ ) van de procoagulante respons. Deze remming van procoagulante respons kon worden hersteld met valinomycine, een kaliumionofoor, die de membraan selectief permeabel maakt voor $\mathrm{K}^{+}$ ionen. De defecte procoagulante respons, na collageen/trombine activatie van plaatjes van een patient met het Scott syndroom, bleek gedeeltelijk hersteld te kunnen worden door preincubatie met valinomycine.

In hoofdstuk 5 zijn we verder ingegaan op de betekenis van de $\mathrm{K}^{+}$ efflux op de scramble activiteit. Simultane metingen van de $\mathrm{K}^{+}$efflux en de snelheid van lipiden- scrambling, gemeten aan de ontwikkeling van een procoagulant oppervlak in aan en afwezigheid van van Gardoskanaalblokkers in erythrocyten, suggereren het bestaan van een direct modulerend effect van $\mathrm{K}^{+}$-ionen op de scramble-snelheid. Valinomycine versnelt de $\mathrm{Ca}^{2+}$-geinduceerde lipidenscrambling in erythrocyten en heft de remmende werking van de $\mathrm{K}^{+}$kanaalblokkers op.

Experimenten waarbij de intracellulaire $\mathrm{K}^{+}$-concentratie met behulp van valinomycine werd gemanipuleerd tonen een duidelijke relatie tussen de intracellulaire $\mathrm{K}^{+}$-concentratie en de scramble-snelheid. Wanneer de intracellulaire $\mathrm{K}^{+}$-concentratie verhoogd wordt van 0 tot $140 \mathrm{mM}$ neemt de scramble-snelheid met ca $50 \%$ af. Voorts tonen onze studies met resealed ghosts, geïsoleerde gesloten erythrocyten membranen, aan dat de remmende werking van $\mathrm{K}^{+}$-ionen rechtstreeks is en beduidend sterker dan in intacte erythrocyten. Bovendien laten de resultaten beschreven in hoofdstuk 5 zien dat lipidenscrambling in resealed ghosts kan optreden onafhankelijk van celkrimp en vorming van microvesicles, processen die in intacte erythrocyten sterk geassocieerd blijken te zijn. Samenvattend kunnen we zeggen dat in niet geactiveerde cellen de hoge intracellulaire $\mathrm{K}^{+}$-concentratie onderdrukkend werkt op het scramble -proces. Verhoging van de intracellulaire $\mathrm{Ca}^{2+}$-concentratie veroorzaakt activatie van de scramblase maar tevens opening van de Gardoskanalen als gevolg waarvan de cel $\mathrm{K}^{+}$-ionen verliest en het 
intrinsiek remmend effect van deze ionen op de scramblase activiteit vermindert. In hoofdstuk $\mathbf{6}$, tenslotte, worden de in dit proefschrift beschreven resultaten besproken in de bredere context van de meest relevante publicaties over dit onderwerp. 
List of publications 


\section{List of publications}

Wolfs JLN, Comfurius $\mathrm{P}$, Bevers EM, Zwaal RFA. Influence of erythrocyte shape on the rate of $\mathrm{Ca}^{2+}$-induced scrambling of phosphatidyl-serine. Mol. Membr. Biol. 2003;20:83-91.

Bevers EM, Wolfs JLN, Comfurius P, Zwaal RFA. Platelets and the propagation of coagulation. In: Thrombosis: Fundamental and Clinical Aspects, chapter 9, 143-159, Arnout, J., de Gaetano, G., Hoylaerts, M., Peerlinck, K., Van Geet, C. and Verhaeghe, R. (ed.), Leuven Universtity Press. 2003.

Wolfs JLN, Comfurius P, Rasmussen JT, Keuren JF, Lindhout T, Zwaal RFA, Bevers EM. Activated scramblase and inhibited aminophospholipid translocase cause phosphatidylserine exposure in a distinct platelet fraction. Cell. Mol. Life Sci. 2005;62:1514-1525.

Wolfs JLN, Wielders SJ, Comfurius $P$, Lindhout T, Giddings JC, Zwaal RFA, Bevers EM. Reversible inhibition of the platelet procoagulant response through manipulation of the Gardos channel. Blood 2006;108: 2223-2228.

Hansen HR, Wolfs JL, Bruggeman L, Sommeijer DW, Bevers E, Hauer $A D$, Kuiper J, Spek CA, Spronk HM, Reitsma PH, ten Cate $H$. Hyperglycemia accelerates arterial thrombus formation and attenuates the antithrombotic response to endotoxin in mice. Blood Coagul. Fibrinolysis. 2007;18: 627-636.

Wolfs JLN, Comfurius P, Bekers O, Zwaal RFA, Balasubramanian K, Schroit AJ, Lindhout T, Bevers EM. Direct inhibition of phospholipid scrambling activity in erythrocytes by potassium ions. Cell. Mol. Life Sci. 2008;66: 314-323 


\section{Dankwoord}




\section{Dankwoord}

Met enige weemoed kijk ik terug op de fantastische periode van mijn promotieonderzoek waar euforie en teleurstelling dicht bij elkaar lagen.

De basis voor mijn promotieonderzoek werd jaren geleden gelegd tijdens één van mijn afstudeeronderwerpen voor mijn doctoraal Biologie op het Biomedisch Centrum onder supervisie van Prof.dr. R.F.A. Zwaal. Het is daar geweest dat ik de microbe voor wetenschappelijk onderzoek heb opgedaan.

Ondanks de generatiekloof voelde ik mij als een vis in het water op de afdeling Biochemie. Een afdeling die bruist van spirit en creativiteit. Daarom een welgemeend woord van dank aan de hele vakgroep Biochemie, onder leiding van Prof.dr. Jan Rosing, voor de prettige en relaxte sfeer waarin ik al die jaren heb kunnen werken.

De leden van de beoordelingscommissie, Prof.dr. J.F.C. Glatz, Prof.dr. C.A. Bruggeman, Prof.dr. M.C.E. van Dam-Mieras, Prof.dr. F.C.S. Ramaekers en Prof.dr. H.A.J. Struijker Boudier wil ik bedanken voor de tijd en moeite die ze hebben besteed aan het beoordelen van mijn proefschrift.

Op de eerste plaats dank ik mijn promotores Prof.dr. R.F.A. Zwaal, Prof.dr. J. Rosing en mijn Co-promotor Dr. E.M. Bevers. Jullie bijdrage, enthousiasme en deskundigheid, waren onmisbaar bij het tot stand komen van dit proefschrift. Ik dank jullie voor de 'kritische onderzoeksgeest' die jullie me bijgebracht hebben, alsook voor het advies en de hulp bij de verwerking van de resultaten tijdens onze werkbesprekingen.

Beste Rob, Jan, en Edouard, jullie ideeën en vooral de kritische commentaren hebben dit werk mogelijk gemaakt. Dank voor de plezierige samenwerking, het vertrouwen in mij en mijn onderzoek.

Dr. Bevers, beste Edouard, onze jarenlange samenwerking is voor mij een grote uitdaging geweest met als resultaat dit proefschrift.

Zonder te overdrijven was jij de laatste jaren de drijvende kracht achter dit promotieonderzoek. Het was niet altijd gemakkelijk, maar jij weet als geen ander mensen te motiveren om het beste uit zichzelf te halen. Je was een enorme steun bij het uitvoeren van de experimenten en schrijven van de artikelen. Daarnaast liet je me 
steeds weer versteld staan van je enorme kennis, niet alleen van je eigen vakgebied maar ook van ver daarbuiten. Je bent een geweldig voorbeeld van een leidinggevende die werkt en laat werken "aan de grenzen van het weten".

Naast mijn promotores en co-promotor hebben ook veel andere collega's bijgedragen aan het tot stand komen van mijn promotieonderzoek, door zich spontaan beschikbaar te stellen als bloeddonor. Dank! Zonder jullie zou dit proefschrift er niet zijn.

Dr. Paul Comfurius, beste Paul, van jou heb ik altijd heel veel steun gehad. De laatste jaren heb ik het helaas zonder jou moeten stellen, toch kon ik altijd bij je terecht. Dank dat je mijn datamanager was, mijn computerdokter en nog veel meer. Bedankt, gewoon voor alles!

Dr. Theo Lindhout, dank voor de uitermate fijne samenwerking en je kritische blik op mijn onderzoek.

Jaap en Armand dank ik voor de uiterst plezierige samenwerking. Jullie kaliumbepalingen hielpen mij enorm vooruit. Ondanks jullie eigen drukke bezigheden op de afdeling klinische chemie van het azM, stonden jullie steeds voor mij klaar.

Simone en Marjon dank ik voor hun daadwerkelijke steun en collegialiteit.

Trees, bedankt voor je administratieve hulp op velerlei vlakken, zelfs voor je instructies hoe ik de koffieautomaat wel diende te gebruiken.

Tot slot een woord van dank aan mijn belangrijkste persoon. Bea, jij hebt als geen ander met me meegeleefd gedurende mijn doctoraat. Ik besef ten volle dat ik door mijn veelvuldige afwezigheid en avondwerk aan de computer niet altijd beschikbaar was. Ik ben blij dat ik steeds mijn verhaal kwijt kon aan jouw altijd luisterend oor, ook wanneer ik van pure wetenschappelijke extase maar bleef doordrammen over het scramble mechanisme en het procoagulant oppervlak. Mijn promotieonderzoek werd ook door jou als een passie van mij beschouwd. En het is inderdaad een fascinerende passie geworden. Bedankt om lief en leed met mij te delen. Dankzij jou heb ik nu mijn doel bereikt. Dikke kus! 
Curriculum Vitae 


\section{Curriculum Vitae}

Ik ben niet uit mezelf geboren boven op een pilaar in niemandsland. Ik kom uit Louis en Anna: mijn vader en moeder. Uit het gezin Wolfs, dertien kinderen, ik ben de middelste. Uit Eijsden, een prachtig dorpje aan de Maas. Uit een welvarend continent. Ik ben bewoner van de Aarde en van dit zonnestelsel. Daardoor ben ik van alle kanten al ingekleurd door de wereld buiten mij, een gegeven dat niet ter discussie staat.

Toen ik geboren werd, 20 maart 1940, was al veel vastgelegd. Door de natuur met haar wetten en door de mensen met hun afspraken. Die bepaaldheid is niet iets dat tégen mij is of dat mij onvrij maakt. Het hoort bij mijn identiteit, omdat ik een stukje ben van de wereld. Wat de wereld van de natuur en de natuurwetten betreft is alles duidelijk: de zon komt al sinds jaren voor mijn tijd links op en gaat rechts onder; de zwaartekracht, de verdeling tussen dag en nacht, tussen zomer en winter, tussen continenten en zeeën.... Ik heb ze niet uitgevonden en leg me daar bij neer.

Wat de wereld van de mensen betreft, daar is voor mijn komst, noodgedwongen heel wat geregeld zonder mij. De wereld van de mensen heeft ervaringen opgedaan, inzichten gekregen en uitvindingen gedaan die ik nu gebruik. Een leger van wetenschappers heeft kennis op schrift gesteld over wiskunde, fysica, biologie en biochemie. Ook ik heb, weliswaar bescheiden, hieraan mogen deelnemen.

$\mathrm{Na}$ de lagere en middelbare school behaalde hij achtereenvolgens het diploma Algemeen Klinisch Chemisch analist S.A.L. (1967), Klinisch chemisch laboratorium- assistent HBO-B aan het IHBO te Eindhoven (1970), het eerste graad diploma MO Plant en Dierkunde aan de Rijksuniversiteit Utrecht, Subfaculteit Biologie (1983), het diploma Didactiek der Biologie voor MO en doctoraal Biologie aan de Rijksuniversiteit Utrecht, subfaculteit der Biologie (1983), de eerste graad bevoegdheid in het vak Hematologie voor het Hoger Laboratorium Onderwijs van het Ministerie van Onderwijs en Wetenschappen (1984) en doctoraal Biologie aan de Katholieke universiteit Nijmegen(1987).

$\mathrm{Na}$ zeven jaren werkzaam geweest te zijn als laboratoriummedewerker, in diverse functies, op het Klinisch Chemisch en Hematologisch laboratorium van het Psychiatrisch Zlekenhuis "Voorburg" te Vught werd in 1971 de overstap gemaakt naar het Hoger Beroeps Onderwijs. 
Tot 1987 is hij werkzaam geweest als docent in de vakken Biologie, Microbiologie en Hematologie aan de Zuidlimburgse Laboratoriumschool Sittard (ZLS) te Sittard. In 1987 werd hij aangesteld als Hogeschooldocent aan de medisch/ biologische opleiding (HLO) en als coördinator van de Post HBO opleiding "Immunologie/hematologie" van de Hogeschool Limburg, thans geheten Hogeschool Zuyd te Heerlen. Sinds 2002 is hij als externe relatie actief als onderzoeker/ promovendus aan de faculteit Geneeskunde van de Universiteit Maastricht.

In zijn vrije tijd is hij meer dan 16 jaar actief geweest als voorzitter van het Hoeselts Toneelgezelschap en bestuurslid van het Limburgs Toneel Verbond.

Leven is voor mij iets doen en grenzen verleggen. Ik heb dan ook de pretentie de wereld een beetje mooier en menselijker achter te laten nadat ik gepasseerd ben. 